\title{
Technical Assessment of Bulk Vitrification Process/Product for Tank Waste Treatment at the Department of Energy Hanford Site
}

U.S. Department of Energy Reference SR-311-2-511

Technical Expertise Project \#608 FINAL REPORT

Prepared for the U.S. Department of Energy Assistant Secretary for Environmental Management

Contractor for the U.S. Department of Energy Office of River Protection under Contract DE-AC27-99RL14047

\section{CH2MHILL \\ Hanford Group, Inc.}

P.O. Box 1500

Richland, Washington

Approved for Public Release;

Further Dissemination Unlimited 


\section{Technical Assessment of Bulk Vitrification Process/Product for Tank Waste Treatment at the Department of Energy Hanford Site.}

\section{U.S. Department of Energy Reference SR-311-2-511}

Technical Expertise Project \#608 FINAL REPORT

\section{EM-21 Technical Assistance Team}

Date Published

July 2006

Prepared for the U.S. Department of Energy

Assistant Secretary for Environmental Management

Contractor for the U.S. Department of Energy

Office of River Protection under Contract DE-AC27-99RL14047

\section{CH2MIHILL \\ Hanford Group, Inc.}

P.O. Box 1500

Richland, Washington

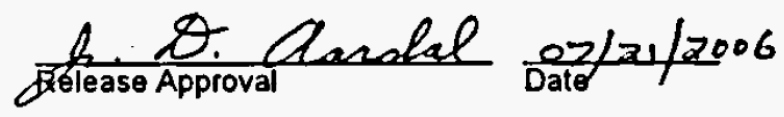

Approved for Public Release;

Further Dissemination Unlimited 
LEGAL DISCLAIMER

This report was prepared as an account of work sponsored by an agency of the United States Govemment. Neither the Untied States Government nor any agency thereof, nor any of their employees, nor any of their contractors, subcontractors or their employees, makes any warranty, express or implied, or assumes any legal liability or responsibility for the accuracy, completeness, or any third party's use or the results of such use of any information, apparatus, product, or process disclosed, or represents that its use would not infringe privately owned rights. Reference herein to any specific commercial product, process. or service by trade name, trademark, manufacturer, or otherwise, does not necessarily constitute or imply its endorsement, recommendation, of favoring by the United States Government or any agency thereof or its contractors or subcontractors. The views and opinions of authors expressed herein do not necessarily state or reffect those of the United States Government or any agency thereof.

This report has been reproduced from the best available copy. 


\section{RPP-30570, Rev. 0 \\ TABLE OF CONTENTS}

Page

EXECUTIVE SUMMARY IV

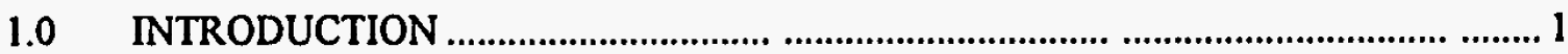

1.1 PROBLEM.............................................................................................

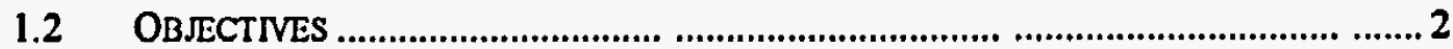

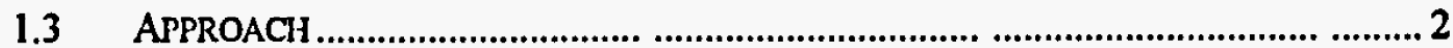

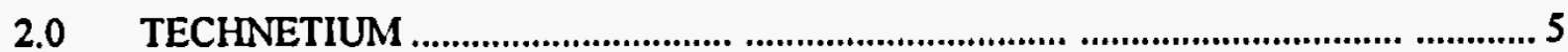

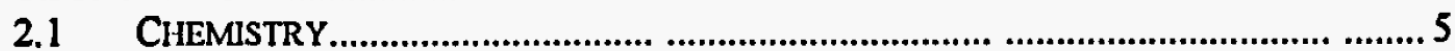

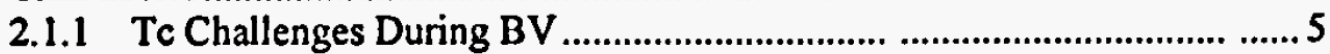

2.1.2 Tc Volatilization ............................................................................... 5

2.1.3 Rhenium (Re) as a Tc Surrogate during BV Cold Testing ........................ 6

2.2 FATE OF TECIINETIUM .................................................................................. 7

2.2.1 Mass Balance.................................................................................... 7

2.2.2 Off-gas Recycle ............................................................................ 8

2.2.3 Chemical Feed Considerations ............................................................ 9

2.3 RECOMMENDATIONS FOR MITIGATION OF TC LOSS ........................................... 9

2.3.1 Increase Tc Retention in the Melt................................................... 10

2.3.2 Reduce Vaporization of Tc Species from Top Surface.......................... 10

2.3.2.1 Quantify rate-controlling parameters of $\mathrm{Tc}$ (and $\mathrm{Re}$ ) loss from fusion layer of cold cap ...................................................................... 10

2.3.2.2 Maintain a constant cold cap thickness with a cool top surface .10

2.3.2.3 Improve uniformity of feed distribution over the melt surface... 12

2.3.3 Reduce Tc Penetration into the Refractory Liner .................................. 12

2.3.3.1 Substitute sintered amorphous silica for the mullite CRB ......... 13

2.3.3.2 Trap $\mathrm{Tc}$ in a thick layer of porous refractory ............................. 13

2.3.3.3 Coat mullite CRB with high-silica frit ...................................... 14

2.3.3.4 Coat refractory walls with molten glass ....................................14

2.3.4 Limit Tc Loss with Faster Reaction in Strong Feed Pellets .................... 16

2.3.4.1 Tailor raw materials and order of addition ................................. 17

2.3.4.2 Quantify melting behavior of strong pellets .............................. 17

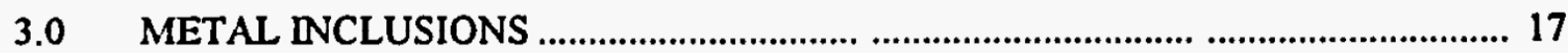

3.1 IMPACT ON GLASS PERFORMANCE ......................................................... 17

3.2 RECOMMENDATIONS FOR DESIGN AND OPERATION TO ELDMINATE METAL INCLUSIONS..................................................................................................... 18

3.2.1 Determine Mechanisms.................................................................. 19

3.2.1.1 Formation of metal inclusions on graphite flake starter path ..... 19

3.2.1.2 Formation of metal inclusions on graphite electrodes................. 19

3.2.2 Reduce Role of Starter Path in Production of Inclusions....................... 20

3.2.2.1 Eliminate iron in starter path and first batch of feed................... 20

3.2.2.2 Substitute small graphite plates................................................. 20

3.2.2.3 Use graphite-free starter path...................................................... 21 
RPP-30570, Rev. 0

3.2.3 Reduce Role of Electrodes in Production of Inclusions........................ 21

3.2.3.1 Lower power input ..................................................................... 21

3.2.3.2 Increasing electrode area ......................................................... 21

3.2.3.3 Cool the electrode/melt interface ............................................... 22

3.2.3.4 Prevent electrochemical reduction ............................................ 22

3.2.3.5 Preferred approach to eliminate metal inclusions ....................... 23

3.2.4 Develop a Low-iron Glass Composition............................................... 23

3.2.4.1 General considerations and schedule implications...................... 24

3.2.4.2 Effect on Tc chemistry and Tc loss from the cold cap................ 25

3.2.4.3 Recommendations for low-iron glass....................................... 25

3.3 RECOMMENDATIONS TO CONTROL FORMATION OF METAL INCLUSIONS.............. 26

4.0 PRODUCT PERFORMANCE .......................................................................... 27

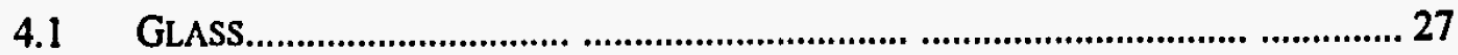

4.2 CRYSTALS....................................................................................... 28

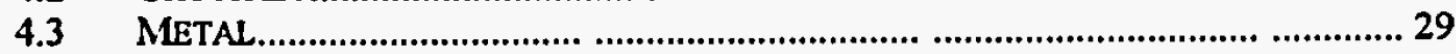

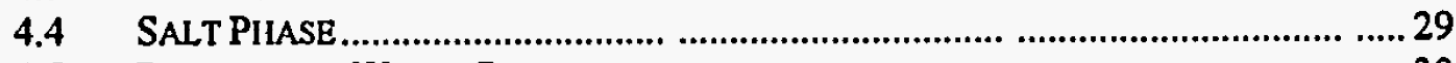

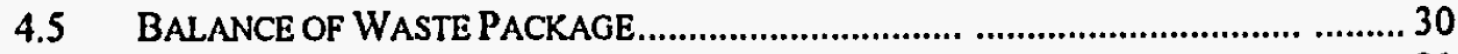

4.6 PRODUCT PERFORMANCE RECOMMENDATIONS ............................................... 31

5.0 PROCESS INTEGRATION AND RELATED ISSUES ……....................................... 33

5.1 TEST PROGRAM....................................................................................... 33

5.2 SINTERED METAL FILTERS........................................................................ 34

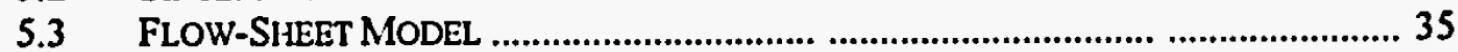

5.4 MAXIMUM ACliEVABLE CONTROL TECINOLOGY COMPLIANCE......................... 36

5.5 FATE OF CESIUM ...................................................................................... 36

5.6 CONFIRMATION OF TECHNETIUM DISTRIBUTION................................................ 37

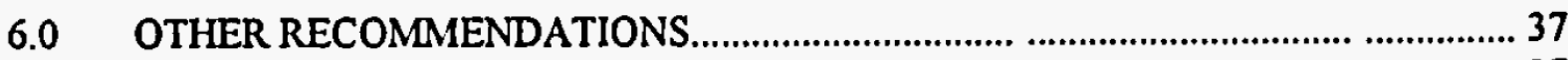

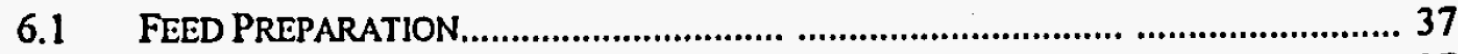

6.1.1 Eliminate Zirconia Segregation ............................................................ 37

6.1.1.1 Add zirconia with soil in mixer.............................................. 38

6.1.1.2 Substitute fine zircon for zirconia ........................................... 38

6.1.2 Consider Gravity Feed from Mixer/dryer into Melter ............................. 38

6.2 MELTER .................................................................................................... 38

6.2.1 Add Ground Fault Detection System.................................................... 38

6.2.2 Place a Curb Around the Melter ............................................................. 39

6.2.3 Consider Placing the Melter in a Ramped Trench.................................. . .39

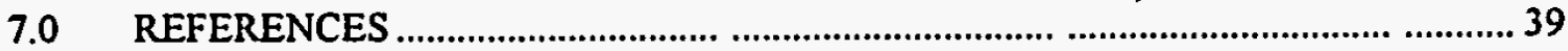


RPP-30570, Rev. 0

LIST OF APPENDICES

APPENDIX A: REQUEST FOR TECHNICAL SOLUTION

APPENDIX B: BULK VITRIFICATION TECHNICAL ASSESSMENT WORKSHOP ATTENDEE LIST

APPENDIX C: BULK VITRIFICATION PROJECT COMMENTS

APPENDIX D: COMMENT AND RESPONSE SUMMARY FOR TECHNICAL ASSESSMENT OF BULK VITRIFICATION PROCESS AT THE DOE HANFORD SITE UNDER TECHNICAL EXPERTISE PROJECT 608 


\section{RPP-30570, Rev. 0 \\ EXECUTIVE SUMMARY}

\section{Background}

At the U.S. Department of Energy (DOE) Hanford Site, the Waste Treatment Plant (WTP) is being constructed to immobilize both high-level waste (HLW) for disposal in a national repository and low-activity waste (LAW) for onsite, near-surface disposal. The schedulecontrolling step for the WTP Project is vitrification of the large volume of LAW; current capacity of the WTP (as planned) would require 50 years to treat the Hanford tank waste, if the entire LAW volume were to be processed through the WTP. To reduce the time and cost for treatment of Hanford Tank Waste, and as required by the Tank Waste Remediation System Environmental Impact Statement Record of Decision and the Hanford Federal Facility Consent Agreement (Tri-Party Agreement), DOE plans to supplement the LAW treatment capacity of the WTP. Since 2002, DOE, in cooperation with the Environmental Protection Agency and State of Washington Department of Ecology has been evaluating technologies that could provide safe and effective supplemental treatment of LAW. Current efforts at Hanford are intended to provide additional information to aid a joint agency decision on which technology will be used to supplement the WTP. A Research, Development and Demonstration permit has been issued by the State of Washington to build and (for a limited time) operate a Demonstration Bulk Vitrification System (DBVS) facility to provide information for the decision on a supplemental treatment technology for up to $50 \%$ of the LAW.

In the Bulk Vitrification (BV) process, LAW, soil, and glass-forming chemicals are mixed, dried, and placed in a refractory-lined box. Electric current, supplied through two graphite electrodes in the box, melts the waste feed, producing a durable glass waste-form. Although recent modifications to the process have resulted in significant improvements, there are continuing technical concerns, described below.

- During the melting process, some of the technetium (Tc) in the waste feed deposits in the refractory material as a soluble salt. In the performance assessment, this salt has the potential to create a Tc concentration peak in the groundwater extracted from a 100-meter down-gradient well. Although this peak is below drinking-water standards, DOE desires to reduce the amount of soluble salt in the BV waste package and reduce the resulting groundwater peak to the extent possible to further enhance the performance of the BV product and improve regulatory acceptance of the technology.

- Metal inclusions have been observed in the resulting glass product. It is unknown whether these inclusions will have a deleterious effect on the long-term performance of the waste form.

- Although the vitrified waste form is a borosilicate glass, similar to that currently being produced at the Savannah River Site and planned for production at Hanford's WTP, there are questions about whether the BV product is comparable to referenced borosilicate glasses. 
RPP-30570, Rev. 0

The DOE Office of River Protection (ORP) requested technical assistance from subject matter experts to address the above three technical concerns. Funded by DOE EM-20's Technical Expertise Program, an expert panel, comprised of Dr. Frank Woolley, retired Corning Glass, Dr. David Shuh, Lawrence Berkeley National Laboratory, and Dr. Ian Pegg, Catholic University, was convened for a three-day workshop in Richland, Washington in January 2006. Prior to the workshop, the panel was sent a limited set of existing publications related to the project for review. At the workshop, the panel was given technical briefings, as well as additional written materials, by BV project staff. It is noted that, given the level of effort budgeted for this technical review, the scope of this project is limited to addressing the three issues outlined above; comments provided do not represent a full review of the BV technology, project status, and plans. At the conclusion of the workshop, the panel provided an out-briefing to DOE, CH2MHill Group, and Pacific Northwest National Laboratory (PNNL) staff. A draft report of findings and recommendations was then prepared by the panel, reviewed by BV project staff, revised by the panel, and then reviewed again by project staff. Appendix C contains panel responses to comments that have not been incorporated into the final report. This appendix does not contain information regarding comments where edits were made in the report, but addresses areas where a consensus opinion could not be reached. A summary of Comment and Team Responses is included as Appendix D.

The panel was tasked with the following actions:

- assess and provide recommended refinements to existing methods and/or new methods to reduce the amount of soluble Tc salts that form in the BV waste package and provide comments regarding the Tc mass balance;

- assess impact of metal inclusions on glass product quality and recommend potential process improvements that would mitigate their impact;

- evaluate potential performance of BV product with respect to reference borosilicate glasses and glass quality standards, and recommend potential process improvements that would enhance product durability and leach properties.

\section{Technetium}

Tc presents challenges and uncertainties for high-temperature vitrification processes, including BV, because of its volatility, mobility, and longevity. For BV some of these challenges have changed, because the BV process was fundamentally altered from a top-down to a bottom-up melting process. The volatility of $\mathrm{Tc}$ determines its level of incorporation in the glass product and the corresponding amount in the off-gas, which is captured in the off-gas treatment system and recycled. Major factors controlling its volatility include oxidation-reduction conditions in the melt and vitrification process operational factors, such as temperature. In addition to the volatility challenge, $\mathrm{Tc}$ is soluble in potential salt phases and can deposit in the refractory liner.

Current knowledge of Tc chemistry in the LAW waste feed is sufficient to predict that Tc will primarily be present as the pertechnetate species, but the feed may also contain some fraction of 


\section{RPP-30570, Rev. 0}

lower oxidation-state species. However, gaps in our knowledge of Tc chemical and physical properties pertinent to $\mathrm{BV}$ and other vitrification processes remain. In particular, there is limited information on Tc solution chemistry in highly alkaline solutions, Tc species in vitrification off-gas, and mechanisms for Tc immobilization in borosilicate glasses. In terms of mitigation of Tc loss, the best approach is to implement improvements in the BV system to reduce Tc volatility, and thereby, improve the percentage of Tc immobilized in the primary waste package. For example, it is well known that Tc volatilization is greatly dependent upon the temperature of the melt and nature of the cold cap. Recycling of Tc from the off-gas filter system will change the amount and possibly the form of Tc in the melter feed; this effect has not yet been studied.

It is important to fully understand the fate of Tc within the BV process, including the significant losses of $\mathrm{Tc}$ from the melt. This is especially important for $\mathrm{BV}$, because soluble forms of Tc could reside outside the glass, but within the waste package, and the task of sampling the glass and other parts of the package is much more challenging. In the ES 32B engineering-scale test, $24 \%$ of the Tc was unaccounted for, possibly due to an underestimate of the amount of Tc volatilized into the off-gas system. (Note that ES-32B is the only test of the bottom-up melting process on which a full material balance was performed. The problem is not so much the fact that $24 \pm 17 \%$ of the Tc was not accounted for in this test, as that this was the only test to date on which a full material balance was performed.)

The panel recommends in future tests 1) addition of a removable filter material, such as glass wool, in a filter assembly in front of the HEPA filter (easily analyzed for Tc), or 2) an off-gas sampler in combination with a liquid scrubber. Because Tc is a ppm-level trace constituent, there are significant difficulties in achieving closure on the Tc mass balance. Reliable conclusions depend on obtaining analyses of both glass and non-glass portions of the waste package to ensure that leachable Tc is not present at unacceptable levels.

Because the sintered metal filters (SMF) in the off-gas system have not been used for this type of application, uncertainties regarding SMF performance remain; the SMF should be tested prior to full-scale startup. The planned operating temperature for the $\mathrm{SMF}, 300^{\circ} \mathrm{C}$, is close to the boiling point of a volatile $\mathrm{Tc}_{2} \mathrm{O}_{7}$ species $\left(311^{\circ} \mathrm{C}\right)$.

Rhenium ( $\mathrm{Re}$ ), the best surrogate for $\mathrm{Tc}$, has been used appropriately in the BV cold testing. However, there are recognized differences in the chemical behavior of these two elements in vitrification processes, which have been observed during BV testing. This requires that results using Re be interpreted and adjusted to reflect Tc behavior, followed by "hot" validation using feed containing Tc.

Recommendations to mitigate the loss of Tc can be categorized as: 1) reduce vaporization of Tc species from the top surface of the melt, 2 ) reduce the penetration of Tc into the refractory liner, and 3) promote a faster reaction in the cold cap of the waste feed material. Reduction of vaporization of Tc species from the top surface of the melt can be accomplished through maintaining a constant cold cap thickness with a cool top surface and improving the uniformity 


\section{RPP-30570, Rev. 0}

of the feed distribution over the melt surface. Specific methods to accomplish each of these improvements are provided in Section 2.3.

Reducing penetration of $\mathrm{Tc}$ into the refractory liner is a very difficult problem; the panel had the opportunity to review only a fraction of the work done to address it. Thus, the panel recommends that further efforts be made to identify an alternative lower-permeability liner material as the preferred approach. Various methods are suggested, some of which may already have been considered for coating the existing liner as a backup approach. Recent efforts by PNNL to alter the composition and hence the mobility of the molten salts that carry Tc into the refractory liner by sequencing boron additions are considered promising. The panel recommends further testing of the mixer/dryer operation to optimize feed reaction time. Raw materials and the order of addition in the dryer can be tailored to produce faster-reacting, pelletized feed.

\section{Metal Inclusions}

Test results have shown that the metal inclusions formed in the vitrified product contain higher concentrations of $\mathrm{Tc}$ (and the Re surrogate) than the glass. Because the metal phase, which is predominantly iron, is more soluble than the glass in the expected disposal environment, its presence may significantly impact glass performance by increasing the rate of release of Tc from the waste package. Accordingly, it is essential that the extent of this impact be understood and minimized.

In addition, the total mass fraction of metal in the product and its distribution within the product are also key factors in performance. It seems reasonable to expect that the overall rate of release of Tc would decrease as the Tc enrichment factor decreases; as the total mass fraction of metal decreases; and as the distribution of the metal phase moves from large ingots near the bottom of the glass product towards finely divided inclusions uniformly distributed throughout the glass phase. The effects of process chemistry and operating conditions on these factors need to be better understood. Efforts to date have reasonably focused on minimizing the total mass fraction of metal in the product.

The primary objective should be to eliminate all evidence of metal production during melting. Unless operating conditions that normally result in a complete absence of metal inclusions are identified, it is likely that inclusions will occur, sometimes in large amounts, as the result of normal variations in conditions from melt to melt.

Large reductions in the amount of metal inclusions produced in a large-scale test, 38-B, have recently been achieved by reducing the amount of graphite in the starter path, and by tighter control of current density and bath temperature. This demonstrates the potential for further reduction or possible elimination of these inclusions. The panel recommends that an effort be made to determine the mechanisms by which metal inclusions are formed, as the fastest and most economical way to learn how to eliminate them. 


\section{RPP-30570, Rev. 0}

Two fundamental processes probably account for most of the reduction of iron and other metals to their elemental state during melting: carbothermic reduction, both by starter-path materials and by electrodes, and electrochemical reduction on the electrodes. With improved knowledge of the relative importance of these fundamental processes and their sensitivity to temperature and iron content of the bath, actions intended to counter them (Section 3.2.2 and 3.2.3) can be prioritized, leading to further reductions in the amount of metal inclusions. Lab-scale testing is recommended to quantify the rate of formation of inclusions by each fundamental mechanism, because the effects of each mechanism cannot be separated in large-scale tests, where it is impractical or impossible to control and measure local conditions adequately.

Anticipating the results of this recommended testing, and assuming that the dominant mechanism by which metal inclusions are formed is carbothermic reduction at the hot surface of the graphite electrodes, the panel recommends that serious consideration be given to the use of externally-cooled plate electrodes in place of the uncooled cylindrical electrodes, which are a legacy of the AMEC technology. Although difficult to implement, it may be easier than the option discussed below.

If none of the above measures can be developed into a viable approach to eliminate metal inclusions, the plan to use native soil as a raw material should be reconsidered and other lowcost raw materials, such as low-Fe clays, sands and volcanic ash, or conventional glass-forming chemicals should be considered. The lab-scale testing described above should provide guidance on the iron content below which the reduction mechanisms are ineffective and metal inclusions are unlikely to form. The recommended iron content would probably be $-0.1 \mathrm{wt}$. \% $\mathrm{Fe}_{2} \mathrm{O}_{3}$ to obtain the best compromise between low raw-materials cost and high infrared transmission in the melt (better heat transfer). In any electric glass-melting process, there are numerous process advantages to a low-iron glass, all resulting from the improved heat transfer within the melt. These include: a) better radiative cooling of the electrodes, which lowers the temperature at the graphite interface and hence lessens the tendency to form metal inclusions, b) less tendency to coring (hot channels in bath), which increases melter stability during startup, c) higher melting rate, which increases processing rate, and d) more uniform temperature throughout the melt volume, which provides a larger safety margin against the possibility of devitrification in edges and corners. For the DBVS, an iron content somewhat higher than $0.1 \mathrm{wt} . \% \mathrm{Fe}_{2} \mathrm{O}_{3}$ may be a better compromise when the issue of product performance (discussed below) is considered.

A considerable disadvantage of moving towards a low-iron glass composition, however, is the relative paucity of data and the departure from the "main-stream" waste vitrification experience around the world, which is dominated by iron-containing glass compositions. Although the magnitude of the composition change is relatively small, it will result in significant changes in properties, such as infrared absorption and redox chemistry in the melt. Consequently, it should be expected that such a change, while likely beneficial in the long run, will require its own learning curve in terms of how it impacts the process. In addition, there may be a variety of subtle consequences, such as effects on the behavior of $\mathrm{Tc}$ in the absence of iron, which need to be considered. While it should be expected that there will also be changes in product properties, there is no reason to believe that these cannot be compensated, such that acceptable 


\section{RPP-30570, Rev. 0}

product quality can still be achieved. If metal inclusions cannot be eliminated, a comprehensive testing program is recommended to demonstrate that their impact on product performance is acceptable over the full range of operating conditions. 


\section{Product Performance}

\section{RPP-30570, Rev. 0}

The $\mathrm{BV}$ process produces a relatively complex waste package. In addition to the glass, in which there may be crystals and metal inclusions, the waste package is currently expected to contain a salt phase plus the container, refractory lining, graphite electrodes, and the lid structure with associated ports and fittings. Issues associated with contributions of each of these components to the overall performance of the waste package are discussed below.

In many respects, the glass represents the simplest part of the overall waste package. The glass testing program appears to be reasonable and results to date support the contention that the homogeneous glass phase is capable of providing acceptable performance. However, the fullscale process will likely be subject to additional complications from effects, such as glass homogeneity (given the size of the waste package), thermal history, and redox state.

The graphite electrodes create a reducing condition in the melt, the magnitude of which is unique among current radioactive waste vitrification processes. As a result, there are few product leach test data available for such highly reduced glasses. Because the redox state may have significant effects on glass properties, its impact should be determined, and appropriate redox control ranges established for the process.

Depending on composition and thermal history, varying amounts and types of crystalline phases can form during cooling within the amorphous glass; this process, called devitrification, can serve to complicate the assessment of product performance. While multi-phase materials may meet all of the product quality requirements, additional data may be required to demonstrate that product quality requirements are met, even though there is no current requirement to measure or report crystal content for WTP LAW or BV glasses. In addition, because of the large size of the BV container, the representativeness of samples collected to test product quality needs to be understood. In view of the large size and appreciably different aspect ratio of the $\mathrm{BV}$ container (as compared to traditional vitrification facilities), it is not clear that container centerline cooling (CCC) heat-treatment approach provides a worst-case bound for the BV product.

The presence of a higher-solubility metal phase, with preferential incorporation of $T c$, exhibits further complications in the assessment of the overall performance of the waste package. In addition, test data indicate that a molten sulfate salt phase, which may incorporate various heavy metals and radionuclides and has higher solubility in water, forms on top of the glass melt. Efforts to minimize the presence of both of these phases should continue. The reducing character of the BV melt promotes sulfur volatilization (20-40\% retained in the melt). The sulfur species in the off-gas, depending upon its form, may be captured by the SMF and then recycled, along with $\mathrm{Tc}$, back into the feed for the melt. Concentrations of sulfur in the feed may increase as the recycle is included in the waste feed, further promoting formation of the salt phase on top of the silicate melt surface. Further testing is recommended to assess the extent of this issue and to support development of appropriate mitigation strategies. 


\section{RPP-30570, Rev. 0}

The balance of the waste package consists of various materials, including the outer steel container, the internal engineered refractory lining, the lid structure and associated fittings and flanges, and the graphite electrodes. While this diversity of materials and components makes this more complicated that the prototypical nuclear-waste glass package composed of glass in a stainless steel canister, the more crucial difference stems from the fact that the glass is melted in the container rather than simply poured into it. The potential impact of generation of dust, transient molten salts and gas during the BV feed and melting process needs to be understood, because key contaminants of concern (e.g., Tc, other radionuclides, heavy metals) may be present in the waste package in a non-vitrified form that could potentially be available for release to the environment. A considerable amount of testing to assess the likely fate of Tc within the waste package and the fraction that might be leachable has been performed. None of the tests to date have, however, included the recycle stream. Tc recycle will likely increase the $\mathrm{Tc}$ deposits in the refractories and on the lid. The uncertainty in estimates of leachable Tc fraction is considered to be significant issue, not only for qualification of the product, but also for developing a reliable flow sheet for the process.

\section{Other Recommendations}

The panel recommends a large number of small-scale tests. As with any process development, it is important to maintain a balance between large-scale testing, which is often the best way to reveal the effect of unforeseen interactions between complex processes, and small-scale testing, with which the details of the critical processes and mechanisms can be economically and rapidly discovered.

In addition, the panel believes that provisions should be made for more non-radioactive fullscale testing than is presently planned. In view of the decommissioning liabilities and the general complications presented by radioactive testing, such testing should only proceed once the remaining technical risks have been appropriately mitigated. The panel does not believe that full-scale radioactive testing is the appropriate vehicle for mitigating the majority of the remaining risks, but rather, should be viewed primarily as confirmation testing. The review team fully recognizes the value of and need for hot testing, but believes that too many issues have not yet been investigated with simulants to justify starting hot testing now. We are concerned that plans are based primarily on the hope that all will go well with the hot tests, making the simulant testing unnecessary, and not on solid results showing that success is likely with full-scale hot tests. This seems to us imprudent.

The report also provides general comments on the test program, focusing primarily on data gaps and recommendations for future testing, the SMF, the flow sheet model, maximum achievable control technology (MACT) compliance, fate of cesium, confirmation of Tc distribution, feed preparation, and melter enhancements. 


\title{
1.0 INTRODUCTION
}

\author{
RPP-30570, Rev. 0
}

\subsection{Problem}

At the U.S. Department of Energy (DOE) Hanford Site, the Waste Treatment Plant (WTP) is being constructed to immobilize both high-level waste (HLW) for disposal in a national repository and low-activity waste (LAW) for onsite, near-surface disposal. The schedule-controlling step for the WTP Project is vitrification of the large volume of LAW; current capacity of the WTP (as planned) would require 50 years to treat the Hanford tank waste, if the entire LAW volume were to be processed through the WTP. To reduce the time and cost for treatment of Hanford tank waste, and as required by the Tank Waste Remediation System Environmental Impact Statement Record of Decision and the Hanford Federal Facility Consent Agreement (Tri-Party Agreement), DOE plans to supplement the LAW treatment capacity of the WTP. Since 2002, DOE, in cooperation with the Environmental Protection Agency and State of Washington Department of Ecology has been evaluating technologies that could provide safe and effective supplemental treatment of LAW. Current efforts at Hanford ase intended to provide additional information to aid a joint agency decision on which technology will be used to supplement the WTP. A Research, Development and Demonstration permit has been issued by the State of Washington to build and (for a limited time) operate a bulk vitrification (BV) facility to provide information for the decision on a supplemental treatment technology for up to $50 \%$ of the LAW.

In the BV process, LAW, soil, and glass-forming chemicals are mixed, dried, and placed in a refractory-lined box. Electric current, supplied by two graphite electrodes in the box, melts the waste feed, producing a durable glass wasteform. Although recent modifications to the process have resulted in significant improvements, there are continuing technical concerns.

- During the melting process, some of the technetium (Tc) in the waste feed deposits in the refractory material as a soluble salt. In the performance assessment, this salt has the potential to create a Tc concentration peak in the groundwater extracted from a 100-meter downgradient well. Although this peak is below drinking-water standards, DOE desires to reduce the amount of soluble salt in the BV waste package and reduce the resulting groundwater peak to the extent possible to further enhance the performance of the BV product and improve regulatory acceptance of the technology.

- Metal inclusions have been observed in the resulting glass product. It is unknown whether these inclusions will have a deleterious effect on the long-term performance of the waste form. 
RPP-30570, Rev. 0

- Although the vitrified waste form is a borosilicate glass, similar to that currently being produced at the Savannah River Site (SRS) and planned for production at Hanford's WTP, there are questions about whether the BV product is comparable to referenced borosilicate glasses.

\subsection{Objectives}

The DOE Office of River Protection submitted a request for technical assistance to DOE EM-21 for provision of Subject Matter Experts in the areas of glass science, melter technology, refractories, and Tc chemistry to:

- assess and provide recommended refinements to existing methods and/or new methods to reduce the amount of soluble Tc salts that form in the BV waste package and provide comments related to the overall Tc mass balance;

- assess impact of metal inclusions on glass product quality and recommend potential process improvements that would mitigate their impact;

- evaluate potential performance of the BV product with respect to reference borosilicate glasses and glass quality standards, and recommend potential process improvements that would enhance product durability and leach properties.

The technical assistance request is provided in Appendix $\mathbf{A}$.

\subsection{Approach}

A panel of Subject Matter Experts was convened for a three-day workshop at Richland, Washington in January 2006. The technical experts were Dr. Frank Woolley, Corning Incorporated (retired), Dr. David Shuh, Lawrence Berkeley National Laboratory, and Dr. Ian Pegg, Catholic University. The panel was facilitated by Dr. Dawn Kaback of Geomatrix Consultants. Prior to the workshop, the expert panel was provided selected background materials (a subset of existing reports, meeting minutes, etc.) for review. At the workshop, additional written materials were provided to the panel. The materials provided for review include the following:

- General Background Information

- RPP-17403, Demonstration Bulk Vitrification System Specification

- Engineering Scale In-container Vitrification Test Results - Final Report, 8/03 
RPP-30570, Rev. 0

- Soluble Technetium in Refractory

- PNNL-15126, Rev. 1, Pierce EM, et.al. Laboratory Testing of Bulk Vitrified Low Activity Waste Forms to Support the 2005 Integrated Disposal Facility Performance Assessment, June 2005

- $\quad \operatorname{Re} / \mathrm{Tc}$ ES Test Summary Table (Preliminary Draft - 12/9/05)

- PNNL-15193, Hrma P, et.al. Bulk Vitrification Castable Refractory Block Protection Study. Pacific Northwest National Laboratory, Richland, WA, 5/05

- PNNL-15131, Kim D-S., et.al., Tc Reductant Chemistry and Crucible Melting Studies with Simulated Hanford Low-Activity Waste, March 20

- 35004-RT-0001, Rev. 1, Engineering-Scale Quantitative Test Report, Test ES-32B Final Report, AMEC Earth \& Environmental, Inc., GeoMeltTM Division, Richland, WA, June 2005

- Metal Inclusions

- Meeting Minutes - Recommendations for Mitigating Negative Effects Fe Metal in BV Melts (4/29/05)

- Summary: Estimate of Iron Metal Decrease for AMEC Test LS38B

- AMEC-TP-06-01, Rev. 0, Test Plan: AMEC/DBVS Project - NoIron Glass Formulation Crucible Tests

- 46611-2005-01, Rev. 0, Test Plan: Durability Measurements on Metal Inclusions Found in Bulk Vitrified Glass Using the SinglePass Flow-Through (SPFT) Test Method

- Glass Performance

- 35004-RT-0004, Rev. 0, Matrix Crucible Testing of Bulk Vitrification Glasses for Hanford Low-Activity Waste (Series 21 Test Report), AMEC Earth \& Environmental, Inc., GeoMelt ${ }^{\text {TM }}$ Division, Richland, WA, June 2005

- Information Provided at the Workshop

- AMEC 34005-PL-0010, Rev. 0, Demonstration Bulk Vitrification System (DBVS) Series 38 Testing, Large Scale Test 38B, Test Plan, October, 2005

- AMEC 34005-TI-0011, Rev. 0, Demonstration Bulk Vitrification System (DBVS) Series 38 Testing, Large Scale Test 38B, Test Instruction, November, 2005

- PNNL-15107, Testing of Large-Scale ICV Glasses with Hanford LAW Simulant, March, 2005 


\section{RPP-30570, Rev. 0 \\ - Table Summarizing Current Best Estimates of $\mathrm{Tc}$ and Re Distribution and Mass Balance Data from Engineering-Scale Tests, $1 / 16 / 06$ \\ - Miscellaneous materials, including copies of presentation materials, bulk vitrification system process-flow diagram, and schematics of SMF units.}

This review did not include review of the report on the latest large-scale test, 38-B; however, the Test Plan and Test Instructions were provided for review at the Workshop.

At the workshop, the panel was given technical briefings by BV project staff. It is noted that, given the limited time available for the panel to review background materials and hold discussions with Hanford staff, the scope of this project addressed the three issues previously identified; comments provided do not represent a full review of the BV technology, project status, and plans. At the conclusion of the workshop, the panel provided an out-briefing to DOE, CH2MHill Group, and Pacific Northwest National Laboratory (PNNL) staff. This report of findings and recommendations was then prepared by the panel. Workshop participants are shown in Appendix B. A draft report of findings and recommendations was then prepared by the panel, reviewed by $B V$ project staff, and revised by the panel to complete a final report. Additional comments were received after the period of performance of the expert panel. The panel does not agree with the majority of the comments but did agree that they should be included as an appendix.

The report contains a number of findings and recommendations made by the experts. An attempt was made to prioritize the recommendations in order of appearance, with the easiest to implement and most likely to succeed first. However, because of limited time, the panel was not able to prioritize all recommendations. Some of the recommendations listed last are presented as a first step in brainstorming new solutions to problems that have surfaced during the development efforts to date. Appendix $\mathrm{C}$ contains panel responses to comments that have not been incorporated into the final report. This appendix does not contain information regarding comments where edits were made in the report, but addresses areas where a consensus opinion could not be reached. A summary of Comment and Team Responses is included as Appendix D. 


\subsection{TECHNETIUM}

\section{RPP-30570, Rev. 0}

\subsection{Chemistry}

\subsubsection{Tc Challenges During BV}

Tc presents challenges and uncertainties for any high-temperature vitrification process, including BV, because of its volatility, mobility, and longevity. For BV, some of these challenges may have changed as the BV process was modified from a top-down to a bottom-up process. During vitrification, the major $\mathrm{Tc}$ concern relates to its volatility, which determines its level of incorporation into the glass product and the corresponding amount in the off-gas sent to the off-gas treatment system for recycle. Another challenge for the BV process has been limiting the deposition of soluble $\mathrm{Tc}$ in the refractory liner.

Tc volatility is affected by:

- the oxidation-reduction conditions of the melt

- vitrification process operational factors, such as temperature and the nature of the cold cap.

Current knowledge of Tc chemistry in the LAW waste stream feed is sufficient to predict that $\mathrm{Tc}$ will primarily be present as the pertechnetate $\left(\mathrm{TcO}_{4}\right)$ species, but may also contain a fraction of lower valent $\mathrm{Tc}$ species. There are limited data regarding the thermochemical properties of Tc species, which make it difficult to quantitatively predict its behavior in glass melts and off-gas produced during vitrification. This situation is further complicated by the incomplete knowledge of how Tc is immobilized in borosilicate glass waste forms regardless of the method of synthesis (Lukens, 2004; Anonini, 1985, and Lanza, 1992). Recent studies have demonstrated that $\mathrm{Tc}$ can be incorporated in a complete range of oxidation states, including metallic inclusions with iron and rhenium ( $\mathrm{Re}$ ) (Lukens et al., 2006). However, the actual speciation of Tc is not the critical factor; its leaching characteristics provide the final basis for performance assessments.

\subsubsection{Te Volatilization}

It has been recognized that $\mathrm{Tc}$ residence time at the melt surface, prior to being wetted and incorporated in the melt, is the time when it is extremely volatile. Tc volatilization diminishes sharply once limited by viscosity and diffusivity of $T c$ to the surface of the glass melt (Darab, 1996). The results from Kim et al. (2005) show that Tc is clearly volatilized from the glass melt in addition to being volatilized prior to incorporation in the melt. The melt conditions in the BV process may be 
RPP-30570, Rev. 0

sufficiently reducing so that $\mathrm{Tc}$, once in the melt is reduced to a lower oxidation state. Hence, Tc volatilization is greatly dependent on the temperature of the melt, glass viscosity, and the nature of the cold cap.

It has been previously believed that the oxidation state of $\mathrm{Tc}$ in the waste feed could have a significant effect on Tc volatility during vitrification. Reducing the oxidation state of the Tc species from $\mathrm{Tc}$ (VII) to $\mathrm{Tc}(\mathrm{IV})$, might result in reduced Tc volatility. However, this has been shown to be dependent on the exact conditions of vitrification and effective Tc reducing agents to be added to the feed have not been identified (see Section 2.2.3).

The volatile species during $\mathrm{BV}$ are likely one or some combination of the metal-TcO4 species (MTcO4): $\mathrm{NaTcO} 4, \mathrm{KTcO}_{4}$, and $\mathrm{CsTcO} 4$. The boiling point of $\mathrm{KTcO} 4$ is $1000^{\circ} \mathrm{C}$; other $\mathrm{MTcO} 4$ species have similar boiling points and all are believed to have appreciable vapor pressures above their melting points (Rard et al., 1999). Cold finger experiments by $\mathrm{Kim}$ et al. (2005) identified $\mathrm{KTcO} 4$ as an evolved product, which is reasonable, as it is the most stable of the $\mathrm{MTcO} 4$ species. The most volatile of the $\mathrm{Tc}$ oxides, $\mathrm{Tc} 2 \mathrm{O} 7$, has a generally recognized boiling point of $311^{\circ} \mathrm{C}$ (Rard et al., 1999). At the BV melt surface, rapid off-gassing of nitrates and sulfates could result in bubbling in the bottom-up melting process. This is likely to substantially contribute to Tc volatilization. Local hot spots, as at the electrodes in the current configuration, may also enhance volatilization of Tc.

Current plans call for the volatilized Tc to be transported to the off-gas system, where it will be recycled from a particulate filter and/or a secondary liquid. This recycling will effectively increase the Tc load in the waste stream to a level that depends upon the amount of Tc incorporated into the glass. Consequences of Tc recycling on the overall $\mathrm{BV}$ process are addressed in Section 3.3, 4.3, 4.5, and 4.6.

\subsubsection{Rhenium (Re) as a Tc Surrogate during BV Cold Testing}

Re has been employed as a cold-test surrogate for Tc in most of the tests conducted to date, whereas the ES-13 test utilized Re and Tc simultaneously to determine the validity of $R e$ as a surrogate. Although their chemistry is similar, there are differences in chemical speciation and thermodynamic properties under the range of conditions used for vitrification. The panel believes that $R e$ is the best surrogate for $T c$ in the cold BV tests; however, results must be validated in hot tests with Tc, prior to full-scale radioactive testing in the DBVS.

Prediction of $\mathrm{Tc}$ behavior through direct correlation with measured Re behavior needs to be done with care, due to differences in oxidation state between the two during incorporation into glass (Lukens, 2006). Re 


\section{RPP-30570, Rev. 0}

starting materials can disproportionate and be incorporated as both the $\mathrm{Re}$ (VII) and metallic droplets in the glass. In addition, the relative leaching behaviors of $\mathrm{Re}$ and $\mathrm{Tc}$ from borosilicate glasses is generally not well known. This is compounded by the lack of knowledge of Tc speciation in borosilicate glasses (Marples, 1991; Ebert 1996; Ebert, 1997). In this respect, care must be taken when performance assessments of the BV glass product are made.

The panel recommends that research-scale experiments be conducted to verify the continued validity of the surrogate relationship in glass or to establish a new relationship, if substantial BV process changes that could modify $\mathrm{Tc}$ or Re speciation in the glass are implemented.

When comparing $T c$ and $R e$ volatility under the same conditions during BV, close parallels can be established and relative behavior assessed accurately. However, if conditions are changed markedly (e.g., melting temperature or redox conditions), the relationship between the two in terms of volatility may change. Once again, the panel recommends research-scale melt experiments be effectively used to establish boundaries or re-establish correlations to map to the larger scale tests when needed.

In addition, chemical interactions with the refractory will be different for $\mathrm{Re}$ and $\mathrm{Tc}$, based on the large number of differences between the chemical behavior of the two elements. However, the use of $\operatorname{Re}$ as a surrogate for $\mathrm{Tc}$, with surrogate testing preceeding hot testing remains the best approach.

\subsection{Fate of Technetium}

It is imperative to understand the fate of Tc within the BV process, including significant Tc losses from the melt. This information is needed so that the overall impact of Tc fate on the BV process can be properly assessed and steps taken to mitigate the impact of the Tc not incorporated into the glass product. The overriding priority should be to incorporate as much non-leachable $\mathrm{Tc}$ as possible into the glass product (limit volatilization of Tc species) in a form and/or manner compliant with satisfactory performance assessments. Recommendations for Tc mitigation are contained in Section 2.3.

\subsubsection{Mass Balance}

Early BV engineering-scale studies were performed in a top-down manner, which resulted in excellent retention of $>90 \% \mathrm{Tc}$ in the waste package. In contrast, the switch to a bottom-up melt process resulted in retention of about half of the Tc in the BV product in the ES-12 engineering-scale test (where a full quantitative material balance was not performed) and $35 \%$ of the $\mathrm{Tc}$ in the glass product in the BV product in 
RPP-30570, Rev. 0

the ES-13 engineering-scale test. In ES-13 (ES-32B) where mass balance measurements were attempted, $24 \%$ of the Tc was unaccounted for. Of particular concern is the $2 \% \mathrm{Tc}$ on the container lid (ES-13), which could impact the performance assessment and/or require either cleaning or replacement at the completion of vitrification. A very small fraction is found in the refractory; there are active efforts underway to identify alternatives to further minimize this issue.

The most probable fate of the Tc unaccounted for in the bottom-up tests is volatilization into the off-gas system. However, the total amount of Tc in HEPA filters can be problematic to ascertain; substantial underestimates may result from the analytical measurements. The panel makes two suggestions to alleviate this difficulty: 1) addition of a removable filter material, such as glass wool, in a filter assembly in front of the HEPA filter to provide a more easily measured material, 2) an off-gas sampler with the gas run through a liquid scrubber (or mass filter) system for calculation of the Tc load.

Although not likely, it is also possible that some portion of the unaccounted for Tc may actually reside in the glass product, but has not been measured because of possible inhomogeneity (i.e. metal inclusions) within the glass product. Hence, the panel recommends that additional tests of Tc distribution within the glass be conducted.

If the unaccounted for $\mathrm{Tc}$ is found to be volatilizing into the off-gas system, this would present additional challenges for the overall BV system in terms of increased demands on the off-gas system and lid contamination. The current plan to reduce the impact of low Tc retention and increased off-gas load is to recycle the material removed from the off-gas and collected on the filter (see Section 2.3).

\subsubsection{Off-gas Recycle}

A major component of the proposed off-gas system is the sintered metal filter (SMF), which is the main particulate barrier limiting the downstream loading of the HEPA filter and the secondary waste stream. The SMF is designed to capture ejected particulates and return them to the feed of the BV dryer upon application of a sonic pulse, but is yet to be tested.

The current SMF is a stainless-steel design meant to operate at a temperature of about $300^{\circ} \mathrm{C}$ under normal conditions. Particulates containing Tc in several chemical forms could reach the SMF and become lodged in the filter material. To minimize volatilization of Tc that might arrive in particulate form and/or by in-situ oxidation in the filter, the SMF must be operated well below $311^{\circ} \mathrm{C}$, the generally 
RPP-30570, Rev. 0

recognized boiling point of Tc207. (The DBVS project team has noted this and made flowsheet adjustments to decrease the SMF operating temperature to $230^{\circ} \mathrm{C}$ ). Furthermore, it is likely that $\mathrm{Tc}$ will combine with $\mathrm{Cs}$ to form the species $\mathrm{CsTcO}_{4}$, which has vapor pressure characteristics similar to other $\mathrm{MTcO}_{4}$. As Tc is a known corrosion inhibitor, it is possible that solid-state or vapor-phase materials may not cause degradation of the SMF. However, the catalytic properties and activity of a 316-stainless steel surface in contact with several solid- state and/or gas-phase Tc species is not known. Further discussion of the SMF is contained in Section 5.2.

\subsubsection{Chemical Feed Considerations}

The pre-treatment of the waste stream to reduce $\mathrm{Tc}$ (VII) to a lower valence $\mathrm{Tc}(\mathrm{IV})$ species is an initially attractive approach to possibly limit the vaporization of $\mathrm{Tc}$ and enhance its incorporation in the glass. However, there are no known Tc reductants, which can accomplish this, because of rapid re-oxidation of $\mathrm{Tc}$ in the waste stream feed above $\mathrm{pH} 10$. $\mathrm{Tc}(\mathrm{IV})$ under these conditions has been shown to be thermodynamically unstable (Kim et al., 1999; Darab, 1996; Rard et al., 1999). A strategy to reduce $\mathrm{Tc}$ (VII) under the conditions that exist in the waste stream must be kinetic in nature, similar to the reason for the stability of $\mathrm{Tc}(\mathrm{I})$ in certain Hanford waste tanks (Lukens et al., 2004). A kinetic process would utilize an inorganic metal oxide or hydrous oxide matrix with a metal with the same ionic radius as $\mathrm{Tc}(\mathrm{IV}), \mathrm{Ti}(\mathrm{IV})$, or $\mathrm{Fe}$ (III) (Muller, 1964). However, initial attempts at kinetic stabilization have proven ineffective under waste-stream conditions. Furthermore, it is not clear that reduction to a $\operatorname{Tc}(\mathrm{IV})$ species, particularly the hydrous oxide, is desirable, because it could be rapidly oxidized to extremely volatile Tc207 or possibly disproportionate into two Tc species, one of which may be volatile, when introduced.

Another approach to control $\mathrm{Tc}$ volatilization might include addition of specialized materials to the feed in the dryer to control the chemical and/or physical nature of the melt cap. Section 2.3 .4 provides recommendations related to forming more reactive pellets, which could minimize Tc losses.

\subsection{Recommendations for Mitigation of Tc Loss}

The panel prefers to make concrete actionable recommendations for process improvements to the BV system. However, the limited information available to the panel makes this impractical. Instead, the recommendations that follow are intended to stimulate discussion. Although these ideas are known to work in apparently similar glass melting processes, the panel recognizes that some of them may be impractical in the DBVS, for reasons that may be unknown to us, 
RPP-30570, Rev. 0

and that others may have already been considered and tried or rejected for valid reasons. With these caveats, our recommendations are listed in the order in which the panel suggests they be considered. In each case, some of the advantages and potential pitfalls are described.

\subsubsection{Increase Tc Retention in the Melt}

Direct incorporation of $\mathrm{Tc}$ into the borosilicate melt occurs in the heating and dissolution processes that take place in and just above the fusion layer on the lower part of the cold cap. If the Tc goes into a liquid silicate phase (and not into a separate molten salt phase) at that point, then it is more likely to be retained in the glass. Three different categories of process changes are proposed to: 1) reduce Tc vaporization from top surface of the melt, 2) reduce Tc penetration into the refractory liner, and 3) promote faster reaction of waste feed pellets.

\subsubsection{Reduce Vaporization of Tc Species from Top Surface}

\subsubsection{Quantify rate-controlling parameters of $\mathrm{Tc}$ (and $\mathrm{Re}$ ) loss from fusion layer of cold cap}

A good empirical quantitative understanding of the rate of loss of $\mathrm{Tc}$ (and Re) as a function of bath temperature, cold cap thickness, Tc concentration in feed, raw materials (and their effect on initial liquid composition), and reductants is needed to design and prioritize tests aimed at reducing vaporization. Because of the difficulty of making measurements inside large melters, and of producing and controlling all the key process parameters, it is much more practical to do this testing on a lab or engineering scale rather than in full-scale equipment.

\subsubsection{Maintain a constant cold cap thickness with a cool top surface}

Anticipating the results of the testing recommended in the previous paragraph, it is safe to say that maintaining complete coverage of the melt surface by a cold cap having a top surface close to room temperature is the surest way to limit Tc loss by vaporization. In addition, insulating the melt surface allows the bulk melt temperature to be increased, which would result in increased processing rates.

In a cold cap of constant thickness, a condensation layer will develop just above the fusion layer. The concentration of $\mathrm{Tc}$ in that condensation layer will quickly equilibrate at whatever (high) level is necessary to cause the Tc concentration in the molten glass to equal that in the feed. The inventory of condensate in the 


\section{RPP-30570, Rev. 0}

cold cap depends critically on its thickness. Two conditions are necessary to maintain that condensation layer: the melt must be held at a constant temperature and its surface must be cooled continuously by the incoming feed stream. Under these conditions, the cold cap thickness and its inventory of condensates will remain constant. The following options can be considered to maintain constant cold cap thickness, thus mitigating Tc loss. They are listed in order of decreasing desirability. Comments provided describe ease of implementation.

- Maintain a constant bath temperature.

Constant thickness and Tc inventory of the condensation layer depend on maintaining a constant temperature gradient through the cold cap. This is best accomplished by holding bath temperature constant and adjusting feed rate to maintain a constant cold cap thickness.

- Feed continuously and never melt the cold cap

It is very important that feeding not be internupted, because that allows the cold cap to melt, releasing its inventory of condensed $\mathrm{Tc}$ and other volatile radionuclides (Cs, I). The following approaches to continuous feed might be feasible in the proposed DBVS.

- Add a second dryer/mixer (in parallel).

- This is the most desirable method of maintaining constant cold cap thickness, because it provides redundancy as well as continuous feed under normal conditions.

- Add a feed surge tank between the dryer and the melter.

- This introduces another feed transfer step, which increases the risk of plugging.

- Mix and dry continuously, not batchwise.

This requires either continuous weighing of each component, or addition of a batchwise dry mixing step prior to continuously adding liquid waste and drying, followed by continuous feeding of the boron source only. This is a complicated approach, and is suggested for consideration, only if a second dryer or surge tank is truly impractical. A reviewer's suggestion for semi-continuous, partial dryer batch additions at higher frequency deserves consideration. 
RPP-30570, Rev. 0

- Cool the melt surface aggressively when feed is not available.

Although no product is being made when there is no feed, it may be possible to retain most of the $\mathrm{Tc}$ in the melt and in the layer of condensate that forms in the cold cap, if the surface is kept cool. Reducing electrical power and introducing a strong flow of cooling air may provide adequate cooling, but if not, air/water mists could be used to extract much more energy. There should be less of a safety issue with water mists than with slurry feeding, but the uniformity of cooling required to maintain the cold cap makes cooling with water mists difficult to implement.

\subsubsection{Improve uniformity of feed distribution over the melt surface}

Three options for improving the uniformity of feed distribution over the melt surface are suggested in order of increasing technical difficulty.

- Add a third fill port or angled chutes through the two existing ports.

- Distribute feed laterally below each port, using deflector plates or cones, rotating sweeper arms, or a rotating angled chute. All of these devices ase prone to fouling and would require significant development effort.

- Convert the feed into hard round pellets in the mixer/ dryer.

This last approach can be extremely difficult, but it has the potential to also address the refractory problem, so it is discussed in Section 2.3 .4 below.

\subsubsection{Reduce Tc Penetration into the Refractory Liner}

Migration of volatile species of Tc through a refractory liner containing connected porosity can occur by vaporization/condensation mechanisms or by liquid flow. Based on the test results presented, it appears that the principal mechanism for migration of Tc into the porous refractory liner is the capillarity-driven flow of Tc-containing molten salts having melting temperatures as low as $300^{\circ} \mathrm{C}$. At such a low temperature, molten salts react slowly or not at all with the porous refractory; hence, salts continue to penetrate rather than forming a viscous glassy phase that prevents further penetration into the refractory.

The most robust solution to this problem is obviously to find a refractory with no porosity or only closed porosity. The amount of material needed 
RPP-30570, Rev. 0

to line the entire melter, the need for good resistance to corrosion by molten glass, and the economic constraint imposed by the short life of the melter, severely limit the choices. This panel did not have the opportunity to review the considerable information that has been produced by the project on this issue, but suggests consideration (or reconsideration) of the following approaches to limit penetration of Tc-containing molten salts and vapor species into the castable refractory block (CRB) in contact with molten glass. The preferred approach to reduce Tc penetration should be to find a refractory material that has lower permeability in its as-received condition. The various options to make only the surface of the refractory lower in permeability will always result in a material that is more complicated and more prone to failure than a homogeneous refractory of intrinsically lower permeability.

\subsubsection{Substitute sintered amorphous silica for the mullite CRB}

Sintered amorphous silica, a material commonly used in the specialty glass industry and in metal melting, may have a lower permeability for both vapors and molten salts containing $T c$ than the mullite CRB. It may be possible to either substitute silica for the mullite or to clad the mullite CRB with sintered fused silica plates, if an adequate bond could be obtained. Because of its high thermal shock resistance, silica can be used in thinner layers than most other refractory materials. In the presence of alkalies, amorphous silica slowly crystallizes, losing its structural integrity; it probably would last long enough in this application, because of the short melt-cycle time. The silica can be made impermeable by flame- or arc-glazing, a process that would need to be applied before it is installed in the melter. Vesuvius is one manufacturer of sintered amorphous silica.

\subsubsection{Trap Tc in a thick layer of porous refractory}

If a material that is both corrosion resistant and impermeable to Tc-containing vapors and molten salts cannot be found, then a strategy to separate the functions of corrosion resistance and impermeability might be considered. A liner with adequate corrosion resistance (like the mullite CRB presently used) could be installed, then coated or clad with a sacrificial inner liner. This inner lining would be designed to absorb molten salts and vapors at low temperature as the cold cap approaches and contacts it, preventing penetration into the corrosion-resistant liner. As the cold cap rises above the Tc-containing sacrificial layer, it would dissolve in the melt at high temperature, perhaps taking most of the $T c$ into solution in the melt. This inner liner needs to be reactive toward the $\mathrm{Tc}$-containing salts and vapors, and have a 
RPP-30570, Rev. 0

high solubility for sulfates and chlorides, but be totally soluble in the alkali alumino-borosilicate melt.

A suggested starting point in the search for a suitable material would be a low-temperature insulating brick with a high silica content and high internal surface area, either as-manufactured or saturated with compounds designed to react with the Tccontaining species to form a low-melting glassy phase. The inner lining might be placed as panels or gunned on as a continuous liner.

The work currently underway to add sodium silicate to the current CRB material to cast a low- durability, inner liner with a highdurability outer layer seems promising.

\subsubsection{Coat mullite CRB with high-silica frit}

Because addition of silica to alkali silicate melts increases their viscosity dramatically, it may be possible to stop the penetration of Tc-containing molten salts and alkali vapors by coating or impregnating the mullite $\mathrm{CRB}$ with silica in the form of a high surface-area powder. A binder would be needed to keep the powder in place until it reacts with vapors or salts, forming a high-viscosity surface layer of reduced permeability.

Promising work currently under way at PNNL is based on a similar idea, but adds fine silica materials to the batch to react with the molten ionic salts (MIS) at lower temperatures, preventing its movement into the CRB wall. If successful, this approach would be much simpler and more reliable.

Because this fundamentally changes the sequence of reactions in the cold cap, Tc retention will certainly be changed and will need to be determined by small-scale tests.

\subsubsection{Coat refractory walls with molten glass}

If the above measures do not reduce $T c$ penetration to an acceptable level, it may be worth considering coating the interior walls of the CRB with molten glass, which will penetrate the porous refractory, effectively sealing against subsequent penetration by both molten salts and vapors. If a glass composition that has a thermal expansion coefficient close to that of the refractory is chosen, it should be possible to seal the refractory prior to introducing feed. Other than the thermal expansion, there are few constraints on the glass composition. A 


\section{RPP-30570, Rev. 0}

glass with a very low viscosity curve would be easier to apply. One that exhibits a strong increase in viscosity as refractory dissolves in the glass would remain near the surface and provide better protection against penetration.

Five methods for applying hot glass to the refractory are offered for consideration. Four of these methods coat the refractory before any feed is introduced; the last method uses the molten glass in the melter during waste processing as a coating. These ideas might be best treated as starting points for brainstorming, because each of them have serious practical issues that need inputs from those more familiar with the BV process than this panel.

- Fuse frit onto refractory panels before assembly.

The simplest approach would be to have the refractory supplier coat the panels before shipping them to the assembly site. A good thermal expansion match is required to prevent spalling during shipping and assembly, and a thinner layer would increase the chances of survival of the panels.

- Melt glass frit held with a binder in the assembled melter.

Fine-particle size distribution (PSD) frit, held in place by a binder that hardens at room temperature, could be melted and allowed to penetrate the refractory. Heat could be supplied with burners inserted through the fill holes before feed is started. (Heat from the melting process would not be adequate to fuse the frit before vapor and salt penetration had occurred.) Cooling or thermal shielding may be needed to protect the electrodes from oxidation, unless electrodes could be inserted after the coating process is completed.

- Blow frit blown hot refractory in the assembled melter.

It may be easier to coat the refractory by first preheating it with gas burners, then blowing coarse frit against the hot walls, where frit particles will stick and fuse into a continuous layer before soaking into the refractory.

- Puddle molten frit on the refractory.

While the melter is still in its assembly location, it may be possible to heat the refractory interior with gas burners and allow a shallow pool of molten frit to soak into the refractory bottom. By rotating the melter nearly 90 degrees onto each long side, the 
RPP-30570, Rev. 0

sides could be similarly coated. It is impractical to coat the ends in this fashion.

- Tilt the melter during operation

The container walls could be coated with hot glass during the melting cycle. If the melter were placed on a tilting platform, it should be possible to tilt it slowly on its long axis, allowing the walls just above the melt level to be coated. Inclining the melter about 20 degrees would coat the wall about one foot above the melt level. This would have to be repeated about every 6 inches as the melt level rose, to keep the wall coated at least 6 inches above the fusion zone. This implies 10-12 tilting operations in each direction per melter cycle, not a very attractive proposition.

\subsubsection{Limit Tc Loss with Faster Reaction in Strong Feed Pellets}

The combination of strongly alkaline liquid and fine particle-size refractory components in the feed presents an ideal situation for producing a feed form that will react quickly, incorporating the Tc in a molten silicate phase, before it can vaporize or segregate as a MIS. A major goal of the mixer/dryer should be to produce strong pellets, with each pellet having essentially the same composition as the overall feed. The close proximity of the fluxes to the fine refractory components in each pellet will ensure that the glass-forming reactions occur faster and at a lower temperature than would occur in loose (unpelletized) feed. This should result in less $T c$ vaporization, less molten salt penetration of refractory, less segregation of slow-dissolving components, and faster melting.

Hard round pellets should have a consistently low angle of repose, allowing them to be distributed more uniformly over the melter surface.

The panel recommends testing operation of the mixer/dryer to make strong feed pellets. Littleford Day should be able to provide assistance and perhaps test facilities to be used to determine how to operate the mixer/ dryer as an efficient pelletizer. It may be necessary to select raw materials of different surface characteristics (particle size and shape) and to add materials that act as binders to give good mechanical properties at low drying temperatures. Organic binders may play a dual role, acting also as reductants. As one reviewer pointed out, any organic added must be compatible with the nitrate salts at dryer temperatures to avoid uncontrolled exothermic reactions in the dryer. 
RPP-30570, Rev. 0

\subsubsection{Tailor raw materials and order of addition}

To produce uniformly-sized, hard, round pellets at a low dryer temperature, some of the materials must have a very fine particle size and be quite reactive toward the alkaline waste solution. Clays, other fine refractory raw materials, and organic and inorganic binders may be helpful. The order of addition is frequently important, as it determines which components have the greatest contact with other components.

\subsubsection{Quantify melting behavior of strong pellets}

During heat up of the feed in the cold cap, a liquid phase is formed by reactions between components of the feed. This liquid then incorporates other soluble components. These reactions usually begin at low temperatures in pellets formed by reaction between alkali solutions (e.g., liquid waste) and fine oxides. The melting rate and the rate of $\mathrm{Tc}$ vaporization should be measured on a small scale before full-scale tests are undertaken.

\subsection{NIETAL INCLUSIONS}

\subsection{Impact on Glass Performance}

Test results have shown that the metal inclusions formed in the vitrified product have higher concentrations of Tc (and its Re surrogate) than the glass. The enrichment factor, the ratio of the concentration of $\mathrm{Tc}$ in the metal to that in the host glass matrix, has been measured to be on the order of 100 -fold. Because the metal phase, which is predominantly iron, is more soluble than the glass in the expected disposal environment, its presence may increase the rate of release of Tc. Accordingly, if metal inclusions are present, it is essential that the extent of this impact be understood and minimized.

In addition to the $\mathrm{Tc}$ enrichment factor, the total mass fraction of metal in the product and its distribution within the product are also key factors in determining the overall rate impact on performance. It seems reasonable to expect that, other things equal, the overall rate of release of Tc would decrease as the Tc enrichment factor decreases, as the total mass fraction of metal decreases, and as the distribution of metal phase changes from large ingots near the surface of the glass product towards finely divided inclusions uniformly distributed throughout the glass phase. At present, the effects of process chemistry and operating conditions on these factors are not totally understood. Efforts to date have focused on minimizing the total mass fraction of metal in the product. Recent tests have indicated some success in reducing the total amount of ingots at the bottom of the product. While this emphasis is reasonable in terms of prioritizing 
RPP-30570, Rev. 0

the testing efforts, the potential for mitigation focused on Tc enrichment and metal distribution should not be overlooked.

Earlier tests (done on non-oxidizing feed with the test objectives for thermal loading of the ICV) have shown that the majority of the metal was in the form of ingots at the bottom of the product; more recent test results (with feed materials including oxidants) have shown progress in reducing the amount of metal in the form of ingots. However, several test conditions were changed at once to maximize the likelihood of "success." While this permits a form of empirical progress, it complicates subsequent optimization steps, because the relative effects of the earlier changes are not known, nor is it known which changes were essential and which were redundant. Thus, while the progress is encouraging, the panel recommends that subsequent testing should seek to separate the effects of these changes.

The test data indicate that the glass product also contains inclusions of metal particles of various sizes distributed through the glass phase. For a given total amount of $\mathrm{Tc}$, the surrounding glass phase is depleted in proportion to the $\mathrm{Tc}$ enrichment in the metal particles. Then, in terms of release, if it is assumed that the surrounding glass phase must be dissolved before a metal particle becomes available for dissolution, one could argue that the rate of $\mathrm{Tc}$ release is still dominated by the rate of dissolution of the glass phase. While such a simple model of this kind is a start, the importance of this issue warrants a more sophisticated analysis and supporting testing. A number of complicating factors need to be considered:

- metal particle size and distribution in relation to the ultimate mean fractured glass particle size (because the thermally stressed glass product will fracture into chunks);

- effects on glass fracturing of differential thermal expansion and potential presence of crystals formed by devitrification of the glass phase during cooling;

- potential for agglomeration and sedimentation of the metal inclusions, because it provides a mechanism to bring Tc-enriched metal phase to the bottom surface, thus eliminating the dependence on dissolution of the glass matrix as the rate-controlling parameter.

\subsection{Recommendations for Design and Operation to Eliminate Metal Inclusions}

This section of the report covers recommended actions to eliminate metal inclusions. Total elimination of all metal inclusions may not be possible, but these approaches are suggested as ways to minimize the amount of metal produced. Because the reactions that produce metal inclusions are very sensitive to small changes in temperature and concentrations in the melt, they should not 
RPP-30570, Rev. 0

be expected to occur uniformly throughout a large melter or consistently from melt to melt. The panel recommends that, considering this inherent variability, the goal should be total elimination of metal inclusions.

Large reductions in the mass of metal inclusions produced in large-scale tests have recently been achieved (in Test 38-B) by reducing the amount of graphite in the starter path, and by better control of both start up and operational temperatures in the melt pool through tighter control of current density and bath temperature. This demonstrates the potential for further reducing or even totally eliminating these inclusions.

The panel recommends that an effort be made to determine the details of the mechanisms by which metal inclusions are formed as the fastest and most economical way to learn how to eliminate them.

\subsubsection{Determine Mechanisms}

Two fundamental processes probably account for most of the reduction of iron and other metals to their elemental state during melting: carbothermic reduction, both by starter-path materials and by electrodes, and electrochemical reduction on the electrodes. With better knowledge of the relative importance of the fundamental processes, and of their sensitivity to temperature and iron content of the bath, actions intended to counter them (discussed below) can be prioritized, leading to further reductions in the mass of metal inclusions.

The panel recommends lab-scale testing to quantify the rate of formation of inclusions by each fundamental mechanism, because the effects of each mechanism cannot be separated in large-scale tests, where it is impractical or impossible to control and measure local conditions adequately.

\subsubsection{Formation of metal inclusions on graphite flake starter path}

Tests should be designed to quantify the effects of the key parameters: iron concentration in the glass phase, melt temperature along the starter path, and the graphite surface area available for reaction.

\subsubsection{Formation of metal inclusions on graphite electrodes}

Tests should be designed to quantify the effects of key parameters: 
RPP-30570, Rev. 0

- for unpowered graphite electrodes in the melt, the key parameters will be iron concentration in the glass phase and temperature at the graphite/melt interface;

- for powered electrodes, iron concentration in the glass phase and interface temperature will be the key parameters, along with current density at the electrode surface, DC bias, and frequency of the power supply.

Note that the melt is very non-uniformly heated with cylindrical electrodes, as the melt adjacent to the electrode is sometimes several hundred degrees hotter than the bulk melt. This overheating is directly related to the current density. DC bias arises when there is an asymmetry (geometric or thermal) between the two electrodes. Current density and frequency together determine the total charge transferred each half cycle per unit area of electrode surface, and hence, the extent to which metal inclusions are produced by a process sometimes referred to as Faradaic rectification.

\subsubsection{Reduce Role of Starter Path in Production of Inclusions}

The steps that have already been taken to reduce the size of the starter path have been successful. The panel recommends the following actions, with the most promising listed first, to continue this progress.

\subsubsection{Eliminate iron in starter path and first batch of feed}

Because the graphite introduced in the starter path probably remains in the melt for some time before it burns off, the first portion of the feed should be low-iron. Substituting low-iron raw materials for Fe-bearing soil in the first complete batch of feed may provide enough time for most of the graphite to be eliminated, before it can contact iron-containing glass. At the time of this review, this action was planned.

\subsubsection{Substitute small graphite plates}

The graphite is oxidized either by reaction with reducible metal ions in the melt (clearly undesirable), or with molten salts (nitrates, sulfates) in the fusion layer of the cold cap, or with oxygen in the atmosphere above the cold cap. Thus, it is helpful if the graphite used to create a conductive path floats quickly to the melt surface. Substituting plates for at least part of the fine graphite flakes presently used in starter path should accelerate the graphite burnout. 
RPP-30570, Rev. 0

\subsubsection{Use graphite-free starter path}

It may be possible to start the process with a paste of ionic salts, which would form a conductive path for initial heating, then decompose or dissolve in the melt that forms around the path. The panel considers this to be the least likely approach, and has no specific materials to propose.

\subsubsection{Reduce Role of Electrodes in Production of Inclusions}

It seems likely that carbothermic reduction at the surface of the electrodes is the major source of metal inclusions. Anticipating the results of the testing recommended above to quantify the rate of production of inclusions, it is reasonable to assume that the key parameter will prove to be interface temperature, which is driven by current density. The following actions are recommended, subject to results of the mechanism testing recommended above. The approaches are listed with the easiest to implement first.

\subsubsection{Lower power input}

Current density is the most important parameter, because higher current densities directly cause electrochemical reduction, and indirectly cause carbothermic reduction by raising the interface temperature. The simplest way to lower current density is to lower the total power fed to the melter. The obvious disadvantage is the resulting reduction in melting rate.

The most critical period is the initial part of the cycle, when a small volume of melt contacted by a very limited electrode area is providing the energy to raise the temperature of the entire melter.

\subsubsection{Increasing electrode area}

A better, but more difficult, way to lower current density on electrodes throughout the melt cycle is to increase the surface area of the electrodes. Two approaches are proposed, both well beyond the AMEC technology base, but the first is well established in commercial electric melters:

- Plate electrodes

Covering the entire ends of the melt chamber with graphite plates improves the design in two ways: 
RPP-30570, Rev, 0

- The effective surface area of each electrode would be increased by about 3 times, and plate electrodes would be much easier to cool. (The back third of a vertical rod electrode is usually considered to be inactive because of the longer current pathway.) Electrical connection to the plates could be through the top or through the end walls, with metal-to-graphite connections cooled by air or water.

- Inverted-T electrode.

A horizontal graphite bar, placed across the full width of the bottom under each cylindrical electrode, would greatly increase the electrode area during the initial part of the melting cycle. The vertical and horizontal electrodes could be connected electrically with graphite paste. The panel is unaware of such an electrode configuration in commercial electric melters, but this would require fewer design changes than the preferred plate electrode configuration.

\subsubsection{Cool the electrode/melt interface}

Because the glass is quite electrically conductive well below bulk melt temperatures, reactions at the electrode surface can be slowed or nearly stopped by cooling the electrodes. Although it would be possible to install cooling inside the cylindrical electrodes, it is more practical to cool plate electrodes on the ends of the melter. A high-conductivity electrical-insulating refractory (e.g., alumina) would conduct heat out of plate electrodes to the air-cooled steel shell. Graphite paste could be used, if necessary, to improve thermal contact between the alumina and graphite plates.

\subsubsection{Prevent electrochemical reduction}

Although most of the production of metallic inclusions is probably carbothermic, there may be some electrochemical reduction, especially early in the process, when current densities are typically higher. Two approaches are available to counter this mechanism:

\section{- Applying a DC bias}

If each electrode is connected to a small graphite plate electrode on the bottom in the center of the melter, a DC potential can be applied to offset the tendency, to some extent, to reduce ions to 
RPP-30570, Rev. 0

the metallic state on the cathodic half cycle. The feasibility of this approach would need to be demonstrated on a lab scale.

- Powering at a higher frequency

Electrochemical reduction with an $\mathrm{AC}$ power supply occurs when the metal produced on the cathodic half cycle moves out of electrical contact with the electrode, before it has a chance to be re-oxidized on the anodic half cycle. The amount of metal produced depends on the mobility of the metallic inclusions and is directly proportional to the amount of charge transferred on each half cycle. Increasing the frequency of the $\mathrm{AC}$ power reduces the charge transferred in inverse proportion to the frequency. Moderately-high frequency (e.g., $1000 \mathrm{~Hz}$ ) power supplies of the capacity needed for this process are used in some inductionheating applications.

\subsubsection{Preferred approach to eliminate metal inclusions}

Assuming that testing shows that carbothermic reduction at the surface of the electrodes is the major source of metal inclusions, the most likely way to unequivocally eliminate metal inclusions is to employ externally-cooled plate electrodes. Technically, the most important parameter to control is the interface temperature, and this approach gives direct and powerful control over that parameter. This is a major change from the present technology, but the issues are likely to be almost entirely technical and economic. Alongside the alternative discussed next, where the issues are technical, economic, and especially regulatory, it may not be an unreasonable approach.

\subsubsection{Develop a Low-iron Glass Composition}

If none of the above measures eliminate metal inclusions, the plan to use native soil as a raw material should be reconsidered. Other low-cost raw materials, such as low-Fe clays, sands volcanic ashes, and conventional glass-forming chemicals are reasonable alternatives to the proposed $\mathrm{Fe}$ rich soil. Their use would give additional benefits of flexibility in the $\mathrm{Si} / \mathrm{Al}$ ratio (which impacts the maximum waste loading) and in tailoring the feed for better pelletizing in the mixer/ dryer to obtain a non-caking, free-flowing feed, which would react more rapidly during melting.

The total iron content of the glass should probably be around $0.1 \mathrm{wt} . \%$ $\mathrm{Fe}_{2} \mathrm{O}_{3}$, to obtain the best compromise between low raw materials cost and high infrared transmission in the melt (better heat transfer). Process advantages of a low-Fe glass, all resulting from the improved heat 
RPP-30570, Rev. 0

transfer within the melt, include: a) better radiative cooling of the electrodes, b) less tendency to coring (hot channels in bath), c) higher melting rate, and d) more uniform temperature throughout the melt volume (less tendency to devitrification in cooler regions).

\subsubsection{General considerations and schedule implications}

The inherently reducing environment created by the graphite electrodes and the high local temperature around the electrodes as a result of the rod geometry potentially can drive the more reducible species present in the feed to their metallic states. Because iron is both sufficiently reducible and abundant in the feed, it dominates the composition of the metallic phase that is observed. While a variety of potential mitigating approaches are possible, one of the more obvious and effective approaches is to simply remove most of the iron from the feed. Because iron has a very low solubility in the caustic supernate, there is very little iron in the LAW material. Essentially all of the iron (totaling around 4 to $4.6 \mathrm{wt} \%$ as $\mathrm{Fe}_{2} \mathrm{O}_{3}$ in the final glass) originates in the soil that is used as a glass-forming feed material. It is worth noting that in addition to iron, the Hanford soil also contains a significant amount of sodium (about $3 \mathrm{wt} \%$ as $\mathrm{Na}_{2} \mathrm{O}$ ), which necessitates a reduction in waste loading for the high-sodium LAW material, the cost of which probably will far outweigh any savings on raw material costs. Thus, for process and cost reasons it may be worth considering either alternative soils that are low in iron (and preferably also low in sodium) or, preferably, switching to more standard glass-forming materials that would also provide better process control and flexibility.

An important disadvantage of changing to a low-iron glass composition, however, is the relative paucity of data and the departure from the "main-stream" waste vitrification experience around the world, which is dominated by iron-containing glass compositions. Although the magnitude of the composition change is relatively small (amounting to just a few weight percent), this results in significant changes in properties, such as infrared absorption and redox chemistry in the melt. Consequently, it should be expected that such a change, while likely beneficial in the long run, will require its own learning curve in terms of how it impacts the process. This includes a variety of subtle possible consequences, such as effects on the behavior of $\mathrm{Tc}$ in the absence of iron, which need to be considered. While it should be expected that there will also be changes in product properties, there is no reason to believe that these cannot be compensated, such that acceptable product quality 


\section{RPP-30570, Rev. 0}

(as well as melt properties such as viscosity, electrical conductivity, and phase stability) can still be achieved. This is supported by results of preliminary studies performed on low-iron glasses for the BV Project.

The panel recommends that efforts to eliminate metal inclusions, as outlined in Sections 3.2.1 to 3.2.3, should be the preferred strategy. While the low-iron glass strategy (Section 3.2.4) has lower technical risk and a higher probability of success in terms of total elimination of the separate metal phase, it is likely to take longer to implement and is also subject to risks related to acceptance (Section 3.2.4.1), which are difficult to quantify at this time. Consequently, it is recommended that the low-iron glass strategy be pursued in parallel, while these risks are evaluated.

\subsubsection{Effect on Tc chemistry and Tc loss from the cold cap}

By changing to a low-iron glass, overall redox conditions of the melt would most likely change, but the resulting effect on $\mathrm{Tc}$ fate and transport is uncertain. Given the current reducing conditions, the redox change may not be significant with respect to $\mathrm{Tc}$ speciation. Possible chemical interactions between iron and Tc may affect $\mathrm{Tc}$ volatility, thereby affecting $\mathrm{Tc}$ retention. If a lowiron glass is adopted, the lab testing proposed above to quantify the rate-controlling parameters in Tc vaporization from the surface would need to be expanded to the low-Fe compositions under consideration.

\subsubsection{Recommendations for low-iron glass}

As a result of the above discussion, the following recommendations are made. These recommendations do not preclude starting the DBVS test facility, because they can be investigated in parallel with the planned DBVS operations. Modifications resulting from these recommendations could be implemented later in the test program.

- In the long run, the potential advantages of employing a low-iron glass composition are sufficiently great that testing should be continued to support a change to a lowiron composition. It may be easier to gain acceptance of this change in composition, if a serious effort is made first to find the highest iron content at which metal inclusions are no longer formed in the process. 
RPP-30570, Rev. 0

- While there are obvious data needs in terms of supporting an appropriate glass composition-property envelope to support process operations, the impacts on the behavior of the process should not be neglected. Sufficient engineering and full-scale testing should be allocated to support understanding and re-baselining the "normal" process behavior and the revision of acceptable operating parameter ranges for the low-iron flow-sheet.

- In view of its importance and complexity, potential changes in the behavior of $\mathrm{Tc}$ in a low-iron flow-sheet should be assessed.

- It is not recommended that a low-iron composition be implemented for the next full-scale test, because changes in several variables are already planned. Testing of the low-iron composition should be conducted as part of a full-scale test program once the recommended supporting lab- and engineering-scale data become available. . It is recognized that crucible-scale glass testing data that have already been collected support the viability of such an approach to achieve suitable glass properties.

\subsection{Recommendations to Control Formation of Metal Inclusions}

The panel believes that the primary strategy with respect to metal inclusions should be to eliminate them totally, if possible. If the methods recommended in Section 3.2 to entirely eliminate metal inclusions in the glass, either by design and operational changes or by a change to a low-iron composition, are found to be untenable, the following recommendations are offered to assess and minimize the negative impact of metal inclusions on product performance.

- Additional testing should be performed to determine the key factors that influence and control: (i) enrichment of Tc in the metal phase; (ii) mass fraction of metal that is formed; and (iii) size and spatial distribution of the metal phase within the product. The results should be used to determine the preferred combination of process changes to best mitigate the impacts of metal inclusions. Based on this information, the process operating envelope could be defined to ensure that only "acceptable" inclusions (in terms of, e.g., amount, sizes, distribution, enrichment) are produced.

- Testing should be performed to determine the effects of including the projected Tc recycle stream into the feed on the Tc enrichment in the metal phase. 


\section{RPP-30570, Rev. 0}

- Modeling should be performed to address the expected impact on Tc release of a glass phase with Tc-enriched metal inclusions. While it is possible that a bounding model may be sufficient, the effects of particle size (metal vs. fractured glass), differential thermal expansion, and the presence of crystals, should be assessed.

- Leach testing should be performed on prototypical product material composed of glass, metal inclusions, and crystals. The potential for enhanced glass dissolution rates in the presence of metallic iron alloy should be addressed. Tests using actual metal samples obtained from the engineering-scale test, ES-32B, are already planned.

\subsection{PRODUCT PERFORNLANCE}

In comparison to the products from other nuclear waste vitrification processes (e.g., the Immobilized Low Activity Waste [ILAW] product to be produced at the IVTP, glasses produced at the West Valley Demonstration Project [WVDP] in New York, and the Defense Waste Processing Facility [DWPF] at the SRS in South Carolina), the BV product is considerably more complex. In addition to the glass, in which there may be crystals and metal inclusions, the waste package is currently expected to contain a salt phase plus the container, refractory lining, graphite electrodes, and possibly the lid structure with associated ports and fittings. Issues associated with the contributions of each of these components to the overall performance of the waste package are discussed in this section.

\subsection{Glass}

In many respects, the glass represents the simplest part of the overall waste package. The glass testing program appears to be reasonable and results to date support the contention that the homogeneous glass phase is capable of providing acceptable performance. Simple comparisons of the compositions with known compositions and properties of similar glasses are also consistent with this expectation. However, the full-scale process may be subject to additional complications from effects, such as glass homogeneity (given the size of the waste package), thermal history, and redox state. Such factors must be addressed through appropriate testing and their effects or lack thereof dispositioned accordingly.

The graphite electrodes create reducing conditions in the melt. Test data indicate that redox ratios as high as $\mathrm{Fe}^{2+} /\left(\mathrm{Fe}^{2+}+\mathrm{Fe}^{3+}\right)=0.80$ have been found in glass product samples from large-scale tests. Such high redox ratios are considerably above the testing and operating experience base of other nuclear waste vitrification processes (e.g., WVDP, DWPF, WTP LAW, WTP HLW, German, French, UK, and Japanese HLW). As a result, there are few product leach test data available for such highly reduced glasses. Because the redox state is, in many respects, also a composition variable (i.e., in the sense of determining the 


\section{RPP-30570, Rev. 0}

relative proportions of, e.g., $\mathrm{Fe}_{2} \mathrm{O}_{3}$ vs. $\mathrm{FeO}$, which have quite different effects on glass properties), its impacts on glass properties must be determined, and appropriate redox control ranges established for the process. Because the electrodes create a localized reducing condition, there may be substantial redox gradients or inhomogeneities across the glass product. Sampling and productquality and performance-assessment testing of full-scale products should be sufficiently extensive to address this issue.

\subsection{Crystals}

Depending on their composition and thermal history, varying amounts and types of crystalline phases can form during cooling within the amorphous glass; this process is called devitrification. In addition, the melts can separate into two or more amorphous phases of differing compositions; this process is called amorphous phase separation. These processes complicate the assessment of the performance of the resulting multiphase material, as compared with a single homogeneous glass phase. While it is possible that multi-phase materials may meet all of the product-quality requirements, demonstration that that is, indeed the case, typically requires significantly more data. Despite the fact that there is no current requirement to measure or report crystal content for WTP LAW or BV glasses, it is required by the LAW product-acceptance specifications that their impact on product quality be determined. In this respect, their presence is undesirable. This issue is particularly acute in view of the large size of the BV container and the multitude of local environments within it. These environments can arise compositionally, for example, due to dissolution of the refractory, or because of the reducing environment near the electrodes, or thermally as different regions of glass in the container cool at different rates. The challenge is that this complex, spatially diverse, multi-phase assemblage must meet all of the product quality requirements over the full range of likely process variations. Clearly, minimizing the amount and diversity of non-glass phases reduces the magnitude of this issue.

While there are relatively extensive data on the amounts and types of phases present in the products from the engineering-scale tests, considerably fewer data were presented from the full-scale tests. Limited data from the full-scale tests indicate crystal contents of only a few percent.

Much of the glass development and testing work has employed the traditional container centerline cooling (CCC) heat treatment profile in an effort to include the potential effects of thermal history on product properties. The logic behind the CCC approach, which has been employed in the United States HLW programs at WVDP and SRS, as well as for WTP HLW and LAW products, is that in a glass container that is essentially a right circular cylinder of large aspect ratio $(\sim 0.6 \mathrm{~m}$ diameter by $\sim 3 \mathrm{~m}$ high), glass near the centerline will experience the slowest cooling rate. Because slower cooling typically induces a larger degree of devitrification, heat treatment according to the CCC-profile is assumed 


\section{RPP-30570, Rev. 0}

to produce the greatest extent of devitrification and, therefore, provides a sensible bounding thermal treatment for the purposes of testing. In view of the much larger size and appreciably different aspect ratio, it is not clear that CCC heat treatment necessarily provides a worst-case bound for the BV product. The sheer size could make the effects of the cooling process more susceptible to perturbations, due to differences in the external environment at different locations throughout the container. In addition, the much larger horizontal cross-section suggests that the BV container would likely support multiple convection cells, potentially allowing a given volume of glass to experience non-monotonic cooling, and perhaps thermal cycling. Such heat treatment schedules can facilitate rapid nucleation on cooling followed by rapid growth on reheating, leading to increased crystallization, a process widely exploited in the production of glass ceramics. These aspects of the cooling process could be usefully addressed by applying fluid-flow models, such as has been done with the TEMPEST code for the melting process. This, in combination with thorough analysis of the full-scale melts, can be used to help determine if the CCC approach is adequate or if alternate cooling cycles are required to use crucible scale tests to predict devitrification at full scale.

\subsection{Metal}

The presence of a metal phase presents complications in the assessment of the overall performance of the waste package, many of which were discussed in Section 3. Although there is potential for interaction of the dissolution of the metal phase with the glass dissolution process, the principal concern stems from the fact that $T c$ is strongly enriched $(\sim 100 x)$ in the metal phase. The presently available test data, none of which include the effects of Tc recycle, suggest that 9 to $14 \mathrm{wt} \%$ of the total Tc was present in the metal phase. The present emphasis on minimizing the amount of metal that is produced is therefore reasonable and appropriate. However, this must be combined with data to support the contention that some minimum level of metal is acceptable and that process controls have been identified and implemented to ensure that that level is not exceeded.

\subsection{Salt Phase}

In some tests a molten sulfate salt phase has been observed on top of the glass melt. Such salt phases may incorporate various heavy metals (particularly chromium) as well as various radionuclides (cesium [Cs], strontium, Tc), which are relatively soluble in water. Accordingly, the presence of such a salt phase, if it contains significant quantities of regulated constituents, in the final product, is undesirable. Efforts have therefore been undertaken to minimize its extent in the final product, including the use of a final "Top Off" feed batch. It should be noted, however, that the "cost" of this Top-Off batch is that one batch in nine contains no waste; although this is a smaller batch, it results in a reduction in the waste sodium-oxide loading in the product. Based on the test data reviewed and 
RPP-30570, Rev. 0

the Test Plan and Test Instructions for the 32-B large-scale test, the nominal total sodium-oxide loading in the target glass composition is $20 \mathrm{wt} \%$. However, when the non-waste sodium from the Top-Off batch, the starter batch, and the soil is subtracted, the actual waste sodium oxide in the product is about $17.2 \mathrm{wt} \%$.

Reducing conditions, due to the graphite electrodes and the high melt temperature, will increase sulfur volatilization (test data indicate that about 20$40 \%$ is retained). Some test data indicate about $20 \%$ is retained, but more than $40 \%$ retention was observed on the most representative engineering-scale melt, ES-32B. Much of the sulfur may be captured as alkali metal sulfates in the SMF. Because these filters are intended to capture $T c$, the solids from these filters are recycled to the feed. As a result, the concentration of sulfur in the feed will increase (at steady state, to 2.5-5 times its nominal value based on $20-40 \%$ retention and assuming all of the sulfur is recycled; to the extent that some of the sulfur is present as sulfur dioxide, it will pass through the metal filters, reducing the feed sulfur level). The tendency for sulfate salt formation is strongly dependent on the sulfur concentration in the feed and, therefore, salt formation is likely to be exacerbated once the recycle stream is included. Further testing should be performed to assess the extent of this issue and to support the development of appropriate mitigation strategies.

\subsection{Balance of Waste Package}

The balance of the waste package consists of various materials, including the outer steel container, the internal engineered refractory lining, the lid structure and associated fitting and flanges, and the graphite electrodes. While this diversity of materials and components make this significantly more complicated than the prototypical nuclear waste glass package composed of glass in a stainless steel canister, the more crucial difference stems from the fact that the glass is melted in the container rather than simply poured into it. The glass melting process is vastly "dirtier" than the process of pouring pre-melted glass into a container. The melting process involves the generation of dust during the process of feed introduction; generates a variety of transient molten salts and other intermediate phases; and generates substantial volumes of gas and various vaporized and entrained feed constituents. These processes provide multiple opportunities for infiltration, condensation, plating, and deposition of feed species into the balance of the waste package. This is facilitated by the relative complexity of the waste package, which has multiple materials, layers, and seams exposed to the process. The impact of these phenomena needs to be understood, because they may provide mechanisms whereby the key contaminants of concern (e.g., Tc, other radionuclides, heavy metals) are present in the waste package, but are not vitrified and, therefore, are potentially available for rapid release to the environment. In addition, distribution of high specific gamma activity radionuclides, such as $\mathrm{Cs}$ (which is very volatile), to non-glass locations within the waste package can potentially compromise shielding estimates. As such, it should be noted that the data available show small 
RPP-30570, Rev. 0

fractions of Tc deposits in the CRB, higher amounts on the lid (where it can be handled if necessary), and much smaller amounts on the glass surface and sand. Accordingly, data pertaining to these issues are considered to be a crucial component of the effort to qualify the waste package and will have to be obtained at full-scale.

A considerable amount of testing to assess the likely fate of $\mathrm{Tc}$ within the waste package and the fraction that might be leachable has been performed. The current best estimate (based on engineering-scale tests) is that $0.37 \mathrm{wt} \%$ of the total Tc resides in the waste package (excluding the lid) in a leachable form. However, because the estimate is derived from tests that did not include the Tc recycle stream, it is likely underestimated by about a factor of two, assuming that about $50 \%$ of the Tc is volatilized (as is indicted by the present test data) and that all of it is captured by the SMF. The best estimate of leachable Tc on the lid is approximately $2+w t \%$ of the total, based on tests that did not include the Tc recycle stream; applying the same assumptions as above, it is likely underestimated by about a factor of two. Therefore, a more likely estimate of the total fraction of the $\mathrm{Tc}$ in a leachable form in the waste package is about 4$5 \mathrm{wt} \%$.

The above estimates are based on the $\mathrm{Tc}$ (or the Re surrogate) that was recovered in various locations. A significant complication, however, is the fact that about a quarter of the Tc was not recovered in the engineering scale test with S-109 actual waste and remains unaccounted for. It is recognized that a mass balance for a ppm level trace constituent in a bench scale test that produces several hundred kgs of test materials is difficult. The difficulties associate with the Tc mass balance will require analyses of the non-glass portions of the waste package to ensure that leachable Tc is not present at unacceptable levels. This is considered to be a crucial issue for qualification of the product.

The review team believes that this is an especially important issue for this mode of vitrification, because soluble forms of Tc could reside outside the glass and the task of sampling other parts of the package after it is made could be much more challenging. We consider it a problem that ES-32B is the only test to date of the bottom-up melting process on which a full material balance was performed. The problem is not so much the fact that $24 \pm 17 \%$ of the Tc was not accounted for in this test, as that this was the only test to date on which a full material balance was performed.

\subsection{Product Performance Recommendations}

The panel makes the following recommendations regarding product performance:

- The potential ranges of compositional inhomogeneity, redox-state inhomogeneity, and thermal histories of glass distributed throughout the 
RPP-30570, Rev. 0

full-scale container need to be established. Test data need to be collected to show that the entire volume of glass meets the requirements. In particular, based upon the limited data set that was reviewed by the panel, it is not clear that glass samples that are representative of the most reduced state found during process tests have been tested.

- Interactions of the glass product during leaching should be assessed for all of the waste-package materials, including the refractories, metal inclusions, and graphite electrodes. Because of the complexity of the BV waste package, this issue is likely to be greater than that required for more conventional waste packages (e.g., canistered vitrified HLW, WTP LAW).

- The apparent disparity between the amount of crystallization seen in samples from engineering-scale and full-scale tests needs to be resolved. The expected range of crystal contents and types of phases need to be determined and the dependence on process conditions assessed. Based on these results, appropriate operating parameter ranges need to be established to ensure that the impact of crystallization on product quality is properly bounded with respect to likely process variations.

- The appropriateness of the $\mathrm{CCC}$ heat treatment as a realistic worst case needs to be evaluated. Fluid flow modeling of the waste-package cooling process may be helpful in making this assessment and in identifying representative bounding heat- treatment schedules.

- The composition of the recycled solids from the SMF needs to be determined, with particular emphasis on sulfur content, as well as halides and Tc. The impact of inclusion of this stream into the feed and the tendency for salt formation needs to be addressed and mitigation strategies developed.

- The amount of leachable $\mathrm{Tc}$ in the waste package needs to be better understood and the effects of $\mathrm{Tc}$ recycle need to be included. Confidence in the estimates of the amount of leachable $\mathrm{Tc}$ would be increased if a higher fraction of the $\mathrm{Tc}$ were accounted for.

- The distribution of high specific gamma activity radionuclides, such as Cs (which is very volatile), to non-glass locations within the waste package needs to be determined, because this can potentially compromise shielding estimates that assume that these species are confined to the glass. 


\subsection{PROCESS INTEGRATION AND RELATED ISSUES}

\subsection{Test Program}

The test program performed to date appears to have been well executed, and much useful information has been collected. At the same time, the extent of "new discovery," with consequent changes in the base process, apparently has been greater than was anticipated. As a result, while the process itself is still evolving in relatively major ways, the present schedule has only three additional full-scale cold tests planned before the startup of a series of 50 full-scale radioactive tests at the DBVS.

The panel does not believe that full-scale radioactive testing is the appropriate vehicle for mitigating the majority of the remaining risks, but rather, should be viewed primarily as confirmation testing. The importance of radioactive testing is fully appreciated, but the decommissioning costs and the general complications presented by radioactive testing demand that such testing be preceded by a more extensive effort to understand the causes of the potential problems and to test proposed solutions. The limited number of test runs that have been performed to date, coupled with the technical issues that have been discovered, has resulted in several test variables being changed concurrently from one test to the next. Often, the key variables with respect to mitigating a given issue remain unidentified. This situation is much less desirable with respect to being able to identify key process-control variables and set corresponding operating ranges for the process. In cases in which a particular issue appears to have been mitigated, it is often unknown whether the fix is tenuous, in the sense of being very sensitive to process variations, or robust. The panel is unaware of adequate test data using simulant feed for the following key unit operations and process sub-systems:

- SMF - This is a key component with respect to the fate of Tc and the disposition of secondary waste.

- Integrated off-gas system - All tests performed to date have employed a non-prototypic off-gas system. No tests have been performed on the baseline off-gas treatment system.

- Integrated feed system - While vendor testing of the dryer has been performed, all of the vitrification tests to date have been performed with a non-prototypic feed system.

- Prototypical feed material - All full-scale tests performed to date have been performed with a chemical simulant of the feed material produced by mixing the requisite chemicals as opposed to drying a wet LAIV simulant with soil and adding glass-forming additives, as will be the case for the production system. The differences in physical form and 
RPP-30570, Rev. 0

properties are likely to produce significantly different material flow and feed-melting behavior.

- Recycle- None of the tests performed to date has included the projected recycle stream from the SMF. Because this stream is likely to be rich in Tc and sulfur, both crucial process constituents, this represents an important omission.

- Fully-integrated system - No tests have been performed to date on a prototypical fully-integrated system as per the baseline design.

- Instrumentation and controls - In view of the considerable differences between the test systems employed to date and the baseline design, prototypical instrumentation and control systems need to be developed and tested.

In view of these rather extensive information needs, the panel recommends sufficient non-radioactive testing (from small-scale through full-scale at the DBVS) be conducted prior to initiation of radioactive testing. Radioactive testing should only proceed when the remaining technical risks have been appropriately mitigated. We also suggest that because few of the sub-systems have been tested, adequate time should be allowed between tests to implement system changes and modifications that are likely to be necessary.

Because the DBVS appears to be intended to function as both a test system and a production process demonstration system, it is recommended that an evaluation be performed to ensure that the somewhat disparate needs of these functions are fully met by the design. For example, a test system may include more extensive instrumentation than would a production system and might also include allowances for working around system failures that would shut down a production system in order to be able to complete the other objectives of a given test.

\subsection{Sintered Metal Filters}

The off-gas stream from the BV container is passed through two stages of a 316stainless steel SMF, which are planned to be operated at $300^{\circ} \mathrm{C}$. The filter elements are of a tube-type geometry and the process flow is from outside in. The elements are cleaned by applying a sonic- gas back-pulse of low volume, but high pressure. While these are commercially available filters, no testing has been performed in this specific application. The gas stream exiting the filters flows through a wet quencher-scrubber system, the liquid effluent from which is directed to the site liquid efmuent treatment facility. Accordingly, the scrubber effluent must meet the waste acceptance criteria (WAC) for that facility. Thus, there is a crucial process reliance on the performance of the SMF to: 
RPP-30570, Rev. 0

- decontaminate the off-gas stream of radionuclides and hazardous metals to sufficiently low levels to ensure that the liquid effluent from the scrubber meets the necessary WAC; and

- capture Tc (as well as other radionuclides and hazardous metals) in a form that can be recycled to the feed in order to compensate for the relatively low fraction of $\operatorname{Tc}(\sim 50 \%)$ that may be retained in the glass product.

In view of the importance of these functions, we consider the fact that no process testing has yet been performed to represent a considerable technical risk. The ability to reliably blow-back or flush and recycle the deposits collected from the off-gas is obviously crucial.

The nominal operating temperature of $300^{\circ} \mathrm{C}$ has been deliberately chosen to be high in order to minimize the chances of condensation in the filters.

Condensation can lead to blinding of the filters, which is not easily blown-back and can provide a means of transport of soluble species (such as Tc and Cs) through the filters. In addition, because the LAW materials can contain significant amounts of chlorides, which will produce $\mathrm{HCl}$ gas and alkali chlorides that will deposit on the filters, any moisture can lead to rapid corrosion of the filter elements. The high soluble salt content of the material that will collect on the filters will also significantly increase the boiling point of any absorbed moisture, necessitating temperatures of significantly above $100^{\circ} \mathrm{C}$. However, there are also potential issues associated with operation at high temperature. In view of the high contents of sodium, sulfur, halides, boron, nitrates, etc., it is not inconceivable that low melting eutectic salt mixtures could be formed on the filters. Such molten salt would almost certainly present a considerable corrosion issue.

The panel recommends consideration of an alternative SMF material, such as one of the Inconels or Hastelloys, if available to address the concerns above. In addition, the spectrum of potential $\mathrm{Cs}$ and $\mathrm{Tc}$ compounds should be reviewed to ensure that none are sufficiently volatile at $300^{\circ} \mathrm{C}$ to present a significant means of transport through the filters (as noted in Section 2.2.2 the proposed operating temperature is disturbingly close to the $\mathrm{Tc}_{2} \mathrm{O}_{7}$ boiling point of $311^{\circ} \mathrm{C}$ ).

\subsection{Flow-Sheet Model}

An integrated flow-sheet model, which includes all secondary waste and recycle streams needs, to be developed. Although such a model is apparently under development, in view of the lack of prototypical process test data discussed above, the necessary decontamination factor (DF) data for each of the unit operations are not available. However, such a model can be used to support assessments of what DFs are required for each unit operation. It should be noted that some fraction of volatile species, such as chromium and selenium, may pass 
RPP-30570, Rev. 0

through the SMF; thus, the impact on the ability of the scrubber effluent to meet the necessary WAC should be assessed.

\subsection{Maximum Achievable Control Technology Compliance}

The BV system will be required to meet the maximum achievable control technology (MACT) standards. Based on the results of extensive testing performed to investigate MACT compliance for the WTP vitrification systems, it may be a challenge for the present DBVS design to meet the MACT requirement for $99.99 \%$ destruction-removal efficiency (DRE) for organics. In the dryer, all of the allyl alcohol and a portion of the naphthalene will bypass the melter and be treated only by the carbon bed and the SCR. Consequently, the melter will contribute little to the overall DRE for the bypassed organics. The off-gas stream from the dryer currently bypasses the wet scrubber and there is no thermal catalytic oxidizer (TCO) in the DBVS off-gas train. As a result, much of the $99.99 \%$ DRE requirement is borne by the carbon bed and the SCR. Because carbon units are typically utilized as polishing units rather than for bearing the entire load of organic absorption, it is recommended that the expected system performance be reviewed against the MACT requirements to ensure that the carbon bed is adequately sized and that provisions for replacement and disposal are in place as the material becomes exhausted. In addition, the available capacity of the units can be expended on a variety of compounds that are present in much greater concentration than are the target organics. Flow-sheet evaluations are either completed (S-109) or underway to determine if the system, as currently designed, will meet MACT requirements, and if the carbon bed is adequately sized with provisions for replacement and disposal in place. If these evaluations or DBVS MACT testing show that the off-gas design is not adequate as configured, the full-scale production operations will need to reconfigure the off-gas system (e.g. flow the dryer outlet through the wet scrubber) or add additional unit operations (e.g. add a TCO).

\subsection{Fate of Cesium}

Cs, a high specific-gamma activity radionuclide that is also relatively volatile, is quite readily incorporated into many aluminosilicate refractories, particularly as polucite-type phases (Buechele et al., 1998). Cs volatilized during the melting process will likely deposit in the cooler areas of the waste package. As previously indicated, there are well-known interactions of $\mathrm{Cs}$ with $\mathrm{Tc}$, which result in enhanced volatility through the formation of Cs pertechnetate. The panel understands that $\mathrm{Cs}$ and $\operatorname{Re}$ (or $\mathrm{Tc}$ ) have been used in tests since 2003 to ensure that the potential interaction is observed. PNNL has already conducted engineering-scale tests to determine the interaction of $\mathrm{Cs}$ with $\mathrm{Tc}$ in terms of potential for increased volatility. The results of this work should be reviewed, and if necessary, further testing should be performed with both of these species present. The consequences of these interactions should be evaluated in terms of 


\section{RPP-30570, Rev. 0}

their impact on the estimated dose from the waste package and the assumptions that are made with respect to shielding.

\subsection{Confirmation of Technetium Distribution}

The present strategy with respect to demonstration of the fate of $\mathrm{Tc}$ and, in particular, the extent of leachable Tc species in the waste package, relies on a combination of engineering-scale and full-scale tests in combination with radioactive tests with $\mathrm{Tc}$ and a Re surrogate. Data from engineering-scale tests that included both $\operatorname{Re}$ and $\mathrm{Tc}$ have been used to establish empirical ratios of the fraction of leachable $T c$ to that of Re. Full-scale tests have been performed with $\mathrm{Re}$ and extensively sampled to determine its distribution and, by use of the ratios, to infer the expected distribution of Tc. Finally, in the DBVS tests that will include Tc from the waste, a Re spike will be added. A single core sample will then be taken from each of the 50 boxes that are produced and the distribution of $\mathrm{Tc}$ and $\mathrm{Re}$ will be used to validate the expectations based on the non-radioactive full-scale tests containing Re where more extensive sampling was conducted. While this logic is reasonable, the panel is unaware of a contingency plan to address the possibility that the single core samples from the radioactive tests do not validate those expectations. In one scenario, it may be necessary to perform extensive core sampling of the radioactive boxes in order to properly disposition them.

Finally, while the use of the ratio of $\mathrm{Tc}$ and Re leachable fractions is reasonable, it is an empirical approach. The underlying physicochemical explanation for the observed values of the ratios is lacking. The considerable disparity between the ratio of the retentions in glass and the ratio of the leachable fractions for $\mathrm{Tc}$ and $\operatorname{Re}$ further highlights this issue. Consequently, testing is recommended to provide a more fundamental understanding of the basis for the observed leachable fraction ratios, as noted in Section 2.1.3.

\subsection{OTHER RECONIMENDATIONS}

\subsection{Feed Preparation}

\subsubsection{Eliminate Zirconia Segregation}

Zirconia and $\mathrm{Zr}$-containing minerals (e.g., zircon) tend to separate during the early stages of melting and settle to the bottom of the melt, often forming high-Zr sludge on the melter bottom. Their high densities and low solubility in silicate melts make them more prone to this melting segregation than most other feed materials. This tendency can be overcome by ensuring good contact with fluxes, by selecting compounds that dissolve more readily, and by selecting finer-grained materials. Some or all of these ideas either have been recently completed or are planned for 2006. 


\section{RPP-30570, Rev. 0}

\subsubsection{Add zirconia with soil in mixer}

The order of addition is important to the contact between fluxes and the more refractory components in the feed. Dry mixing the zirconia with the soil before adding high-soda liquid waste will cause the alkali to be uniformly distributed over the zirconia, ensuring that zirconia will dissolve quickly in the molten glass, which forms in the fusion layer of the cold cap.

Only the hygroscopic boron source needs to be kept out of the dry mix to avoid making a gummy batch when the liquid waste is added. (Note that PNNL is currently pursuing this option and preliminary results look very promising.)

\subsubsection{Substitute fine zircon for zirconia}

Zircon ( $\mathrm{Zr}$ silicate) dissolves faster in the silicate melt than zirconia because, in the presence of alkali, the zircon dissociates into very fine zirconia crystals dispersed in silica. These fine crystals dissolve faster than the larger zirconia crystals usually used as raw materials. The benefit of using zircon is even greater if the particle size is small. (Note that the project has deployed this recommendation in the latest large scale test.

\subsubsection{Consider Gravity Feed from Mixer/dryer into Melter}

Pneumatic feeders have several well-known problems: segregation and particle-size reduction of the feed transported through them, excessive release of particulates into the off-gas, and abrasive wear-related maintenance problems. Because of these potential problems, a gravityfeed system is likely to be a more satisfactory design.

\subsection{Melter}

\subsubsection{Add Ground Fault Detection System}

Electric melters can fail suddenly if conductive paths are created between the bath and the steel shell in two or more locations. Heat generated by current flowing through such a path is difficult to dissipate, so the area heats up quickly. The process is exacerbated by the fact that the electrical conductivity of the refractory (like the glass melt) increases with increasing temperature. The result is the rapid formation of a narrow channel hot enough to melt the refractory and steel. Typically a hole large enough to drain the melter in a short time is produced. Considering the complexity of the refractory lining, it is not unlikely that minor leakage of hot glass into joints could produce at least two electrical leakage points in a melter. 
RPP-30570, Rev. 0

Fortunately, the process described above can be detected in its early stages by a decrease in the electrical resistance between the power circuit and the steel shell. This normally provides sufficient warning to allow the hot spot to be located and cooled from the outside, or at least to turn off the power. A ground fault detection system should be in place on any electric melter.

\subsubsection{Place a Curb Around the Melter}

In spite of the use of a ground fault detection system, it is possible to have a hot spot develop so quickly that it burns through before action is taken. This type of failure causes both the primary refractory containment and the secondary steel box containment to be penetrated at the same time. Curbing could be installed sufficiently high to contain the entire melt within an area where the molten glass will cause minimum damage and can be cleaned up efficiently. The panel recommends that consideration be given to the tradeoff between the difficulty of providing curbing or a trench (as suggested below) and the possibly greater time and expense to clean up an unconfined spill.

\subsubsection{Consider Placing the Melter in a Ramped Trench}

This would provide both leak containment and shielding to the melter, and would lower the height of the mixer/dryer, reducing radiation exposure from that equipment.

\subsection{REFERENCES}

Antonini, M.A., E. Merlini, and R.F. Thornley, EXAFS Structures of Technetium in Glasses Prepared Under Different Redox Conditions, Journal of Non-Crystalline Solids 71, 219 (1985).

Buechele, A.C., S.S. Fu, Q. Yan, and I.L. Pegg, Radionuclide Uptake by Waste Glass Melter Refractories, Ceramic Transactions, Eds. D.K. Peeler and J.C. Marra, vol. 87, p. 583, American Ceramic Society (1998).

Darab, J.G. and P.A. Smith, Chemistry of Technetium and Rhenium Species During Low-Level Radioactive Waste Vitrification, Chemistry of Materials 8, 1004 (1996).

Ebert, W.L., A.J. Bakel, D.L. Bowers, E.C. Buck, and J.W. Emery, J. W. The Incorporation of Technetium into a Representitive Low-activity Waste Glass. ANL/CMT/CP-92096, Argonne National Laboratory, Argonne, IL, (1997).

Ebert, W.L., S.F. Wolf, and J.K. Bates, The Release of Technetium from Defense Waste Processing Facility Glasses, Materials Research Society Symposium Proceedings 412, 221 (1996). 
RPP-30570, Rev. 0

Kim, D.-S., C.Z. Soderquist, J.P. Icenhower, B.P. McGrail, R.D. Scheele, B.K. McNamara, L.M. Bagaasen, M.J. Schweiger, J.V. Crum, D.J. Yeager, J. Matyás, L.P. Darnell, H.T. Schaef, A.T. Owen, A.E. Kozelisky, L.A. Snow, and M.J. Steele, Tc Reductant Chemistry and Crucible Melting Studies with Simulated Hanford Low-Activity Waste, PNNL-15131, March (2005).

Lanza, F., M. Cambini, M. Della Rossa, and E. Parnisari, Investigation of the Form in Which Technetium is Retained in a Borosilicate Glass Containing Simulated High Level Nuclear Waste, Journal of Trace and Microprobe Techniques 10, 257 (1992).

Lukens, W.W., D. A McKeown, A.C. Buechele, I.S. Muller, D.K. Shuh, and I.L. Pegg, Incongruent Behavior of Technetium and Rhenium in Borosilicate Waste Glass as Determined by X-ray Absorption Spectroscopy, to be submitted to Chemistry of Materials, April (2006).

Lukens, W.W. D.K. Shuh, I.S. Muller, and D.A. McKeown, X-ray Absorption Fine Structure Studies of Speciation of Technetium in Borosilicate Glasses, Materials Research Society Symposium Proceedings 208, 101 (2004).

Lukens, W.W., D.K. Shuh, N.C. Schroeder, and K.R. Ashley, Identification of the Nonpertechnetate Species in the Hanford Waste Tanks, Tc(I) Carbonyl Complexes, Environmental Science and Technology 38, 229 (2004).

Marples, J., N. Godon, F. Lanza, P. Van Iseghem. In Radioactive Waste Management and Disposal: Proceedings of the Third European Community Conference on Radioactive Waste Management; Cecille, L., Ed.; Elsevier: London, (1991); p 287.

Muller, O., W.B. White and Roy, Crystal Chemistry of Some Technetium-containing Oxides, Journal of Inorganic Nuclear Chemistry 26, 2075 (1964).

Rard, J.A., M.H. Rand, G. Anderegg, and H. Wanner, Chemical Thermodynamics of Teclmetium; Elsevier Science: Amsterdam, (1999). 


\section{RPP-30570, Rev. 0 \\ APPENDIX A: \\ REQUEST FOR TECINICAL SOLUTION}

Tracking Number:

Request Title:

Technical Assessment of Bulk Vitrification Process/Product

Requesting

Organization:

Contacts: Billie Mauss (ORP), (509) 373-5113; fax: (509) 372-1215,

Billie M Mauss@orp.doe.gov

Steve Schaus (CH2MHILL Hanford), (509) 372-1149;

fax: (509) 373-3833

Paul S Steve Schaus@rigov

PK Brockman (CH2MHIILL Hanford), (509) 376-9942;

fax: (509) 372-2871

Pk Brockman@r.gov

\section{Scope of Work}

What is the problem that needs to be addressed?

In the bulk vitrification (BV) process, low-activity waste, soil, and glass forming chemicals are mixed, dried and placed in a refractory lined box. Electric current, supplied by two graphite electrodes in the box, melts the waste feed and produces a durable glass waste form. Although recent modifications to the process have resulted in significant improvements, there are continuing technical concerns regarding the bulk vitrification process:

- During the melting processing, a small quantity of the Tc in the waste feed deposits in the refractory material as a soluble salt. in the performance assessment, this salt creates a Tc concentration peak in the groundwater extracted from a 100-meter down gradient well. Although this peak is below drinking water standards, Hanford would like to reduce the amount of soluble salt in the BV waste package and the resulting groundwater peak to the extent possible to further enhance the performance of the BV product and improve regulator acceptance of the technology.

- Metal inclusions have been observed in the resulting glass product. It is unknown at whether these inclusions will have a deleterious effect on the long-. term performance of the waste form.

- Although the vitrified waste form is a borosilicate glass, similar to that currently 
RPP-30570, Rev. 0

being produced at Savannah River and planned for production at Hanford's Waste Treatment Plant, there are questions about whether the product resulting from the Bulk Vitrification process is equal to, or better than, the reference borosilicate glasses.

How is this problem impeding site closure?

The Waste Treatment Plant (WTP) is under construction and will immobilize both highlevel waste (HLW) for disposal in a national repository and low-activity waste (LAW) for onsite, near-surface disposal at Hanford. Vitrifying the high volume of LAW is the rate limiting step in the WTP, and would result in a 50-year project duration, if the entire LAW volume were to be processed through WTP. If accepted by regulators, Bulk Vitrification is a supplemental treatment technology that could be used to treat $40-70 \%$ of the LAW, thereby significantly reducing the project duration and accelerating site closure.

What is the current baseline approach and estimated cost and schedule? The current baseline approach is to process all LAW through the WTP melter. The current life cycle cost for cleanup has been estimated at nearly $\$ 50$ billion over a 50 year period.

What are the potential benefits of solving this problem (cost, schedule, safety, etc.)?

Regulator acceptance of the BV supplemental technology would result in a 25 year reduction in the project schedule and a life cycle baseline cost reduction of $\$ 17.2$ billion.

What type of assistance is requested (analysis and report, develop/modify technology, etc.)?

The River Protection Project is requesting a technical assessment from Subject Matter Experts in the areas of high temperature technetium behavior, long-term glass performance, and waste form qualification to:

- Recommend refinements to existing methods and/or new methods to reduce the amount of soluble technetium salts that form and deposit in the BV waste package

- Assess impact of metal inclusions, and recommend potential process improvements that would mitigate their impact

- Based on glass chemistry, evaluate potential performance of BV product with respect to reference borosilicate glasses and recommend potential process improvements that would enhance product durability and leach properties. 
RPP-30570, Rev. 0

What are the anticipated major tasks/activities, start/end dates, milestones, and/or deliverables?

\section{Technical Assistance Tasks}

Major Tasks/Activities: This task will convene a panel of 3-5 of Subject Manner Experts who will address the identified technical issues related to Bulk Vitrification. This expert panel will spend approximately one week of in-depth investigation of the issues (technical briefings by Bulk Vitrification project staff, review of test results, etc.). Based on their findings, they will formulate and document a set of recommendations that would result in process/product improvements.

Start/End Dates: 1/1/06 to 3/31/06

Milestones:

- Hold workshop - 1/17 - 19/06

- Draft recommendation -2/15/06

- Review recommendations with BV project and finalize report -3/10/06

Deliverables: The deliverable for this task will be a written report which includes recommendations related to each of the three technical issues described above. 


\section{RPP-30570, Rev. 0 \\ APPENDIX B: \\ BULK VITRIFICATION TECINICAL ASSESSMENT WORKSHOP ATTENDEE \\ LIST}

January 16-20, 2006

\begin{tabular}{|c|c|c|c|}
\hline Name & Organization & Phone & Email \\
\hline Dawn Kaback & Gcomatrix & 303-534-8722 Ext 111 & dkaback(egeomatrix.com \\
\hline Tom Ivory & CTC & $703-310-5662$ & ivoryt@ctc.com \\
\hline Ian Pegg & Catholic University & $202-319-6700$ & Pegg@èa.cdu \\
\hline Frank Woolley & $\begin{array}{l}\text { Retired, Corning } \\
\text { Glass }\end{array}$ & $978-772-1874$ & frankwoolley@elum.nil.edu \\
\hline David Shuford & CH2M Ilill & $509-372-0703$ & David_II_Dave_Shuford(ärl.gov \\
\hline David Shuh & LBNL & $510-486-6937$ & DKShuh(albl.gov \\
\hline Sieve Schaus & CH2:M Hill & $509-372-1149$ & Paul_S_Stcve_Schaus(èrl.gov \\
\hline P.K. Brockman & CII2,1 Hill & $509-376-99.42$ & PK_Brockmancàrl.gov \\
\hline Tom Brouns & PNNL & $509-372-6265$ & Tom.Brouns@pnl.gov \\
\hline Larry Bagaasen & PNNL & $509-373-0360$ & Larry.Bagaasen(@ pul.gov \\
\hline Billie Mlauss & DOE/ORP & $509-373-5113$ & Billie_M_Mlauss@orp.doe.gov \\
\hline John Van Beck & CII2MI Ulill & $509-372-2813$ & John_E_Van_Bcek(èrl.gov \\
\hline
\end{tabular}

Technical Assessment of Bulk Vitrification Process/Product for Tatk Waste Trealunent at the Departunem of Iinergy lfanford Site 
RPP-30570, Rev. 0

APPENDIX C:

BULK VITRIFICATION PROJECT COMMENTS 
RPP-30570, Rev. 0

\title{
Technical Assessment of Bulk Vitrification Process/Product for Tank Waste Treatment at the Department of Energy Hanford Site
}

\author{
U.S. Department of Energy Reference SR-311-2-511
}

Technical Expertise Project \#608

IFINAL REPORT]

Comment [FW1]: A general comment on the repeated reviews

and revisions of this report

An attempt has been made to

incorporate all the changes

suggested by the project stant. A number of changes, however, have

not been incorporated, in some cases

because the review team leets they

are outside the scope of our review

(0.9. plans for fulure activities, which

wo were not given the opportunity to

review). In other cases, the changes

suggested seemed to hdicat a

desire to minimize or ignore a

potentially important problem of

crystallization of glass during cooling

after melling.

The review team considered that our principal duly is to provide technical principal duty is to provide lochnicions to eddress the

recommendations to eddress

highlighted in the sow. We did not

sec it as our duty either to criticize or

praise the project team for their

efforts. Rather, we bok a anapshot of

the lechnical issues as they stood in

January, 2006, based on a subset of

the them-available reports and

presentations, and made tochnical

recommendations that wo hope will

be helpful to the project team in

resolving those problems. 


\section{TABLE OF CONTENTS}

RPP-30570, Rev. 0

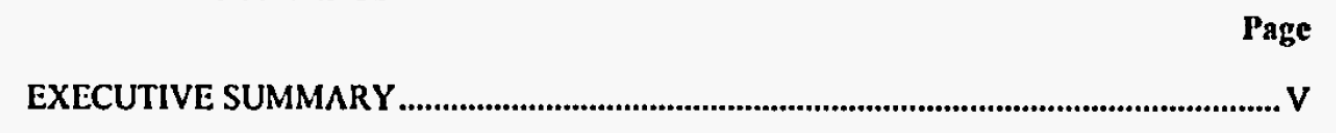

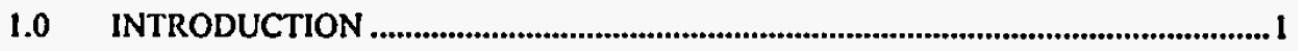

1.1 PROBLEM …................................................ ERROR! BOOKMAKK NOT DEFINED.

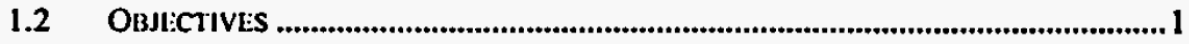

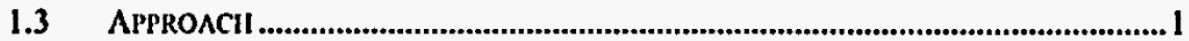

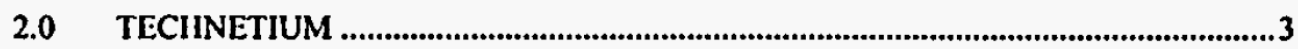

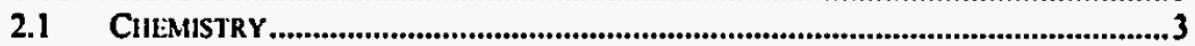

2.1.1 Te Challenges During BV ..........................................................................3

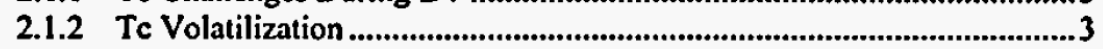

2.1.3 Rhenium (Re) as a Tc Surrogate during BV Cold Testing .......................4

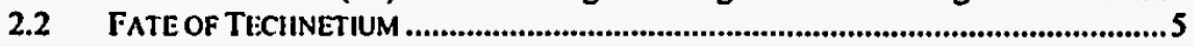

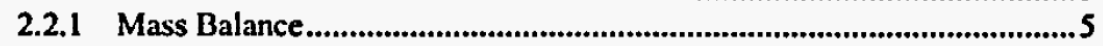

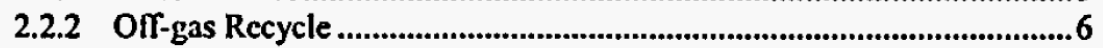

2.2.3 Chemical Feed Considerations ............................................................6

2.3 RI:COMMIINIDATIONS FOR MITIGATION OF TC LOSS...........................................

2.3.1 Increase Tc Retention in the Melt...........................................................

2.3.2 Reduce Vaporization of Tc Species from Top Surface..............................

2.3.3 Reduce Tc Penctration into the Refractory Liner..................................... 9

2.3.4 Limit Tc Loss with Faster Reaction in Strong Feed Pellets.................... 12

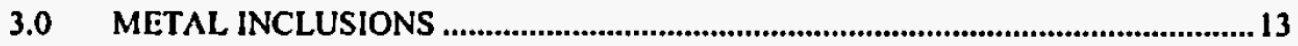

3.1 IMPACT ON GLASS PI:RPORMANCE .............................................................. 13

3.2 RI:COMMIENDATIONS IOOR DESIGN AND OPL:RATION TO ELIMINATE METAL.

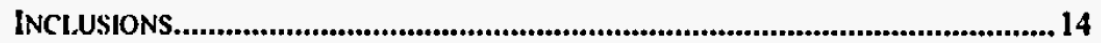

3.2.1 Determine Mechanisms.........................................................................14

3.2.2 Reduce Role of Starter Path in Production of Inclusions..........................15

3.2.3 Reduce Role of Electrodes in Production of Inclusions ...........................16

3.2.4 Develop a Low-iron Glass Composition.................................................18

3.3 RI:COMMIINDATIONS TO CONTROL FORMATION OF MLTAL INCLUSIONS ................20

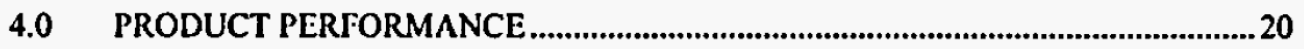

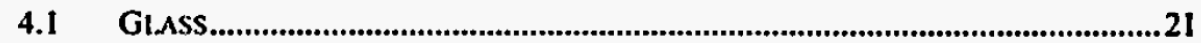

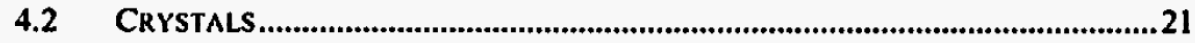

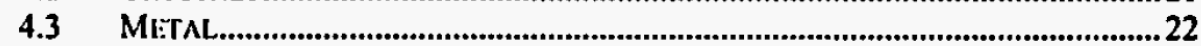

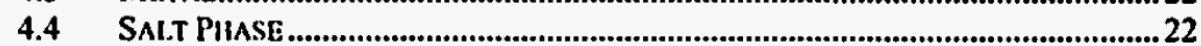

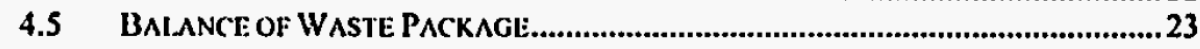

4.6 PRODUCT PI:RFORMANCE RECOMMIINDATIONS ...............................................24

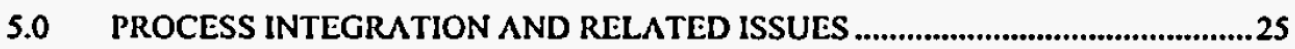

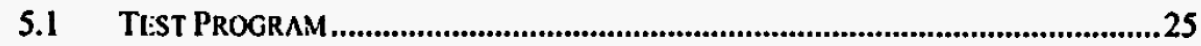

5.2 SINTI:RI:D METAL FILTIRS............................................................................26

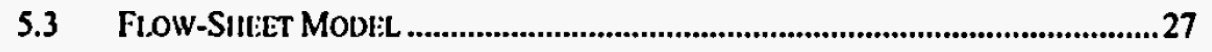


RPP-30570, Rev. 0

5.4 MAXIMUM ACHEVABLLE CONTROL TIECINOLOGY COMPLIANCE..........................28

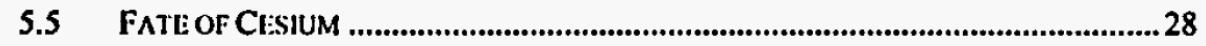

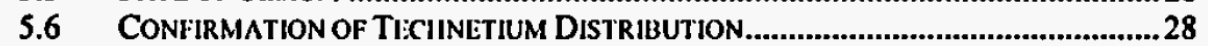

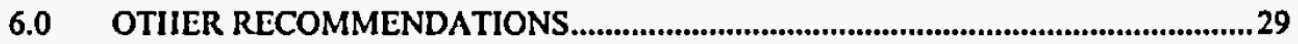

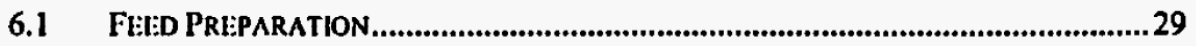

6.1.1 Eliminate Zirconia Segregation ..........................................................29

6.1.2 Consider Gravity Feed from Mixer/dryer into Meler ..............................30

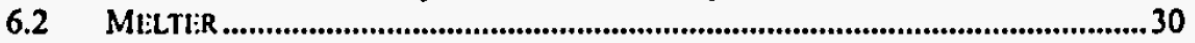

6.2.1 Add Ground Fault Detection System ....................................................30

6.2.2 Place a Curb Around the Melter ............... Error! Bookmark not defined.

6.2.3 Consider Placing the Melter in a Ramped TrenchError! Bookmark not defined.

7.0 REFERENCES . .30

APPENDIX A REQUEST FOR TECIINICAL SOLUTIONA-ERROR! BOOKMARK NOT DEFINED.

APPENDIX B BULK VITRIFICATION TECINICAL ASSESSMENT WORKSIIOP ATTENDEE LIST .......... B-ERROR! BOOKIIARK NOT DEFINED. 


\section{RPP-30570, Rev. 0 EXECUTIVE SUMHIARY}

\section{Background}

At the U.S. Department of Energy (DOE) Hanford Site, the Waste Treatment Plant (WTP) is being constructed to immobilize both high-level waste (HLW) for disposal in a national repository and low-activity waste (LAW) for onsite, near-surface disposal. The schedulecontrolling step for the WTP Project is vitrification of the large volume of LAW; current capacity of the WTP (as planned) would require 50 ycars to treat the Ilanford tank waste, if the entire LAW volume were to be processed through the WTP. To reduce the time and cost for treatment of I Ianford Tank Waste, and as required by the Tank Waste Remediation System Environmental Impact Statement Record of Decision and the Hanford Federal Facility Consent Agreement (Tri-Party Agreement), DOE plans to supplement the LAW treatment capacity of the WTP. Since 2002, DOE, in cooperation with the Environmental Protection Agency and State of Washington Department of Ecology has been evaluating technologies that could provide safe and effective supplemental treatment of LAW. Current efforts at Hanford are intended to provide additional information to aid a joint agency decision on which technology will be used to supplement the WTP. A Rescarch, Development and Demonstration permit has been issued by the State of Washington to build and (for a limited time) operate a Demonstration Bulk Vitrification System (DBVS) facility to provide information for the decision on a supplemental treatment technology for up to $50 \%$ of the LAW.

Comment [FW2]: changed in revised finat report - noted hereater as "changed"

In the Bulk Vitrification (BV) process, LAW, soil, and glass-forming chemicals are mixed, dricd, and placed in a refractory-lined box. Electric current, supplicd through two graphite electrodes in the box, melts the waste feed, producing a durable glass waste-form. Although recent modifications to the process have resulted in significant improvements, there are continuing technical | challenges , described below. Comment [FW] ]: changod

- During the melting process, a portion of the technetium (Tc) in the waste fecd deposits in the refractory matcrial as a soluble salt. In the performance assessment, this salt has the potential to create a Tc concentration peak in the groundwater extracted from a 100 -meter down-gradient well. Although this peak is significantly| below drinking-water standards, DOE desires to reduce the amount of soluble salt in the BV waste package and reduce the resulting groundwater peak to the extent possible to further enhance the performance of the BV product and improve regulatory acceptance of the technology.

- Metal inclusions have been observed in the resulting glass product. It is unknown whether these inclusions will have a deletcrious effect on the long-term performance of the waste form. To date composite glass samples analyzed from enginecr scale and full scale operations, have produced complaint glass in accordance with XXX

Although the vitrified waste form is a borosilicate glass, similar to that currently being produced at the Savannah River Site and planned for production at Ilanford's WTP, there are questions about whether the $\mathrm{BV}$ product is comparable to referenced 
RPP-30570, Rev. 0

borosilicate glasses. It is noted that to date composite glass samples analyzed from engineer scale and full scale operations, have produced complaint glass in accordance with XXXThe DOE Office of River Protection (ORP) requested technical assistance from subject matter experts to address the above hoted kechnical concerns. Funded by DOE EM-20's Technical Expertise Program, an expert panel, comprised of Dr. Frank Woolley, retired Corning Glass, Dr. David Shuh, Lawrence Berkeley National Laboratory, and Dr. Ian Pegg, Catholic University, was convened for a three-day workshop in Richland, Washington in January 2006. Prior to the workshop, the pancl was sent a limited set of existing publications related to the project for review. At the workshop, the panel was given technical briefings, as well as additional written materials, by BV project staff. It is noted that, given the level of effort for this technical review, the scope of this project is limited to addressing the issues outlined above; comments provided do not represent a full review of the BV technology, project status, and plans. At the conclusion of the workshop, the panel provided an out-bricfing to DOE, CI12MHill Group, and Pacific Northwest National Laboratory (PNNL) staff. A draft report of findings and recommendations was then prepared by the panel, reviewed by $B V$ project staff, and revised by the panel to complete a final report.

The pancl was tasked with the following actions:

- assess and provide recommended refinements to existing methods and/or new methods to reduce the amount of soluble Tc salts that form in the BV waste package and provide comments regarding the Tc mass balance;

- assess impact of metal inclusions on glass product quality and recommend potential process improvements that would mitigate their impact;

- evaluate potential performance of $B V$ product with respect to reference borosilicate glasses and glass quality standards, and recommend potential process improvements that would enhance product durability and leach propertics.

\section{Technetium}

Te presents challenges and uncertainties for high-temperature vitrification processes, including BV, because of its volatility, mobility, and longevity. For BV some of these challenges have changed, because the BV process was fundamentally modified based onn early iesting campaignd from a top-down to a bottom-up melting process. The volatility of Te determines its level of incomoration in the glass product and the corresponding amount in the off-gas, which is captured in the off-gas treatment system and recycled. Major factors controlling its volatility include oxidation-reduction conditions in the melt and vitrification process operational factors, such as temperature. In addition to the volatility challenge, $T c$ is soluble in potential salt phases and can deposit in the refractory liner.

Current knowledge of Te chemistry in the LAW waste feed is sufficient to predict that Tc will primarily be present as the pertechnctate species, but the feed may also contain some fraction of 
RPP-30570, Rev. 0

lower oxidation-state species. Ilowever, gaps in our knowledge of Te chemical and physical properties pertinent to BV and other vitrification processes remain due to limits of analytical capabilities In particular, there is limited information on Te solution chemistry in highly alkaline solutions, Tc species in vitrification off-gas, and mechanisms for Tc immobilization in borosilicate glasses. In terms of mitigation of Te loss, the best approach is to implement improvements in the BV system to reduce Tc volatility, and thereby, improve the percentage of Tc immobilized in the primary waste package. For example, it is well known that Tc volatilization is greatly dependent upon the temperature of the melt and nature of the cold cap. Recycling of Tc from the off-gas filter system will change the amount and possibly the form of $\mathrm{Tc}$ in the melter feed; this effect has not yet been studied fon the BV process or other DOE related Vitrification process to date.]

Comment [FW/11]: not changed this is not the only reason for the gaps - the topics listed in the next sentence simply have not been addressed yet

It is important to understand the fate of Tc within the BV process, including the significant losses of Tc from the melt in the ES $32 \mathrm{~B}$ cngineering-scale test $24 \%$ of the Tc was unaccounted for possibly due to an underestimate of the amount of $T e$ volatilized into the off:gas system. Please add noted from email sent by Tom Brouns - PNNL on DOE wide expericnce on Te mass balance as this will balance the statement. The panel recommends in future tests 1) addition of a removable filter material, such as glass wool, in a filter assembly in front of the IIEPA filter (easily analyzed for Tc), or 2) an off-gas sampler in combination with a liquid scrubber. However, a mass balance for a ppm level trace constituent in a bench scale test that produces several hundred kgs of test materials is difficult. The difficulties associate with the Tc mass balance will require analyses of the non-glass portions of the waste package to ensure that leachable $T c$ is not present at unacceptable level\$. within acceptable rangeswill remain

Because the sintered metal filters (SMF) in the off-gas system have not been used for this type of application, uncertaintics regarding SMF performance remain; the SMF should be tested prior to full-scale startup. The planned operating temperature for the $S M F, 300^{\circ} \mathrm{C}$, is close to the boiling point of a volatile $\mathrm{Tc}_{2} \mathrm{O}$, species $\left(311^{\circ} \mathrm{C}\right)$. It is noted that testing of the sintered metal filer is currently scheduled for the initial cold box test which commence approximately 90 days after completion of facility construction!

Rhenium (Re), the best surrogate for $\mathrm{Te}$, has been used appropriately in the BV cold testing. However, there are recognized differences in the chemical behavior of these two clements in vitrification processes, which have been observed during BV testing. This requires that results using Re be interpreted and adjusted to reflect Tc behavior, followed by "hot" validation using fecd containing Td This activity is currently planned within the overall test campaign for 50 ICV box melts.

Recommendations to mitigate the loss of Te can be categorized as: 1) reduce vaporization of Tc species from the top surface of the melt, 2) reduce the penetration of Tc into the refractory liner, and 3) promote a faster reaction in the cold cap of the waste feed material. Reduction of vaporization of Tc species from the top surface of the melt can be accomplished through maintaining a constant cold cap thickness with a cool top surface and improving the uniformity 
RPP-30570, Rev. 0

of the feed distribution over the melt surface. Specific methods to accomplish each of these improvements are provided in Section 2.3.

Reducing penctration of $\mathrm{Tc}$ into the refractory liner is a very difficult problem; the panel had the opportunity to review only a fraction of the work done to address it. Thus, the panel recommends that further efforts be made to identify an alternative lower-permeability liner material as the preferred approach. Various methods are suggested, some of which may already have been considered for coating the existing liner as a backup approach. Recent efforts by PNNL to alter the composition and hence the mobility of the molten salts that carry Tc into the refractory liner by sequencing boron additions are considered promising. The panel recommends further testing of the mixer/dryer operation to optimize fecd reaction time. Raw materials and the order of addition in the dryer can be tailored to produce faster-reacting, pelletized feed.

\section{Metal Inclusions}

Test results have shown that the metal inclusions formed in the vitrified product have higher concentrations of Tc (and the Re surrogate) than the glass, Because the metal phase, which is predominantly iron, is more soluble than the glass in the expected disposal environment, its presence may significantly impact glass performance by increasing the rate of release of Tc from the waste package. Accordingly, it is essential that the extent of this impact be understood and minimized.

In addition, the total mass fraction of metal in the product and its distribution within the product are also key factors in performance. It seems reasonable to expect that the overall rate of relcase of Tc would decrease as the Tc enrichment factor decreases; as the total mass fraction of metal decreases; and as the distribution of the metal phase moves from large ingots near the bottom of the glass product towards finely divided inclusions uniformly distributed throughout the glass phase. Ai present, the effects of process chemistry and operating conditions on these factorshave not been finalized Efforts to date have reasonably focused on minimizing the total mass fraction of metal in the product.

The primary objective should be to eliminate evidence of metal production during melting. Unless operating conditions that normally result in absence of metal inclusions are identified, it is likely that inclusions may occur, sometimes in large amounts, as the result of normal variations in conditions from melt to melt.

Comment [FW23]: changed Comment [FW24]: changed with difierent wording

Comment [Fu25]: not changed for reasons explained in the report. we believe the galal ahouid be to eliminate metalic inclusions, not just reduce them.

Large reductions in the amount of metal inclusions produced in a large-scale test, 38-B, have recently been achieved by reducing the amount of graphite in the starter path, and by tighter control of current density and bath temperatures during start-up and operation $\$$. This demonstrates the potential for further reduction or possible elimination of these inclusions. The pancl recommends that an effort be made to determine the mechanisms by which metal inclusions are formed, as the fastest and most economical way to leam how to climinate them. 
RPP-30570, Rev. 0

Two fundamental processes probably account for most of the reduction of iron and other metals to their clemental state during melting: carbothermic reduction, both by starter-path materials and by electrodes, and electrochemical reduction on the electrodes. With improved knowledge of the relative importance of these fundamental processes and their sensitivity to temperature and iron content of the bath have been realized, actions intended to counter them (Section 3.2.2 and 3.2.3) can be prioritized, leading to further reductions in the amount of metal inclusions. Additional, lab-scale testing is recommended to quantify the rate of formation of inclusions by ...... each fundamental mechanism, because the effects of cach mechanism cannot be scparated in large-scale tests, where it is impractical or impossible to control and measure local conditions adequatcly.

Anticipating the results of this recommended testing, and assuming that the dominant mechanism by which metal inclusions are formed is carbothermic reduction at the hot surface of the graphite clectrodes, the pancl recommends that serious consideration be given to the use of externally-cooled plate electrodes in place of the uncooled cylindrical clectrodes, which are a legacy of the AMEC technology. Although difficult to implement, it may be easier than the option discussed belowt.

If none of the above measures can be developed into a viable approach to minimize metal inclusions, the plan to use native soil as a raw material should be reconsidered and other lowcost raw materials, such as low-Fe clays, sands and volcanic ash, or conventional glass-forming chemicals should be considered. The lab-scale testing described should provide guidance on the iron content| which the reduction mechanisms are ineffective and metal inclusions are unlikely to form. The recommended iron content would likely be $-0.1 \mathrm{wt} \% \mathrm{Fe} \mathrm{O}_{3}$ to obtain the best compromise between low raw-materials cost and high infrared transmission in the melt (better heat transfer). In any electric glass-melting process, there are numerous process advantages to a low-iron glass, all resulting from the improved heat transfer within the melt. These include: a) better radiative cooling of the electrodes, which lowers the temperature at the graphite interface and hence lessens the tendency to form metal inclusions, b) less tendency to coring (hot channels in bath), which increases melter stability during startup, c) higher melting rate, which increases processing rate, and d) more uniform temperature throughout the melt volume, which provides a larger safety margin against the possibility of devitrification in edges and comers. For the DBVS, an iron content somewhat higher than 0.1 wt. $\% \mathrm{Fe}_{2} \mathrm{O}_{3}$ may be a better compromise when the issue of product performance (discussed hs follows) is considered.

A considerable disadvantage of moving towards a low-iron glass composition, however, is the relative paucity of data and the departure from the "main-stream" waste vitrification experience around the world, which is dominated by iron-containing glass compositions. Although the magnitude of the composition change is relatively small, it will result in significant changes in propertics, such as infrared absorption and redox chemistry in the melt. Consequently, it should be expected that such a change, while likely beneficial in the long nun, will require its own learning curve in terms of how it impacts the process. In addition, there may be a varicty of subtle consequences, such as effects on the behavior of $\mathrm{Tc}$ in the absence of iron, which need to be considered. While it should be expected that there will also be changes in product properties, there is no reason to believe that these cannot be compensated, such that acceptable 
RPP-30570, Rev. 0

product quality can still be achieved. If metal inclusions cannot be minimized a comprchensive festing program is recommended to demonstrate that their impact on product performance is acceptable over the full range of opcrating conditions.

\section{Product Performance}

The BV process produces a relatively complex waste package. In addition to the glass, in which there may be krystayene structures and metal inclusions, the waste package is currently expected to contain a salt phase plus the container, refractory lining, graphite clectrodes, and the lid structure with associated ports and fittings. Issues associated with contributions of each of these components to the overall performance of the waste package are discussed below.

In many respects, the glass represents the simplest part of the overall waste package. The glass testing program appears to be reasonable and results to date support the $\mathrm{BV}$ process produces a homogencous glass phase that mects acceptable glass performance standards However, the full-scale process has the potential to be subject to additional complications from effects, such as glass homogeneity (given the size of the waste package), thermal history, and redox state.

....... Comment [FW35]: not changed

Comment [Fw36]: changed

The graphite electrodes create a reducing condition in the melt, the magnitude of which is unique among current radioactive waste vitrification processes. As a result, there are few product leach test data available for such highly reduced glasses. Because the redox state may have significant effects on glass properties, its impact should be determined, and appropriate redox control ranges cstablished for the process.

Depending on composition and thermal history, varying amounts and types of crystalline phases can form during cooling within the amorphous glass; this process can serve to. complicate the assessment of product performancd. However, none have been observed during large scale testing performed to date. While multi-phase matcrials may meet all of the product quality requirements, additional data may be required to demonstrate that product quality requirements are met, even though there is no current requirement to measure or report crystal content for WTP LAIV or BV glasses. In addition, because of the large size of the BV container, the representativeness of samples collected to test product quality needs to be understood. In view of the large size and appreciably different aspect ratio of the BV container (as compared to traditional vitrification facilitics), it is not clear that container centerline cooling (CCC) heat-treatment approach provides a worst-case bound for the BV product.

The presence of a higher-solubility metal phase, with preferential incorporation of $\mathrm{Tc}$, exhibits further complications in the assessment of the overall performance of the waste package. In addition, test data indicate that a molten sulfate salt phase, which may incorporate various heavy metals and radionuclides and has higher solubility in fwater (no water in the melt 7 flashes off early in the process?), frorms on top of the glass mclt. Efforts to minimize the presence of both of these phases should continue. The reducing character of the $B V$ melt promotes sulfur volatilization ( $40 \%$ retained in the melt). The sulfur species in the off-gas, depending upon its form, may be captured by the $\mathrm{SMF}$ and then recycled, along with Tc, back into the feed for the melt. Concentrations of sulfur in the feed may increase as the recycle is

\begin{tabular}{l|l|} 
Comment [FW38]: not changed - \\
Clumsier wording with same moaning
\end{tabular}

... Comment [FW41]: changed 
RPP-30570, Rev. 0

included in the waste fecd, further promoting formation of the salt phase on top of the silicate melt surface. Further testing is recommended ko assess the extent of this issue and to support development of appropriate mitigation strategies.

The balance of the waste package consists of various materials, including the outer steel container, the internal engineered refractory lining, the lid structure and associated fittings and flanges, and the graphite clectrodes. While this diversity of materials and components make this more complicated that the prototypical nuclear-waste glass package composed of glass in a Comment [FW4]]: changed stainless steel canister, the more crucial difference stems from the fact that the glass is melted in the container rather than simply poured into it. The potential impact of generation of dust, transient molten salts and gas during the BV feed and melting process needs to be understood, because key contaminants of concem (e.g., Tc, other radionuclides, heavy metals) may be present in the waste package in a non-vitrified form that could potentially be available for release to the environment. A considcrable amount of testing to assess the likely fate of $\mathrm{Tc}$ within the waste package and the fraction that might be leachable has been performed. None of the tests to date have, however, included the recycle stream. Te recycle will likely increase the Tc deposits in the refractories and on the lid. The uncertainty in cstimates of leachable Tc fraction is considered to be significant issue, not only for qualification of the product, but also for developing a reliable flow sheet for the process.

\section{Other Recommendations}

The panel recommends a large number of small-scale tests. As with any process development, it is important to maintain a balance between large-scale testing, which is often the best way to reveal the effect of unforesecn interactions between complex processes, and small-scale testing, with which the details of the critical processes and mechanisms can be cconomically and rapidly discovered. In addition, the pancl believes that provisions should be made for more non-radioactive full-scale testing than is prescntly planned. If Re is no good that how do we resolve the Tc volitization issue without going hot? Recommendations contradict themselves.

The report also provides general comments on the test program, focusing primarily on data gaps and recommendations for future testing, the SMF, the flow shect model, maximum achievable control technology (MACT) compliance, fate of cesium, confirmation of Tc distribution, feed preparation, and melter enhancements.

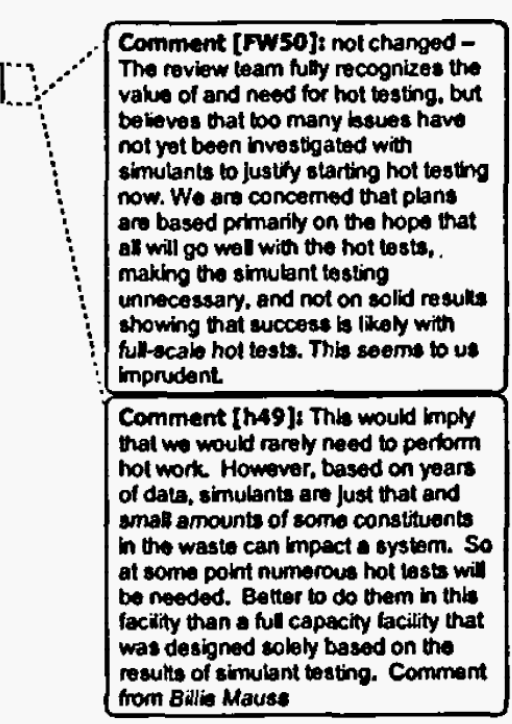




\section{RPP-30570, Rev. 0 1.0 INTRODUCTION}

\section{DELETE-REDUNDANT WITH BACKGROUND NOTED ABOVE.REDUNDANT WITH INTRO1,1 OBJECTIVES}

The DOE Office of River Protection submitted a request for technical assistance to DOE EM-21 for provision of Subject Matter Experts in the areas of glass science, melter technology, refractories, and Tc chemistry to:

- assess and provide recommended refinements to existing methods and/or new methods to reduce the amount of soluble Tc salts that form in the BV waste package and provide comments related to the overall $\mathrm{Tc}$ mass balance;

- assess impact of metal inclusions on glass product quality and recommend potential process improvements that would mitigate their impact;

- evaluate potential performance of the BV product with respect to reference borosilicate glasses and glass quality standards, and recommend potential process improvements that would enhance product durability and leach properties.

Revise above bullets consistent with intro

The technical assistance request is provided in Appendix $\Lambda$.

\subsection{APРRоАСи}

A panel of Subject Matter Experts was convened for a three-day workshop at Richland, Washington in January 2006. The technical experts were Dr. Frank Woolley, Corning Incorporated (retired), Dr. David Shuh, Lawrence Berkelcy National Laboratory, and Dr. Jan Pegg, Catholic University. The pancl was facilitated by Dr. Dawn Kaback of Gcomatrix Consultants. Prior to the workshop, the expert panel was provided selected background materials (a subsct of existing reports, mecting minutes, etc.) for review. At the workshop, additional written materials were provided to the pancl. The materials provided for review include the following:

- General Background Information

- RPP-17403, Demonstration Bulk Vitrification System Specification

- Enginecring Scale In-container Vitrification Test Results - Final Report, 8/ 03

- Soluble Technctium in Refractory

- PNNL-15126, Rev. 1, Pierce EM, ct.al. Laboratory Testing of Bulk Vitrificd Low

Activity Waste Forms to Support the 2005 Integrated Disposal Facility

Performance Assessment, June 2005

- Re/Tc ES Test Summary Table (Preliminary Draft - 12/9/05)

- PNNL-15193, Irma P, ct.al. Bulk Vitrificution Castable Refractory Block

Protcction Study. Pacific Northwest National Laboratory, Richland, WA, 5/05

- PNNL-15131, Kim D-S., ct.al., Tc Reductunt Chemistry and Crucible Mclting Studics with Simulated Ilanford Low-Activity Waste, March 20
Comment [FW51] ] nol changed The review panel foels that both the Executive Summary and the body of the report should be complete, because of the likethood that they will be separated by readers. However, if the sponsor of this review whases io shorten the report by a little over one page, this suggested deletion could certainly be made. 
RPP-30570, Rev. 0

- 35004-RT-0001, Rev. 1, Engincering-Scale Quantitative Test Report, Test ES-32B Final Report, AMEC Earth \& Environmental, Inc., GcoMelt ${ }^{\mathrm{TM}}$ Division, Richland, WA, June 2005 Metal Inclusions

- Mecting Minutes - Recommendations for Mitigating Negative Effects Fe Metal in BV Melts (4/29/05)

- Summary: Estimate of Iron Mctal Decrease for AMEC Test LS38B

- AMEC-TP-06-01, Rev. 0, TEST PLAN: AMEC/DBVS Project - No-Iron Glass Formulation Crucible Tests

- 46611-2005-01, Rev. 0, TEST PLAN: Durability Measurements on Metal Inclusions Found in Bulk Vitrified Glass Using the Single-Pass Flow-Through (SPFT) Test Method

- Glass Performance

- 35004-RT-0004, Rev. 0, Matrix Crucible Testing of Bulk Vitrification Glasses for Ilanford Low-Activity Waste (Scries 21 Test Report), AMEC Earth \& Environmental, Inc., GcoMclt ${ }^{\mathrm{M}}$ Division, Richland, WA, June 2005

- Information Provided at the Workshop

- AMEC 34005-PL-0010, Rev. 0, Demonstration Bulk Vitrification System (DBVS) Series 38 Testing, Large Scale Test 38B, Test Plan, October, 2005

- AMEC 34005-TI-0011, Rev. 0, Demonstration Bulk Vitrification System (DBVS) Scrics 38 Testing, Large Scale Test 38B, Test Instruction, November, 2005

- PNNL-15107, Testing of Large-Scale ICV Glasses with Ilanford LAW Simulant, March, 2005

- Table Summarizing Current Best Estimates of Tc and Re Distribution and Mass Balance Data from Engincering-Scale Tests, 1/16/06

- Miscellancous materials, including copics of presentation matcrials, bulk vitrification system process-flow diagram, and schematics of SMF units.

This panel review did not include a review of the report on the latest large-scale test, 38-B; however, the Test Plan and Test Instructions were provided for review at the Workshop.

At the workshop, the pancl was given technical briefings by $\mathrm{BV}$ project staff. It is noted that, given the limited time available for the pancl to review background matcrials and hold discussions with Ilanford staff, the scope of this project addressed the three issues previously identified; comments provided do not represent a full review of the BV technology, project status, and plans. At the conclusion of the workshop, the pancl provided an out-briefing to DOE, Cl12MIIill Group, and Pacific Northwest National Laboratory (PNNL) staff. This report of findings and recommendations was then prepared by the panel. Workshop participants are shown in Appendix B.

The report contains a number of findings and recommendations made by the experts. An attempt was made to prioritize the recommendations in order of appearance, with the easiest to implement and most likely to succeed first. However, because of limited time, the pancl was not able to prioritize all recommendations. 


\section{RPP-30570, Rev. 0 \\ 2.0 TECHNETIUM}

\section{$2.1 \quad$ CHEMistrky}

\subsubsection{Te Challenges During BV}

Tc presents challenges and uncertainties for any high-temperature vitrification process, including BV, because of its volatility, mobility, and longevity. For BV, some of these challenges may have changed as the $B V$ process was modified from a top-down to a bottom-up process. During vitrification, the major Tc concem relates to its volatility, which determines its level of incorporation into the glass product and the corresponding amount in the off-gas sent to the off-gas treatment system for recycle. Another challenge for the BV process has been limiting the deposition of soluble $\mathrm{Tc}$ in the refractory liner.

Tc volatility is affected by:

- the oxidation-reduction conditions of the melt

- vitrification process operational factors, such as temperature and the nature of the cold cap.

Current knowledge of Tc chemistry in the LAW waste strcam feed is sufficient to predict that Tc will primarily be present as the pertechnetate ( $\mathrm{TcO}_{4}$ ) species, but may also contain a fraction of lower valent Te species. There are limited data regarding the thermochemical properties of Tc species, which make it difficult to quantitatively predict its behavior in glass melts and offgas produced during vitrification. This situation is further complicated by the incomplete knowledge of how Tc is immobilized in borosilicate glass waste forms regardless of the method of synthesis (Lukens, 2004; Anonini, 1985, and Lanza, 1992). Recent studies have demonstrated that Tc can be incorporated in a complete range of oxidation states, including metallic inclusions with iron and rhenium (Re) (Lukens et al., 2006). However, the actual speciation of $\mathrm{Tc}$ is not the critical factor, its leaching characteristics provide the final basis for performance assessments.

\subsubsection{Te Volatilization}

tt has been recognized that Te residence time at the melt surface, prior to being wetted and incorporated in the melt, is the time when it is extremely volatile. Tc volatilization diminishes sharply once limited by viscosity and diffusivity of $\mathrm{Tc}$ to the surface of the glass melt (Darab, 1996). The results from Kim ct al. (2005) show that Tc is clearly volatilized from the glass melt in addition to being volatilized prior to incorporation in the melt. The melt conditions in the BV process may be sufficiently reducing so that $\mathrm{Tc}$, once in the melt, is reduced to a lower oxidation state. IIence, Tc volatilization is greatly dependent on the temperature of the melt, glass viscosity, and the nature of the cold cap.

It has been previously believed that the oxidation state of Tc in the waste feed could have a significant effect on Tc volatility during vitrification. Reducing the oxidation state of the $\mathrm{Tc}$ species from Tc(VII) to Tc(IV), might result in reduced Te volatility. Ilowever, this has been 
RPP-30570, Rev. 0

shown to be dependent on the exact conditions of vitrification and effective Tc reducing agents to be added to the feed have not been identified (see Section 2.2.3).

The volatile species during $\mathrm{BV}$ are likely one or some combination of the metal- $\mathrm{TcO}_{4}$ species $\left(\mathrm{MTcO}_{4}\right): \mathrm{NaTcO}_{4}, \mathrm{KTcO}_{4}$, and $\mathrm{CsTcO}_{4}$. The boiling point of $\mathrm{KTcO}_{4}$ is $1000^{\circ} \mathrm{C}$; other $\mathrm{MTcO}_{4}$ species have similar boiling points and all are believed to have appreciable vapor pressures above their melting points (Rard ct al., 1999). Cold finger experiments by Kim et al. (2005) identified $\mathrm{KTCO}_{4}$ as an evolved product, which is reasonable, as it is the most stable of the $\mathrm{MTcO}_{4}$ species. The most volatile of the $\mathrm{Tc}$ oxides, $\mathrm{Tc}_{2} \mathrm{O}_{7}$, has a generally recognized boiling point of $311^{\circ} \mathrm{C}$ (Rard et al., 1999). At the BV melt surface, rapid off-gassing of nitrates and sulfates could result in bubbling in the bottom-up melting process. This is likely to substantially contribute to Tc volatilization. Local hot spots, as at the electrodes in the current configuration, may also enhance volatilization of $\mathrm{Tc}$.

Current plans call for the volatilized Tc to be transported to the off-gas system, where it will be recycled from a particulate filter and/or a secondary liquid. This recycling will effectively increase the Tc load in the waste stream to a level that depends upon the amount of Tc incorporated into the glass. Consequences of Tc recycling on the overall BV process are addressed in Section 3.3, 4.3, 4.5, and 4.6.

\subsubsection{Rhenium (Re) as a Te Surrogate during BV Cold Testing}

Re has been employed as a cold-test surrogate for $\mathrm{Tc}$ in most of the tests conducted to date, whercas the ES-13 test utilized Re and Tc simultancously to determine the validity of Re as a surrogate. Although their chemistry is similar, there are differences in chemical speciation and thermodynamic properties under the range of conditions used for vitrification. The panel believes that $R e$ is the best surrogate for $T c$ in the cold BV tests; however, results must be validated (and are planned) in hot tests with Tc, prior to full-scale radioactive testing in the DBVS $\downarrow$

Prediction of Tc behavior through direct correlation with measured Re behavior needs to be done with care, due to differences in oxidation state between the two during incorporation into glass (Lukens, 2006). Re starting materials can disproportionate and be incorporated as both the $\mathrm{Re}$ (VII) and metallic droplets in the glass. In addition, the relative leaching behaviors of Re and Tc from borosilicate glasses is generally not well known. This is compounded by the lack of knowledge of Te speciation in borosilicate glasses (Marples, 1991; Ebert 1996; Ebert, 1997). In this respect, care must be taken when performance assessments of the BV glass product or any other radioactive glass product are made.

The panel recommends that research-scale experiments be conducted to verify the continued validity of the surrogate relationship in glass or to establish a new relationship, if substantial BV process clanges that could modify $\mathrm{Tc}$ or Re speciation in the glass are implemented.

When comparing $T c$ and Re volatility under the same conditions during $B V$, close parallels can be established and relative behavior assessed accurately. However, if conditions are changed markedly (c.g., melting temperature or redox conditions), the relationship between the two in 
RPP-30570, Rev. 0

tcrms of volatility may change. Once again, the panel recommends rescarch-scale melt experiments be effectively used to establish boundaries or re-establish correlations to map to the larger scale tests when needed.

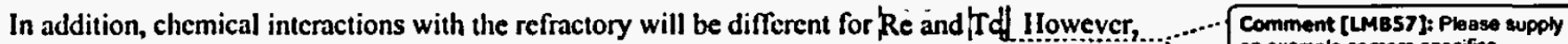
the use of $\mathrm{Re}$ as a surrogate for Tc, with surrogate testing preceeding hot testing remains the best approach.

\subsection{FATE OF TECINETIUM}

It is imperative to understand the fate of Tc within the BV process, including significant Tc losses from the melt. This information is needed so that the overall impact of Tc fate on the BV process can be properly assessed and steps taken to mitigate the impact of the Tc not incorporated into the glass product. The overriding priority should be to incorporate as much non-leachable $\mathrm{Tc}$ as possible into the glass product (limit volatilization of Te species) in a form and/or manner compliant with satisfactory performance assessments. Recommendations for Te mitigation are contained in Section 2.3.

\subsubsection{Mass Balance}

Early BV engincering-scale studics were performed in a top-down manner, which resulted in excellent retention of $>90 \% \mathrm{Tc}$ in the waste package; however, $1-2$ percent /was contained in the Comment [FW59]: changed sand liner. In contrast, the switch to a bottom-up melt process resulted in retention of approximately $53 \%$ of the Tc in the BV product in the ES-12 engincering-scale test and $35 \%$ of the $\mathrm{Tc}$ in the glass product in the BV product in the ES-13 enginccring-scale test. In ES-13 where mass balance measurements were attempted $24 \%$ of the $\mathrm{Tc}$ was unaccounted for. Of particular concem is the $2 \%$ Tc on the container lid (ES-13), which could impact the performance assessment and/or require cither clcaning or replacement at the completion of vitrification. A very small fraction is found in the refractory; there are active cfforts underway to identify alternatives to further minimize this issue.

The most probable fate of the Tc unaccounted for in the boltom-up tests is volatilization into the off-gas system. However, the total amount of Te in IIEPA filters can be problematic to ascertain; substantial under-estimates may result from the analytical measurements. The panel makes two suggestions to alleviate this difficulty: 1) addition of a removable filter matcrial, such as glass wool, in a filter assembly in front of the HEPA filter to provide a more casily measured material, 2) an off-gas sampler with the gas nun through a liquid scrubber (or mass filter) system for calculation of the Tc load.

Although not likcly, it is also possible that some portion of the unaccounted for Tc may actually reside in the glass product, but has not becn measured because of possible inhomogeneity (i.e. metal inclusions) within the glass product. Ilence, the panel recommends that additional tests of Tc distribution within the glass be conducted.

If the unaccounted for $\mathrm{Tc}$ is found to be volatilizing into the off-gas system, Hhis would presents additional challenges for the overall $\mathrm{BV}$ system in terms of increased demands on the 
RPP-30570, Rev. 0

off-gas system and lid contamination. The current plan to reduce the impact of low Tc retention and increased off-gas load is to recycle the material removed from the off-gas and collected on the filter (sce Section 2.3).

\subsubsection{Off-gas Recycle}

A major component of the proposed off-gas system is the sintered metal filter (SMF), which is the main particulate barricr limiting the downstream loading of the HEPA filter and the secondary waste stream. The SMF is designed to capture ejected particulates and return them to the feed of the BV dryer upon application of a sonic pulse, but is yet to be tested.

The current SMF is a stainless-stecl design meant to operate at a temperature of about $300^{\circ} \mathrm{C}$ under normal conditions. Particulates containing $\mathrm{Te}$ in several chemical forms could reach the SMF and become lodged in the filter matcrial. To minimize volatilization of Tc that might arrive in particulate form and/or by in-situ oxidation in the filter, the SMF must be operated well below $311^{\circ} \mathrm{C}$, Kobservation noted by the DBVS project team and flowshect adjustments have bee made to decrease the SMF operating temperature to $230 \mathrm{C}$ ) the gencrally recognized boiling point of $\mathrm{Tc}_{2} \mathrm{O}_{7}$. Furthermore, it is likely that $\mathrm{Tc}$ will combine with $\mathrm{Cs}$ to form the species $\mathrm{CsTcO}_{4}$, which has vapor pressure characteristics similar to other $\mathrm{MTcO}_{4}$. As Tc is a known corrosion inhibitor, it is possible that solid-state or vapor-phase matcrials may not cause degradation of the SMF. However, the catalytic properties and activity of a 316-stainless stecl surface in contact with several solid- state and/or gas-phase Te species is not known. Further discussion of the SMF is contained in Section 5.2.

\subsubsection{Chemical Feed Considerations}

The pre-treatment of the waste stream to reduce $\mathrm{Tc}$ (VII) to a lower valence $\mathrm{Tc}(\mathrm{IV})$ species is an initially attractive approach to possibly limit the vaporization of Tc and enhance its incorporation in the glass. However, there are no known Tc reductants, which can accomplish this, because of rapid re-oxidation of $\mathrm{Tc}$ in the waste stream feed above pl 10. Tc(IV) under these conditions has been shown to be thermodynamically unstable (Kim et al., 1999; Darab, 1996; Rard et al., 1999). A stratcgy to reduce Tc(VII) under the conditions that exist in the waste stream must be kinctic in nature, similar to the reason for the stability of $\mathrm{Tc}(\mathrm{I})$ in certain Ilanford waste tanks (Lukens et al., 2004). A kinctic process would utilize an inorganic metal oxide or hydrous oxide matrix with a metal with the same ionic radius as $\mathrm{Te}$ (IV), $\mathrm{Ti}(\mathrm{IV})$, or Fe(III) (Muller, 1964). Ilowever, initial attempts at kinetic stabilization have proven ineffective under waste-stream conditions. Furthermore, it is not clear that reduction to a Tc(IV) species, particularly the hydrous oxide, is desirable, because it could be rapidly oxidized to extremely volatile $\mathrm{Tc}_{2} \mathrm{O}_{7}$ or possibly disproportionate into two Tc species, one of which may be volatile, when introduced.

Another approach to control Tc volatilization might include addition of specialized materials to the feed in the dryer to control the chemical and/or physical nature of the melt cap. Section 2.3.4 provides recommendations related to forming more reactive pellets, which could minimize Tc losses. 


\subsection{RECOMMENDATIONS FOR MIITIGATION OF TC LOSS}

The panel prefers to make concrete actionable recommendations for process improvements to the BV system. Ilowever, the limited information available to the panel makes this impractical. Instead, the recommendations that follow are intended to stimulate discussion. Although these ideas are known to work in apparently similar glass melting processes, the panel recognizes that some of them may be impractical in the DBVS, for reasons that may be unknown to us, and that others may have already been considered and tried or rejected for valid reasons. With these caveats, our recommendations are listed in the order in which the panel suggests they be considered. In each case, some of the advantages and potential pitfalls are described.

\subsubsection{Increase Te Retention in the Melt}

Direct incorporation of $\mathrm{Tc}$ into the borosilicate melt occurs in the heating and dissolution processes that take place in and just above the fusion layer on the lower part of the cold cap. If the Tc gocs into a liquid silicate phase (and not into a separate molten salt phase) at that point, then it is more likely to be retained in the glass. Three different categories of process changes are proposed to: 1) reduce Tc vaporization from top surface of the melt, 2) reduce Tc penetration into the refractory liner, and 3) promote faster reaction of waste feed pellets.

\subsubsection{Reduce Vaporization of Te Species from Top Surface}

\subsubsection{Quantify rate-controlling parameters of $T c$ (and Re) loss from fusion lajer of cold cap}

A good empirical quantitative understanding of the rate of loss of $\mathrm{Tc}$ (and $\mathrm{Re}$ ) as a function of bath temperature, cold cap thickness, Tc concentration in feed, raw materials (and their effect on initial liquid composition), and reductants is needed to design and prioritize tests aimed at reducing vaporization. Because of the difficulty of making measurements inside large melters, and of producing and controlling all the key process parameters, it is much more practical to do this testing on a lab or enginecring scale rather than in full-scale equipment.

\subsubsection{Maintain a constant cold cap thickness with a cool top surface}

Anticipating the results of the testing recommended in the previous paragraph, it is safe to say that maintaining complete coverage of the melt surface by a cold cap with a top surface close to room temperature is the surest way to limit Tc loss by vaporization. In addition, insulating the melt surface allows the bulk melt temperature to be increased, which would result in increased processing rates.

In a cold cap of constant thickness, a condensation layer will develop just above the fusion layer. The concentration of $\mathrm{Tc}$ in that condensation layer will quickly equilibrate at whatever (high) level is necessary to cause the Te concentration in the molten glass to equal that in the feed. The inventory of condensate in the cold cap depends critically on its thickness. Two conditions are necessary to maintain that condensation layer: the melt must be held at a constant temperature and its surface must be cooled continuously by the incoming feed stream. Under these conditions, the cold cap thickness and its inventory of condensates will remain constant. The following options can be considered to maintain constant cold cap thickness, thus 
RPP-30570, Rev. 0

mitigating $\mathrm{Tc}$ loss. They are listed in order of decreasing desirability. Comments provided describe case of implementation.

- Maintain a constant bath sempcrature.

Constant thickness and Te inventory of the condensation layer depend on maintaining a constant temperature gradient through the cold cap. This is best accomplished by holding bath temperature constant and adjusting feed rate to maintain a constant cold cap thickness.

- Fed continuously and never melt the cold cap.

It is very important that feeding not be internupted, because that allows the cold cap to melt, releasing its inventory of condensed Tc and other volatile radionuclides (Cs, I). The following approaches to continuous feed might be fcasible in the proposed DBVS.

- Add a second dryer/mixer (in parallel).

This is the most desirable method of maintaining constant cold cap thickness, because it provides redundancy as well as continuous feed under normal conditions.

- Add a feed surge tank between the drycr and the melter.

This introduces another feed transfer step, which increases the risk of plugging.

- Mix and dry continuously, not batchwise.

This requires either continuous weighing of each component, or addition of a batchwise dry mixing stcp prior to continuously adding liquid waste and drying, followed by continuous feeding of the boron source only. This is a complicated approach, and is suggested for consideration, only if a second dryer or surge tank is truly impractical. A reviewer's suggestion for semicontinuous, partial dryer batch additions at higher frequency deserves consideration.

- Cool the melt surface aggressively when feed is not available.

Although no product is being made when there is no fecd, it may be possible to retain most of the $\mathrm{Tc}$ in the melt and in the layer of condensate that forms in the cold cap, if the surface is kept cool. Reducing electrical power and introducing a strong flow of cooling air may provide adequate cooling, but if not, air/water mists could be used to extract much more energy. There should be less of a safety issue with water mists than with slurry feeding, but the 
RPP-30570, Rev. 0

uniformity of cooling required to maintain the cold cap makes cooling with water mists difficult to implement.

\subsubsection{Improve uniformity of feed distribution over the melt surface}

Three options for improving the uniformity of feed distribution over the melt surface are suggested in order of increasing technical difficulty.

- Add a third fill port or angled chutes through the two existing ports.

- Distribute feed latcrally below cach port, using deflector plates or cones, rotating swecper arms, or a rotating angled chute. All of these devices are prone to fouling and would require significant development effort.

- Convert the feed into hard round pellets in the mixer/ dryer.

This last approach can be extremely difficult, but it has the potential to also address the refractory problem, so it is discussed in Section 2.3 .4 below.

\subsubsection{Reduce Te Penetration into the Refractory Liner}

Migration of volatile species of Te through a refractory liner containing connected porosity can occur by vaporization/condensation mechanisms or by liquid flow. Based on the test results presented, it appears that the principal mechanism for migration of $\mathrm{Tc}$ into the porous refractory liner is the capillarity-driven flow of Tc-containing molten salts having melting temperatures as low as $300^{\circ} \mathrm{C}$. At such a low temperature, molten salts react slowly or not at all with the porous refractory; hence, salts continue to penctrate rather than forming a viscous glassy phase that prevents further penctration into the refractory.

The most robust solution to this problem is obviously to find a refractory with no porosity or only closed porosity. The amount of material needed to line the entire melter, the need for good resistance to corrosion by molten glass, and the cconomic constraint imposed by the short life of the melter, scverely limit the choices. This panel did not have the opportunity to review the considerable information that has been produced by the project on this issue, but suggests consideration (or reconsideration) of the following approaches to limit penctration of Tccontaining molten salts and vapor species into the castable refractory block (CRB) in contact with molten glass. The preferred approach to reduce Tc penctration should be to find a refractory material that has lower permeability in its as-received condition. The various options to make only the surface of the refractory lower in permeability will always result in a material that is more complicated and more prone to failure than a homogeneous refractory of intrinsically lower permeability.

\subsubsection{Substitute sinfered amorphous silica for the mullite CRB}

Sintered amorphous silica, a material commonly used in the specialty glass industry and in metal melting, may have a lower permeability for both vapors and molten salts containing Tc than the mullite CRB. It may be possible to either substitute silica for the mullite or to clad the mullite CRB with sintered fused silica plates if an adequate bond could be obtained... Because of Comment [FW66]: changed 


\section{RPP-30570, Rev. 0}

its high thermal shock resistance, silica can be used in thinner layers than most other refractory materials. In the presence of alkalies, amorphous silica slowly crystallizes, losing its structural integrity; it probably would last long enough in this application, because of the short melt-cycle time. The silica can be made impermeable by flame- or are-glazing, a process that would need to be applied before it is installed in the melter. Vesuvius is one manufacturer of sintered amorphous silica.

\subsubsection{Trap $T c$ in a thick layer of porous refractory}

If a material that is both corrosion resistant and impermeable to Tc-containing vapors and molten salts cannot be found, then a strategy to separate the functions of corrosion resistance and impermeability might be considered. $A$ liner with adequate corrosion resistance (like the mullite CRB presently used) could be installed, then coated or clad with a sacrificial inner liner. This inner lining would be designed to absorb molten salts and vapors at low temperature as the cold cap approaches and contacts it, preventing penetration into the corrosion-resistant liner. As the cold cap rises above the Tc-containing sacrificial layer, it would dissolve in the melt at high temperature, perhaps taking most of the Tc into solution in the melt. This inner liner needs to be reactive toward the Tc-containing salts and vapors, and have a high solubility for sulfates and chlorides, but be totally soluble in the alkali alumino-borosilicate melt.

A suggested starting point in the scarch for a suitable matcrial would be a low-temperature insulating brick with a high silica content and high intemal surface area, either as-manufactured or saturated with compounds designed to react with the Tc-containing specics to form a lowmelting glassy phase. The inner lining might be placed as panels or gunned on as a continuous liner.

The work currently underway to add sodium silicate to the current CRB material to cast a lowdurability, inner liner with a high-durability outer layer secms promising.

\subsubsection{Coat mullite CRB with high-silica frit}

Because addition of silica to alkali silicate melts increases their viscosity dramatically, it may be possible to stop the penetration of Tc-containing molten salts and alkali vapors by coating or impregnating the mullite $C R B$ with silica in the form of a high surface-arca powder. $A$ binder would be needed to keep the powder in place until it reacts with vapors or salts, forming a highviscosity surface layer of reduced permeability.

Promising work currently under way at PNNL is based on a similar idea, but adds fine silica materials to the batch to react with the molten ionic salts (MIS) at lower temperatures, preventing its movement into the CRB wall. If successful, this approach would be much simpler and more reliable.

Because this fundamentally changes the sequence of reactions in the cold cap, Te retention will certainly be changed and will need to be determined by small-scale tests. 


\subsubsection{Coat refractory walls with molten glass}

RPP-30570, Rev. 0

If the above measures do not reduce Tc penetration to an acceptable level, it may be worth considering coating the interior walls of the CRIB with molten glass, which will penctrate the porous refractory, effectively sealing against subsequent penetration by both molten salts and vapors. If a glass composition that has a thermal expansion coefficient close to that of the refractory is chosen, it should be possible to seal the refractory prior to introducing feed. Other than the thermal expansion, there are few constraints on the glass composition. A glass with a very low viscosity curve would be casier to apply. One that exhibits a strong increase in viscosity as refractory dissolves in the glass would remain near the surface and provide better protection against penctration.

Five methods for applying hot glass to the refractory are offered for consideration. Four of these methods coat the refractory before any feed is introduced; the last method uses the molten glass in the melter during waste processing as a coating. These ideas might be best treated as starting points for brainstorming, because cach of them have serious practical issues that necd inputs from those more familiar with the BV process than this panel.

- Fuse frit onto refractory pancls before assembly.

The simplest approach would be to have the refractory supplier coat the panels before shipping them to the assembly site. $\Lambda$ good thermal expansion match is required to prevent spalling during shipping and assembly, and a thinner layer would increase the chances of survival of the pancls.

- Mclt glass frit held with a binder in the assembled melter.

Fine-particle size distribution (PSD) frit, held in place by a binder that hardens at room temperature, could be melted and allowed to penetrate the refractory. Ileat could be supplied with burners inserted through the fill holes before feed is started. (lleat from the melting process would not be adcquate to fuse the frit before vapor and salt penctration had occurred.) Cooling or thermal shiclding may be needed to protect the electrodes from oxidation, unless electrodes could be inserted after the coating process is completed.

- Blow frit blown hot refractory in the asscmbled melter.

It may be easier to coat the refractory by first preheating it with gas burners, then blowing coarse frit against the hot walls, where frit particles will stick and fuse into a continuous layer before soaking into the refractory.

- Puddle molten frit on the refractory.

While the melter is still in its assembly location, it may be possible to heat the refractory interior with gas bumers and allow a shallow pool of molten frit to soak into the refractory bottom. By rotating the melter nearly 90 degrees onto each long 
RPP-30570, Rev. 0

side, the sides could be similarly coated. It is impractical to coat the ends in this fashion.

\section{- Tilt the melter during operation}

The container walls could be coated with hot glass during the melting cycle. If the melter were placed on a tilting platform, it should be possible to tilt it slowly on its long axis, allowing the walls just above the melt level to be coated. Inclining the melter about 20 degrees would coat the wall about one foot above the melt level. This would have to be repcated about every 6 inches as the melt level rose, to kecp the wall coated at least 6 inches above the fusion zone. This implies 10-12 tilting operations in each direction per melter cycle, not a very attractive proposition.

\subsubsection{Limit Te Loss with Faster Reaction in Strong Feed Pellets}

The combination of strongly alkaline liquid and fine particle-size refractory components in the feed presents an ideal situation for producing a feed form that will react quickly, incorporating the $\mathrm{Tc}$ in a molten silicate phase, before it can vaporize or segregate as a MIS. $A$ major goal of the mixer/ dryer should be to produce strong pellets, with cach pellet having essentially the same composition as the overall feed. The close proximity of the fluxes to the fine refractory components in each pellet will ensure that the glass-forming reactions occur faster and at a lower temperature than would occur in loose (unpelletized) feed. This should result in less Tc vaporization, less molten salt penetration of refractory, less segregation of slow-dissolving components, and faster melting.

Hard round pellets should have a consistently low angle of repose, allowing them to be distributed more uniformly over the melter surface.

The pancl recommends testing operation of the mixer/dryer to make strong feed pellets. Littleford Day should be able to provide assistance and perhaps test facilities to be used to determine how to operate the mixer/ dryer as an efficient pelletizer. It may be necessary to select raw materials of different surface characteristics (particle size and shape) and to add materials that act as binders to give good mechanical propertics at low drying temperatures. Organic binders may play a dual role, acting also as reductants. As one reviewer pointed out, any organic added must be compatible with the nitrate salts at dryer temperatures to avoid uncontrolled exothermic reactions in the dryer.

\subsubsection{Tailor raw materials and order of addition}

To produce uniformly-sized, hard, round pellets at a low dryer temperature, some of the materials must have a very fine particle size and be quite reactive toward the alkaline waste solution. Clays, other fine refractory raw materials, and organic and inorganic binders may be helpful. The order of addition is frequently important, as it determines which components have the greatest contact with other components. 


\subsubsection{Quantify melting behavior of strong pellets \\ RPP-30570, Rev. 0}

During heat up of the feed in the cold cap, a liquid phase is formed by reactions between components of the feed. This liquid then incorporates other soluble components. These reactions usually begin at low temperatures in pellets formed by reaction between alkali solutions (e.g., liquid waste) and fine oxides. The melting rate and the rate of $\mathrm{Tc}$ vaporization should be measured on a small scale before full-scale tests are undertaken.

Some of these recommendations border on impractical $=$ suggest we eliminate these and reduce the list of recommendations.

Comment [PW67]: not changed As explained at the end of Section 1. some of the recommendations are intended bo raise possibilities, the practicality of which the review panel was not provided with enough information to assess.

\subsection{Impact on Glass PERFormance}

Test results have shown that the metal inclusions formed in the vitrificd product have higher concentrations of Tc (and its Re surrogate) than the glass. The enrichment factor, the ratio of the concentration of $\mathrm{Tc}$ in the metal to that in the host glass matrix, has been measured to be on the order of 100 -fold. Because the metal phase, which is predominantly iron, is more soluble than the glass in the expected disposal environment, its presence may increase the rate of release of Tc. Accordingly, if metal inclusions are present, it is essential that the extent of this impact be understood and minimized.

In addition to the Tc enrichment factor, the total mass fraction of metal in the product and its distribution within the product are also key factors in determining the overall rate impact on performance. It seems reasonable to expect that, other things equal, the overall rate of release of Te would decrease as the Tc enrichment factor decreases, as the total mass fraction of metal decreases, and as the distribution of metal phase changes from large ingots near the surface of the glass product towards finely divided inclusions uniformly distributed throughout the glass phase. At present, the effects of process chemistry and operating conditions on these factors are not totally understood. Efforts to date have focused on minimizing the total mass fraction of metal in the product. Recent tests have indicated success in reducing'/climinating metal lingots at the bottom of the product. While this emphasis is reasonable in terms of prioritizing the testing efforts, the potential for mitigation focused on Tc enrichment and metal distribution should not be overlooked.

Earlier tests have shown that the majority of the metal was in the form of ingots at the bottom of the product; more recent iest resulis have indicated success in reducing the amount of metal in the form of ingots. However, several test conditions were changed at once to maximize the likelihood of "success." While this permits a form of empirical progress, it complicates subsequent optimization steps, because the relative effects of the carlicr changes are not known, nor is it known which changes were essential and which were redundant. Thus, while the progress is encouraging, the panel recommends that subsequent testing should seck to separate the effects of these changes. (specify what sequencing is suggested)

The test data indicate that the glass product also contains inclusions of metal particles of various sizes distributed through the glass phase. For a given total amount of $\mathrm{Tc}$, the surrounding glass

Comment [h70]: Need to qualify that these tests were melts done on non-oxidizing feed with the test objectives for thermal bading of the ICV. Once feed materials containing is oxides was used, the amount of metal inclusions dropped significanty. Comment from Billio Mauss, ORP

Comment [FW71R70]; changed 


\section{RPP-30570, Rev. 0}

phase is depleted in proportion to the Tc enrichment in the metal particles. Then, in terms of release, if it is assumed that the surrounding glass phase must be dissolved before a metal particle becomes available for dissolution, one could argue that the rate of Tc release is still dominated by the rate of dissolution of the glass phase. While such a simple model of this kind is a start, the importance of this issue warrants a more sophisticated analysis and supporting testing. $\Lambda$ number of complicating factors need to be considered:

- metal particle size and distribution in relation to the ultimate mean fractured glass particle size (because the thermally stressed glass product will fracture into chunks);

- effects on glass fracturing of differential thermal expansion and potential presence of crystals formed by devitrification of the glass phase during cooling;

- potential for agglomeration and sedimentation of the metal inclusions, because it provides a mechanism to bring Tc-enriched metal phase to the bottom surface, thus climinating the dependence on dissolution of the glass matrix as the rate-controlling parameter.

\subsection{RECOMMENDATIONS FOR DESIGN AND OPERATION TO ELIMINATE METAL INCLUSIONS}

This section of the report covers recommended actions to climinate metal inclusions. Total climination of all metal inclusions may not be possible hor would be required to support the PA but these approaches are suggested as ways to minimize the amount of metal produced. Because the reactions that produce melal inclusions are very sensitive to small changes in temperature and concentrations in the melt, they should not be expected to occur uniformly throughout a large melter or consistently from melt to melt. The panel recommends that, considering this inherent variability, the goal should be total elimination of metal inclusions.

Large reductions in the mass of metal inclusions produced in large-scale tests have recently been achieved (in Test 38-B) by reducing the amount of graphite in the starter path, and by better control of both start up and operational temperatures in the melt pool through tighter control of current density and bath temperature. This demonstrates the potential for further reducing or even totally climinating these inclusions.

The panel recommends that an effort be made to determine the details of the mechanisms by which metal inclusions are formed as the fastest and most economical way to leam how to eliminate them.

\subsubsection{Deternine Mechanisms}

Two fundamental processes probably account for most of the reduction of iron and other metals to their clemental state during melting: carbothermic reduction, both by starter-path materials and by electrodes, and clectrochemical reduction on the electrodes. With better knowledge of the relative importance of the fundamental processes, and of their sensitivity to temperature and iron content of the bath, actions intended to counter them (discussed below) can be prioritized, leading to further reductions in the mass of metal inclusions. 


\section{RPP-30570, Rev. 0}

The panel recommends lab-scale testing to quantify the rate of formation of inclusions by cach fundamental mechanism, because the effects of each mechanism cannot be separated in largescale tests, where it is impractical or impossible to control and measure local conditions adequately.

\subsubsection{Formation of metal inclusions on graphite fake starter path}

Tests should be designed to quantify the effects of the key parameters: iron concentration in the glass phase, melt temperature along the starter path, and the graphite surface area available for reaction.

\subsubsection{Formation of metal inclusions on graphite electrodes}

Tests should be designed to quantify the effects of key parameters:

- for unpowered graphite electrodes in the melt, the key parameters will be iron concentration in the glass phase and temperature at the graphite/melt interface;

- for powered electrodes, iron concentration in the glass phase and interface temperature will be the key parameters, along with current density at the clectrode surface, DC bias, and frequency of the power supply.

Note that the melt is very non-uniformly heated with cylindrical clectrodes, as the melt adjacent to the electrode is sometimes several hundred degrees hotter than the bulk melt. This overheating is directly related to the current density. DC bias arises when there is an asymmetry (geometric or thermal) between the two electrodes. Current density and frequency together determine the total charge transferred each half cycle per unit area of electrode surface, and hence, the extent to which metal inclusions are produced by a process sometimes referred to as Faradaic rectification.

\subsubsection{Reduce Role of Starter Path in Production of Inclusions}

The steps that have already been taken to reduce the size of the starter path have been successful. The pand recommends the following actions, with the most promising listed first, to continue this progress.

\subsubsection{Eliminate iron in starter path and first batch of feed}

Because the graphite introduced in the starter path probably remains in the melt for some time before it bums off, the first portion of the fecd should be low-iron. Substituting low-iron raw matcrials for Fe-bearing soil in the first complete batch of fecd may provide cnough time for most of the graphite to be climinated, before it can contact iron-containing glass. $\Lambda t$ the time of this review, this action was planned.

\subsubsection{Substitute small graphite plates}

The graphite is oxidized either by reaction with reducible metal ions in the melt (clearly undesirable), or with molten salts (nitrates, sulfates) in the fusion laycr of the cold cap, or with 
RPP-30570, Rev. 0

oxygen in the atmosphere above the cold cap. Thus, it is helpful if the graphite used to create a conductive path floats quickly to the melt surface. Substituting plates for at least part of the fine graphite flakes presently used in starter path should accelerate the graphite bumout.

\subsubsection{Use graphite-free starter path}

It may be possible to start the process with a paste of ionic salts, which would form a conductive path for initial heating, then decompose or dissolve in the melt that forms around the path. The panel considers this to be the least likely approach, and has no specific materials to propose.

\subsubsection{Reduce Role of Electrodes in Production of Inclusions}

It seems likely that carbothermic reduction at the surface of the clectrodes is the major source of metal inclusions. Anticipating the results of the testing recommended above to quantify the rate of production of inclusions, it is reasonable to assume that the key parameter will prove to be interface temperature, which is driven by current density. The following actions are recommended, subject to results of the mechanism testing recommended above. The approaches are listed with the casiest to implement first.

\subsubsection{Lower power input}

Current density is the most important parameter, because higher current densities directly cause clectrochemical reduction, and indirectly cause carbothermic reduction by raising the interface temperature. The simplest way to lower current density is to lower the total power fed to the melter. The obvious disadvantage is the resulting reduction in melting rate.

The most critical period is the initial part of the cycle, when a small volume of melt contacted by a very limited electrode area is providing the energy to raise the temperature of the entire melter.

\subsubsection{Increasing clectrode area}

A better, but more difficult, way to lower current density on electrodes throughout the melt cycle is to increase the surface area of the electrodes. Two approaches are proposed, both well beyond the AMEC technology base, but the first is well established in commercial electric melters:

- Plate electrodes

Covering the entire ends of the melt chamber with graphite plates improves the design in two ways:

- The effective surface area of cach electrode would be increased by about 3 times, and plate electrodes would be much easier to cool. (The back third of a vertical rod electrode is usually considered to be inactive because of the longer current pathway.) Electrical connection to the plates could be through the top or through the end walls, with metal-to-graphite connections cooled by air or water. 
- Inverted-T electrode.

RPP-30570, Rev. 0

A horizontal graphite bar, placed across the full width of the bottom under cach cylindrical electrode, would greatly increase the electrode area during the initial part of the melting cycle. The vertical and horizontal electrodes could be connected clectrically with graphite paste. The panel is unaware of such an electrode configuration in commercial electric melters, but this would require fewer design changes than the preferred plate electrode configuration.

\subsubsection{Cool the electrode/melt interface}

Because the glass is quite clectrically conductive well below bulk melt temperatures, reactions at the electrode surface can be slowed or nearly stopped by cooling the electrodes. Although it would be possible to install cooling inside the cylindrical clectrodes, it is more practical to cool plate electrodes on the ends of the melter. A high-conductivity clectrical-insulating refractory (c.g., alumina) would conduct heat out of plate clectrodes to the air-cooled steel shell. Graphite paste could be used, if necessary, to improve thermal contact between the alumina and graphite plates.

\subsubsection{Prevent electrochemical reduction}

Although most of the production of metallic inclusions is probably carbothemic, there may be some electrochemical reduction, especially early in the process, when current densities are typically higher. Two approaches are available to counter this mechanism:

\section{- Applying a DC bias}

If each electrode is connected to a small graphite plate electrode on the bottom in the center of the melter, a DC potential can be applied to offset the tendency, to some extent, to reduce ions to the metallic state on the cathodic half cycle. The feasibility of this approach would need to be demonstrated on a lab scale.

- Powering at a higher frequency

Electrochemical reduction with an $\mathrm{AC}$ power supply occurs when the metal produced on the cathodic half cycle moves out of electrical contact with the clectrode, before it has a chance to be re-oxidized on the anodic half cycle. The amount of metal produced depends on the mobility of the metallic inclusions and is directly proportional to the amount of charge transferred on each half cycle. Increasing the frequency of the $\mathrm{AC}$ power reduces the charge transferred in inverse proportion to the frequency. Moderatelyhigh frequency (e.g., $1000 \mathrm{llz}$ ) power supplics of the capacity needed for this process are used in some induction-heating applications.

\subsubsection{Preferred approach to eliminate metal inclusions}

Assuming that testing shows that carbothermic reduction at the surface of the clectrodes is the major source of metal inclusions, the most likely way to unequivocally climinate metal 
RPP-30570, Rev. 0

inclusions is to cmploy extemally-cooled plate electrodes. Technically, the most important parameter to control is the interface temperature, and this approach gives direct and powcrful control over that parameter. This is a major change from the present technology, but the issucs are likcly to be almost entircly technical and economic. Alongside the altemative discussed next, where the issues are technical, cconomic, and especially regulatory, it may not be an unreasonable approach.

\subsubsection{Develop a Low-iron Glass Composition}

If none of the above measures climinate metal inclusions, the plan to use native soil as a raw material should be reconsidered. Other low-cost raw materials, such as low-Fe clays, sands volcanic ashes, and conventional glass-forming chemicals are reasonable alternatives to the proposed Fe-rich soil. Their use would give additional benefits of flexibility in the Si/Al ratio (which impacts the maximum waste loading) and in tailoring the feed for better pelletizing in the mixer/ drycr to obtain a non-caking, free-flowing fecd, which would react more rapidly during melting.

The total iron content of the glass should probably be around $0.1 \mathrm{wt} . \% \mathrm{Fe}_{2} \mathrm{O}_{3}$, to obtain the best compromise between low raw materials cost and high infrared transmission in the melt (better heat transfer). Process advantages of a low-Fe glass, all resulting from the inproved heat transfer within the melt, include: a) better radiative cooling of the clectrodes, b) less tendency to coring (hot channels in bath), c) higher melting rate, and d) more uniform temperature throughout the melt volume (less tendency to devitrification in cooler regions).

\subsubsection{General considerations and schedule implications}

The inherently reducing environment created by the graphite electrodes and the high local temperature around the electrodes as a result of the rod geometry potentially can drive the more reducible species present in the feed to their metallic states. Because iron is both sufficiently reducible and abundant in the fecd, it dominates the composition of the metallic phase that is observed. While a varicty of potential mitigating approaches are possible, one of the more obvious and effective approaches is to simply remove most of the iron from the feed. Because iron has a very low solubility in the caustic supernate, there is very little iron in the LAW material. Essentially all of the iron (totaling around 4 to $4.6 \mathrm{wt} \%$ as $\mathrm{Fe}_{2} \mathrm{O}_{3}$ in the final glass) originates in the soil that is used as a glass-forming feed material. It is worth noting that in addition to iron, the llanford soil also contains a significant amount of sodium (about $3 \mathrm{wt} \%$ as $\mathrm{Na}_{2} \mathrm{O}$ ), which necessitates a reduction in waste loading for the high-sodium $\mathrm{LAW}$ material, the cost of which probably will far outweigh any savings on raw matcrial costs. Thus, for process and cost reasons it may be worth considering cither alternative soils that are low in iron (and preferably also low in sodium) or, preferably, switching to more standard glass-forming matcrials that would also provide better process control and flexibility.

An important disadvantage of changing to a low-iron glass composition, however, is the relative paucity of data and the departure from the "main-stream" waste vitrification experience around the world, which is dominated by iron-containing glass compositions. Although the magnitude of the composition change is relatively small (amounting to just a few weight percent), this results in significant changes in properties, such as infrared absorption and redox chemistry in 


\section{RPP-30570, Rev. 0}

the melt. Consequently, it should be expected that such a change, while likely beneficial in the long run, will require its own lcarning curve in terms of how it impacts the process. This includes a varicty of subtle possible consequences, such as effects on the behavior of Tc in the absence of iron, which need to be considered. While it should be expected that there will also be changes in product properties, there is no reason to believe that these cannot be compensated, such that acceptable product quality (as well as melt properties such as viscosity, electrical conductivity, and phase stability) can still be achieved. This is supported by results of preliminary studies performed on low-iron glasses for the BV Project.

The panel recommends that efforts to eliminate metal inclusions, as outlined in Sections 3.2 .1 to 3.2.3, should be the preferred strategy. While the low-iron glass strategy (Section 3.2.4) has lower technical risk and a higher probability of success in terms of total elimination of the separate metal phase, it is likely to take longer to implement and is also subject to risks related to acceptance (Section 3.2.4.1), which are difficult to quantify at this time. Consequently, it is recommended that the low-iron glass strategy be pursued in parallel, while these risks are evaluated.

\subsubsection{Effect on Tc chemistry and Tc loss from the cold cap}

By changing to a low-iron glass, overall redox conditions of the melt would most likely change, but the resulting effect on Te fate and transport is uncertain. Given the current reducing conditions, the redox change may not be significant with respect to Tc speciation. Possible chemical interactions between iron and Tc may affect Tc volatility, thereby affecting Tc retention. If a low-iron glass is adopted, the lab testing proposed above to quantify the ratecontrolling parameters in Te vaporization from the surface would need to be expanded to the low-Fe compositions under consideration.

\subsubsection{Recommendations for low-iron glass}

$\Lambda s$ a result of the above discussion, the following recommendations are made. These recommendations do not preclude starting the DBVS test facility, because they can be investigated in parallel with the planned DBVS operations. Modifications resulting from these recommendations could be implemented later in the test program.

- In the long nun, the potential advantages of employing a low-iron glass composition are sufficiently great that testing should be continued to support a change to a lowiron composition. It may be casicr to gain acceptance of this change in composition, if a serious effort is made first to find the highest iron content at which metal inclusions are no longer formed in the process.

- While there are obvious data needs in terms of supporting an appropriate glass composition-property envelope to support process operations, the impacts on the behavior of the process should not be neglected. Sulficient engineering and full-scale testing should be allocated to support understanding and re-baselining the "normal" process behavior and the revision of acceptable operating parameter ranges for the low-iron flow-shect. 
RPP-30570, Rev. 0

- In view of its importance and complexity, potential changes in the behavior of Tc in a low-iron flow-sheet should be assessed.

- It is not recommended that a low-iron composition be implemented for the next fullscale test, because changes in several variables are already planned. Testing of the low-iron composition should be conducted as part of a full-scale test program once the recommended supporting lab-and engineering-scale data become available. It is recognized that crucible-scale glass testing data that have already been collected support the viability of such an approach to achicve suitable glass properties.

\subsection{RECOMMENDATIONS TO CONTROL FORMATION OF METAL INCLUSIONS}

The panel believes that the primary strategy with respect to metal inclusions should be to eliminate them totally, if possible. If the methods recommended in Section 3.2 to entirely climinate metal inclusions in the glass, cither by design and operational changes or by a change to a low-iron composition, are found to be untenable, the following recommendations are offered to assess and minimize the negative impact of metal inclusions on product performance.

- Additional testing should be performed to determine the key factors that influence and control: (i) enrichment of Te in the metal phase; (ii) mass fraction of metal that is formed; and (iii) size and spatial distribution of the metal phase within the product. The results should be used to determine the preferred combination of process changes to best mitigate the impacts of metal inclusions. Based on this information, the process operating envelope could be defined to ensure that only "acceptable" inclusions (in terms of, c.g., amount, sizes, distribution, enrichment) are produced.

- Testing should be performed to determine the effects of including the projected Tc recycle stream into the feed on the Te enrichment in the metal phase.

- Modeling should be performed to address the expected impact on Tc release of a glass phase with Tc-enriched metal inclusions. While it is possible that a bounding model may be sufficient, the effects of particle size (metal vs. fractured glass), differential thermal expansion, and the presence of crystals, should be assessed.

- Leach testing should be performed on prototypical product material composed of glass, metal inclusions, and crystals. The potential for enhanced glass dissolution rates in the presence of metallic iron alloy should be addressed. Tests using actual metal samples obtained from the engincering-scale test, ES-32B, are already planned.

\subsection{PRODLCT PERFORNINCE}

In comparison to the products from other nuclear waste vitrification processes (e.g., the Immobilized Low Activity Waste [ILAW] product to be produced at the WTP, glasses produced at the West Valley Demonstration Project [WVDP] in New York, and the Defense Waste Processing Facility [DWPF] at the SRS in South Carolina), the BV product is considerably 
RPP-30570, Rev. 0

more complex. In addition to the glass, in which there may be crystals and metal inclusions, the waste package is currently expected to contain a salt phase plus the container, refractory lining, graphite electrodes, and possibly the lid structure with associated ports and fittings. Issues associated with the contributions of cach of these components to the overall performance of the waste package are discussed in this section.

\subsection{GLASS}

In many respects, the glass represents the simplest part of the overall waste package. The glass testing program appears to be reasonable and results to date support the contention that the homogencous glass phase is capable of providing acceptable performance. Simple comparisons of the compositions with known compositions and properties of similar glasses are also consistent with this expectation. However, the full-scale process may be subject to additional complications from effects, such as glass homogeneity (given the size of the waste package), thermal history, and redox state. Such factors must be addressed through appropriate testing and their effects or lack thereof dispositioned accordingly.

The graphite electrodes create reducing conditions in the melt. Test data indicate that redox ratios as high as $\mathrm{Fe}^{2+} /\left(\mathrm{Fe}^{2+}+\mathrm{Fe}^{3+}\right)=0.80$ have been found in glass product samples from large-scale tests. Such high redox ratios are considerably above the testing and operating experience base of other nuclear waste vitrification processes (c.g., WVDP, DWPF, WTP LAW, WTP IILW, German, French, UK, and Japanese IILW). As a result, there are few product leach test data available for such highly reduced glasses. Because the redox state is, in many respects, also a composition variable (i.e., in the sense of determining the relative proportions of, c.g., $\mathrm{Fe}_{2} \mathrm{O}_{3}$ vs. $\mathrm{FeO}$, which have quite different effects on glass properties), its impacts on glass propertics must be determined, and appropriate redox control ranges established for the process. Because the electrodes create a localized reducing condition, there may be substantial redox gradients or inhomogencities across the glass product. Sampling and product-quality and performance-assessment testing of full-scale products should be sufficiently extensive to address this issue.

\subsection{Crystals}

Depending on their composition and thermal history, varying amounts and types of crystalline phases can form during cooling within the amorphous glass.. In addition, the melts can separate into two or more amorphous phases of differing compositions; this process is called amorphous phase separation. These processes complicate the assessment of the performance of the resulting multiphase material, as compared with a single homogeneous glass phase. While it is possible that multi-phase materials may mect all of the product-quality requirements, additional data may be required to demonstrate that product quality requirements are met (specify). (by' what? If it is not a requirement what are we collectively doing??). Discussion not needed if there is in fact no requirement $=$ appears to be speculation Comment [FW73]: not changed the text proposed lor deletion to factualiy correct. and to focused on a topic of considerabte importance to the question of glass performance

hecds $\mid$ (need to tie this back to the premise that we have de-constructed several boxes in total and have used this data to prepare a statisticaliy defensible sampling plan for DBV SD Much of the glass development and testing work has employed the traditional container centerline cooling (CCC) heat treatment profile in an effort to include the potential effects of thermal 
RPP-30570, Rev, 0

history on product propertics. The logic behind the CCC approach, which has been employed in the United States IILW programs at WVDP and SRS, as well as for WTP HLW and LAW products, is that in a glass container that is essentially a right circular cylinder of large aspect ratio $(\sim 0.6 \mathrm{~m}$ diameter by $\sim 3 \mathrm{~m}$ high), glass near the centerline will experience the slowest cooling rate. Because slower cooling typically induces a larger degree of fracturing heat treatment according to the CCC-profile is assumed to produce the greatest extent of fracturing and, therefore, provides a sensible bounding thermal treatment for the purposes of testing. In view of the much larger size and appreciably different aspect ratio, it is not clear that CCC heat treatment necessarily provides a worst-case bound for the BV product. The sheer size could make the effects of the cooling process more susceptible to perturbations, due to differences in the external environment at different locations throughout the containcr. In addition, the much larger horizontal cross-section suggests that the BV container would likely support multiple convection cells, potentially allowing a given volume of glass to experience non-monotonic cooling, and perhaps thermal cycling. Such heat treatment schedules can facilitate rapid nucleation on cooling followed by rapid growth on reheating, leading to increased crystallization, a process widely exploited in the production of glass ceramics. These aspects of the cooling process could be usefully addressed by applying fluid-flow models, such as has been done with the TEMPEST code for the melting process. This in combination with thorough analysis of the full scale melts can be used to help determine if the CCC approach is adequate or if alternate cooling cycles are required to use crucible scale tests to predict devitrification at full scaled.

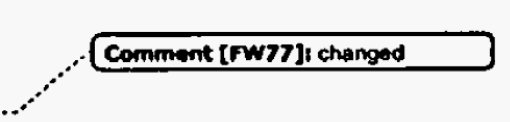

Is $\mathrm{CCC}$ a requirement of $\mathrm{L} \Lambda \mathrm{W}$ glass - if so this is an applicable paragraph, if not I am not sure I understand the relevance of this discussion.

\subsection{METAL}

The presence of a metal phase presents | complications in the assessment of the overall performance of the waste package, many of which were discussed in Section 3 . Although there is potential for interaction of the dissolution of the metal phase with the glass dissolution process, the principal concem stems from the fact that Tc is strongly enriched $(-100 x-$ verify this assessment through reference study) in the metal phase. The presently available test data, none of which include the effects of Te recycle, suggest that 9 to $14 \mathrm{wt} \%$ of the total Tc was present in the metal phase. The present emphasis on minimizing the amount of metal that is produced is therefore reasonable and appropriate. However, this must be combined with data to supporl some minimum level of metal is acceptable and that process controls have becn identifice and implemented to ensure that that level is not exceeded.

\subsection{SALt PHaSe}

Sclect test data indicate that a molten sulfate salt phase forms on top of the glass melt. Such salt phases may incorporate various heavy metals (particularly chromium) as well as various radionuclides (cesium [Cs], strontium, Tc), which are relatively soluble in water. Accordingly, the presence of such a salt phase, if it contains significant quantities of regulated constituents, in the final product, is undesirable. Efforts have therefore been undertaken to minimize its extent in the final product, including the use of a final "Top Off" feed batch. It should be noted, however, that the "cost" of this Top-Off batch is that one batch in nine contains no waste; 
RPP-30570, Rev. 0

although this is a smaller batch, it results in a reduction in the waste sodium-oxide loading in the product. Based on the test data reviewed and the Test Plan and Test Instructions for the 32-B large-scale test, the nominal total sodium-oxide loading in the target glass composition is $20 \mathrm{wt} \%$. However, when the non-waste sodium from the Top-Off batch, the starter batch, and the soil is subtracted, the actual waste sodium oxide in the product is about $17.2 \mathrm{wt} \%$.

Reducing conditions, due to the graphite electrodes and the high melt tempcrature, will increase sulfur volatilization (test data indicate that $\mathrm{kb}$ bout $40 \%$ is retained). Some test data indicate about $20 \%$ is retained, but more than $40 \%$ retention was observed on the most representative enginecring-scale melt, ES-32B. Much of the sulfur may be captured as alkali metal sulfates in the SMF. Because these filters are intended to capture Tc, the solids from these filters are recycled to the feed. As a result, the concentration of sulfur in the feed will increase (at steady state, to $2, \$$ times its nominal value based on $40 \%$ retention and assuming all of the sulfur is recycled; to the extent that some of the sulfur is present as suifur dioxide, it will pass through the metal filters, reducing the feed sulfur level). The tendency for sulfate salt formation is strongly dependent on the sulfur concentration in the feed and, therefore, salt formation is likely to be exacerbated once the recycle stream is included. Further testing should be performed to assess the extent of this issue and to support the development of appropriate mitigation strategics.

\subsection{BALANCE OF IVASTE PACKAGE}

The balance of the waste package consists of various matcrials, including the outcr stecl container, the internal enginecred refractory lining, the lid structure and associated fitting and flanges, and the graphite electrodes. While this diversity of materials and components make this significantly more complicated than the prototypical nuclear waste glass package composed of glass in a stainless stecl canister, the more crucial difference stems from the fact that the glass is melted in the container rather than simply poured into it. The glass melting process is vastly "dirtier" than the process of pouring pre-melted glass into a container. The melting process involves the generation of dust during the process of feed introduction; generates a variety of transient molten salts and other intermediate phases; and generates substantial volumes of gas and various vaporized and entrained feed constituents. These processes provide multiple opportunitics for infiltration, condensation, plating, and deposition of feed species into the balance of the waste package. This is facilitated by the relative complexily of the waste package, which has multiple materials, layers, and scams exposed to the process. The impact of these phenomena should be understood, as they may provide mechanisms whereby the key. contaminants of concem (e.g., Tc, other radionuclides, heavy metals) are present in the waste package, but are not vitrificd and, therefore, are potentially available for rapid release to the environment. In addition, distribution of high specific gamma activity radionuclides, such as $\mathrm{Cs}$ (which is very volatile), to non-glass locations within the waste package can potentially compromise shielding estimates. As such, it should be noted that the data available show small fractions of Te deposits in the CRB, higher amounts on the lid (where it can be handled if necessary), and much smaller amounts on the glass surface and sand. Accordingly, data pertaining to these issues are considered to be a crucial component of the effort to qualify the waste package and will have to be obtaincd at full-scale. 
RPP-30570, Rev. 0

A considerable amount of testing to assess the likcly fate of Tc within the waste package and the fraction that might be leachable has been performed. The current best estimate based on enginecring scale tests is that $0.37 \mathrm{wt} \%$ of the total $T \mathrm{c}$ resides in the waste package (cxcluding the lid) in a leachable form. However, because the estimate is derived from tests that did not include the Tc recycle stream, it is potentially underestimated by about a factor of two, assuming that about $50 \%$ of the Tc is volatilized (as is indicted by the present test data) and that all of it is captured by the SMF. The best estimate of leachable Tc on the lid is approximately $2+w t \%$ of the total, based on tests that did not include the Tc recycle stream; applying the same assumptions as above, it is potentially underestimated by about a factor of two. Therefore, a potential cstimate of the total fraction of the $\mathrm{Tc}$ in a leachable form in the waste package is about $4-5 \mathrm{wt} \%$.

The above cstimates are based on the $\mathrm{Tc}$ (or the Re surrogate) that was recovered in various locations. A significant complication, however, is the fact that about 24 |w1\% of the $\mathrm{Tc}$ was not recovered in the enginecring scale test with S-109 actual waste and remains unaccounted for. However, a mass balance for a ppm level trace constituent in a bench scale test that produces several hundred $\mathrm{kgs}$ of test materials is difficult. The difficulties associate with the Tc mass balance will require analyses of the non-glass portions of the waste package to ensure that leachable $T c$ is not present at unacceptable levels. This is considered to be a crucial issue for qualification of the product. Again need to qualify this statement in the fact that there is no evidence within the DOE system that anyone has demonstrated a mass balance closure greater that was observed at the BV engineering scale with ACTUAL waste TC.

\subsection{Product PERForMaNCE RECOMMENDATIONS}

The panel makes the following recommendations regarding product performance:

- The potential ranges of compositional inhomogeneity, redox-state inhomogencity, and thermal histories of glass distributed throughout the full-scale container need to be established. Test data need to be collected across and that the entire volume of glass meets the requirements. In particular, based upon the limited data set that was reviewed by the panel, it is not clear that glass samples that are representative of the most reduced state found during process tests have been tested. Need to take credit for the de-construction of enginecring/large scale containers and extensive sampling that was completed and which will be used as the basis for a statistically defendable sampling plan for DBVS

- Interactions of the glass product during leaching should be assessed for all of the waste-package matcrials, including the refractorics, metal inclusions, and graphite clectrodes. Because of the complexity of the BV waste package, this issue is likely to be greater than that required for more conventional waste packages (c.g., canistered vitrified IILW, WTP LAW).

- The expected range of erystal contents and types of phases necd to be determined and the dependence on process conditions assessed. Based on these results, appropriate operating parameter ranges need to be established to ensure that the

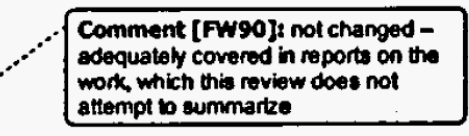
Comment [FW87]: not changed range better indicates the level of uncertainty$$
\text { appropriate operating parameter ranges need to be established to cnsure that the }
$$ 
RPP-30570, Rev. 0

impact of crystallization on product quality is properly bounded with respect to likely process variations.

- The appropriatencss of the CCC heat treatment as a realistic worst case needs to be evaluated. Fluid flow modeling of the waste-package cooling process may be helpful in making this assessment and in identifying representative bounding heattreatment schedules.

- The composition of the recycled solids from the SMF necds to be determined, with particular cmphasis on sulfur content, as well as halides and Tc. The impact of inclusion of this stream into the feed and the tendency for salt formation needs to be addressed and mitigation strategies developed.

- The amount of leachable Tc in the waste package necds to be better understood and the effects of Te recycle need to be included. Closure of the Tc mass balance would provide confidence in the estimates of the amount of leachable Tc. What is the benchmark that the Tc mass balance is to be compared to - specify/qualify herel Comment [FW93]; changed with diflerent wording

- The distribution of high specific gamma activity radionuclides, such as $\mathrm{Cs}$ (which is very volatile), to non-glass locations within the waste package needs to be determined, because this can potentially compromise shiclding estimates that assume that these species are confined to the glass.

\subsection{PROCESS INTEGRATION AND RELATED ISSUES}

\subsection{TEST PROGRAM}

The test program performed to date appears to have been well executed, and much useful information has been collected. At the same time, the extent of "new discovery," with consequent changes in the base process, apparently has been greater than was anticipated. As a result, while the process itself is still evolving in relatively major ways, the present schedule has only three additional full-scale cold tests planned before the startup of a scries of 50 full-scale radioactive tests at the DBVS.

The pancl docs not believe that full-scale radioactive testing is the appropriate vehicle for mitigating the majority of the remaining risks, but rather, should be viewed primarily as confirmation kestind In view of the decommissioning costs and the gencral complications presented by radioactive testing, such testing should proced when the remaining teclinical risks have been appropriately mitigated. The limited number of test runs that have been performed to date, coupled /with the technical issues that have becn discovered, has resulted in screral test variables being changed concurrently from one test to the next. Often, the key variables with respect to mitigating a given issue remain unidentified. This siluation is much less desirable with respect to being able to identify key process-control variables and set corresponding operating ranges for the process. In cases in which a particular issue appears to have been mitigated, it is often unknown whether the fix is tenuous, in the sense of being very sensitive to process variations, or robust. 
RPP-30570, Rev. 0

The panel is unaware of adcquate test data using simulant feed for the following key unit operations and process sub-systems:

- SMF - This is a key component with respect to the fate of Tc and the disposition of secondary waste.

- Integrated off-gas system - All tests performed to date have employed a nonprototypic off-gas system. No tests have been performed on the bascline off-gas treatment system.

- Integrated feed system - While vendor testing of the dryer has been performed, all of the vitrification tests to date have been performed with a non-prototypic feed system.

- Prototypical feed matcrial - All full-scale tests performed to date have been performed with a chemical simulant of the feed material produced by mixing the requisite chemicals as opposed to drying a wet LAW simulant with soil and adding glass-forming additives, as will be the case for the production system. The differences in physical form and properties are likcly to produce significantly different material flow and feed-melting behavior.

- Recycle- None of the tests performed to date has included the projected recycle stream from the SMF. Because this stream is likely to be rich in Tc and sulfur, both crucial process constiluents, this represents an important omission.

- Fully-integrated system - No tests have been performed to date on a prototypical fully-integrated system as per the bascline design.

- Instrumentation and controls - In view of the considerable differences between the test systems employed to date and the baseline design, prototypical instrumentation and control systems need to be developed and tested.

In view of these rather extensive information needs, the panel recommends sufficient nonradioactive testing (from small-scale through full-scale at the DBVS) be conducted prior to initiation of radioactive testing. Radioactive testing should only procecd when the remaining technical risks have been appropriately mitigated. We also suggest that because few of the subsystems have been tested, adequate time should be allowed between tests to implement system changes and modifications that are likely to be necessary.

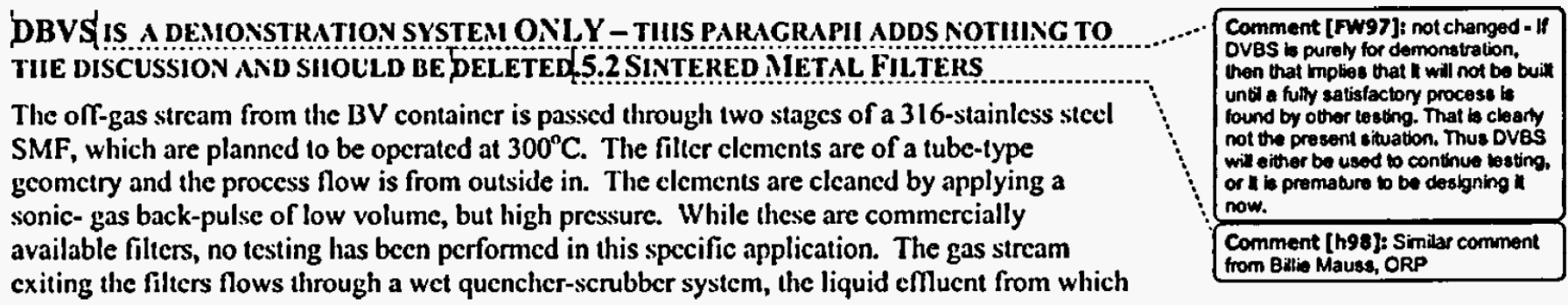


RPP-30570, Rev. 0

is directed to the site liquid effluent treatment facility. Accordingly, the serubber emluent must mect the waste acceptance criteria (WAC) for that facility. Thus, there is a crucial process reliance on the performance of the SMF to:

- decontaminate the off-gas stream of radionuclides and hazardous metals to sufficiently low levels to ensure that the liquid emuent from the scrubber mects the necessary WAC; and

- capture Tc (as well as other radionuclides and hazardous metals) in a form that can be recycled to the feed in order to compensate for the relatively low fraction of Te $(\sim 50 \%)$ that may be retained in the glass product.

In view of the importance of these functions, we consider the fact that no process testing has yet been performed to represent a considerable technical risk. The ability to reliably blow-back or flush and recycle the deposits collected from the off-gas is obviously crucial.

The nominal operating temperature of $300^{\circ} \mathrm{C}$ has been deliberately chosen to be high in order to minimize the chances of condensation in the filters. Condensation can lead to blinding of the filters, which is not casily blown-back and can provide a means of transport of soluble species (such as $\mathrm{Te}$ and $\mathrm{Cs}$ ) through the filters. In addition, because the LAW materials can contain significant amounts of chlorides, which will produce $\mathrm{ICl}$ gas and alkali chlorides that will deposit on the filters, any moisture can lead to mpid corrosion of the filter elements. The high soluble salt content of the material that will collect on the filters will also significantly increase the boiling point of any absorbed moisture, necessitating temperatures of significantly above $100^{\circ} \mathrm{C}$. However, there are also potential issues associated with operation at high temperature. In view of the high contents of sodium, sulfur, halides, boron, nitrates, ctc., it is not inconceivable that low melting cutectic salt mixtures could be formed on the filters. Such molten salt would almost certainly present a considerable corrosion issue.

The panel recommends consideration of an alternative SMF material, such as one of the Inconels or llastelloys, if available to address the concerns above. In addition, the spectrum of potential Cs and Te compounds should be reviewed to ensure that none are sufficiently volatile at $300^{\circ} \mathrm{C}$ to present a significant means of transport through the filters (as noted in Section 2.2.2 the proposed operating temperature is disturbingly close to the $\mathrm{Tc}_{2} \mathrm{O}_{7}$ boiling point of $311^{\circ} \mathrm{C}$ ).

\subsection{FLOW-SHEET MIODEL}

An integrated flow-sheet model, which includes all secondary waste and recycle streams needs, to be developed. Although such a model is apparently under development, in view of the lack of prototypical process test data discussed above, the necessary decontamination factor (DF) data for each of the unit operations maylnot available. However, such a model can be used to support assessments of what DFs are required for each unit operation. It should be noted that some fraction of volatile species, such as chromium and selenium, may pass through the SMF; thus, the impact on the ability of the scrubber effluent to mect the necessary WAC should be assessed. 


\subsection{Maxinum achievable Control Techinology Complance}

The BV system will be required to mect the maximum achicvable control technology (MACT) standards. Based on the results of extensive testing performed to investigate MACT compliance for the WTP vitrification system it may be a challenge for the present DBVS désign to meet the MACT requirement for $99.99 \%$ destruction-removal efficiency (DRE) for organics. In the dryer, all of the allyl alcohol and a portion of the naphthalene will bypass the melter and be treated only by the carbon bed and the SCR $\{$ Consequently, the melter will contribute little to the overall DRE for the bypassed organics. The off-gas stream from the dryer currently bypasses the wet scrubber and there is no thermal catalytic oxidizer (TCO) in the DBVS off-gas train. As a result, much of the $99.99 \%$ DRE requirement is bome by the carbon bed and the SCR Because carbon units are typically utilized as polishing units rather than for bearing the entire load of organic absorption, it is recommended that the expected system performance be reviewed against the MACT requirements to ensure that the carbon bed is adequatcly sized and that provisions for replacement and disposal are in place as the material becomes exhausted. In addition, the available capacity of the units can be expended on a variety of compounds that are present in much greater concentration than are the target organics. Flow-sheet evaluations are either completed (S-109) or underway to determine if the system, as currently designed, will meet MACT requirements, and if the carbon bed is adequately sized with provisions for replacement and disposal in place. If these evaluations or DBVS MACT testing show that the off gas design is not adequate as configured, the full-scale production operations will need to reconfigure the off gas system (e.g. flow the dryer outlet through the wet scrubber) or add additional unit operations (e.g. add a TCO),

\subsection{Fate OF CesiuM}

Cs, a high specific-gamma activity radionuclide that is also relatively volatile, is quite readily incorporated into many aluminosilicate refractories, particularly as polucite-type phases (Buechele et al., 1998). Cs volatilized during the melting process will likely deposit in the cooler areas of the waste package. As previously indicated, there are well-known interactions of $\mathrm{Cs}$ with Tc, which result in enhanced volatility through the formation of $\mathrm{Cs}$ perteclinetate. The panel understands that $\mathrm{Cs}$ and $\mathrm{Re}$ (or Tc) have been used in tests since 2003 to ensure that the potential interaction is observed. PNNL has already conducted engineering-scale tests to determine the interaction of $\mathrm{Cs}$ with $\mathrm{Tc}$ in terms of potential for increased volatility. The results of this work should be reviewed, and if necessary, further testing should be performed with both of these species present. The consequences of these interactions should be evaluated in terms of their impact on the estimated dose from the waste package and the assumptions that are made with respect to shiclding.

\subsection{CONFIRMATION OF TECINETIUM DISTRIBUTION}

The present strategy with respect to demonstration of the fate of $T c$ and, in particular, the extent of Icachable Tc species in the waste package, relies on a combination of engineering-scale and full-scale tests in combination with radioactive tests with $\mathrm{Tc}$ and a Re surrogate. Data from enginecring-scale tests that included both Re and $\mathrm{Tc}$ have been used to establish empirical ratios of the fraction of leachable Tc to that of Re. Full-scale tests have been performed with Re and extensively sampled to determine its distribution and, by use of the ratios, to infer the expected

Comment [LMB 101] I agree that the 99.99\% DRE will be a challenge for DBVS but we are not entirely dependent on carton bed. The Orier operates at 140F so some of the naphthalene will pass through the metter. The RDSD permit dictates that wo use a value of $50 \%$ for naphthalene. The dryer vacuum blower exhaust can easity be rerouted upstream of the wot scrubber to take advantage of the removal elficiency of the wot scrubber. The SCR has destruction efficiencies of $40-60 \%$ even when operated at the planned temperature of $600 \mathrm{~F}$. So the effectiveness of the carton can easily be supplemented by two processes for the ally alcothol and three processes in the case of the naphthalene II necessary. Please consider redline modifications.

Comment [FW 102]: changed 
RPP-30570, Rev. 0

distribution of Tc. Finally, in the DBVS tests that will include Tc from the waste, a Re spike will be added. A single core sample will then be taken from each of the 50 boxes that are produced and the distribution of $\mathrm{Tc}$ and $\mathrm{Re}$ will be used to validate the expectations based on the non-radioactive full-scale tests containing $R e$ where more extensive sampling was conducted. While this logic is reasonable, the panel is unaware of a contingency plan to address the possibility that the single core samples from the radioactive tests do not validate those expectations. In one scenario, it may be necessary to perform extensive core sampling of the radioactive boxes in order to properly disposition them. Need to include the current sampling regime that will set the statistical basis for future sampling activitics. Comment [FW103] not changed this is a topic for a huture project report, not this review

Finally, while the use of the ratio of Tc and Re leachable fractions is reasonable, it is an empirical approach. The underlying physicochemical explanation for the observed values of the ratios is lacking. The considerable disparity (about $a$ factor of five $=$ verify the source of this estimate if it is to be used) between the ratio of the retentions in glass and the ratio of the leachable fractions for Tc and Re further highlights this issue. Consequently, testing is recommended to provide a more fundamental understanding of the basis for the observed leachable fraction ratios, as noted in Section 2.1.3.

\subsection{OTIER RECOMHENDATIONS}

\subsection{FEEd PREPARATION}

\subsubsection{Eliminate Zirconia Segregation}

Zirconia and Zr-containing minerals (e.g., zircon) tend to separate during the carly stages of melting and settle to the bottom of the melt, of en forming high-Zr sludge on the melier bottom. Their high densities and low solubility in silicate melts make them more prone to this melting segregation than most other feed materials. This tendency can be overcome by ensuring good contact with fluxes, by selecting compounds that dissolve more readily, and by selecting finergrained materials. Some or all of these ideas either have been recently completed or are planned for 2006.

\subsubsection{Add zirconia with soil in mixer}

The order of addition is important to the contact between fluxes and the more refractory components in the feed. Dry mixing the zirconia with the soil before adding high-soda liquid waste will cause the alkali to be uniformly distributed over the zirconia, ensuring that zirconia will dissolve quickly in the molten glass, which forms in the fusion layer of the cold cap.

Only the hygroscopic boron source needs to be kept out of the dry mix to avoid making a gummy batch when the liquid waste is added. 'PNNL is currently pursuing this option and preliminary results look very promising

\subsubsection{Substitute fine zircon for zirconia}

Zircon $(\mathrm{Zr}$ silicate) dissolves faster in the silicate melt than zinconia because, in the presence of alkali, the zircon dissociates into very fine zirconia crystals dispersed in silica. These fine crystals dissolve faster than the larger zirconia crystals usually used as raw materials. The 
RPP-30570, Rev. 0

benefit of using zircon is even greater if the particle size is small. The project has deployed this recommendation in the lastest large scale test $38 \mathrm{C}$ - analytical results pending ICV box de: connstruction.

\subsubsection{Consider Gravity Feed from Mlixer/dryer into Melter}

Pncumatic fecders have several well-known problems: scgregation and particle-size reduction of the feed transported through them, excessive release of particulates into the off-gas, and abrasive wear-related maintenance problems. Because of these potential problems, a gravityfeed systcm is likely to be a more satisfactory design.

\subsection{MELTER}

\subsubsection{Add Ground Fault Detection System}

Electric melters can fail suddenly if conductive paths are created between the bath and the steel shell in two or more locations. Ileat generated by current flowing through such a path is difficult to dissipate, so the area heats up quickly. The process is exacerbated by the fact that the electrical conductivity of the refractory (like the glass melt) increases with increasing temperature. The result is the rapid formation of a narrow channel hot enough to melt the refractory and stecl. Typically a hole large enough to drain the melter in a short time is produced. Considering the complexity of the refractory lining, it is not unlikely that minor leakage of hot glass into joints could produce at least two clectrical leakage points in a melter.

Fortunately, the process described above can be detected in its early stages by a decrease in the electrical resistance between the power circuit and the steel shell. This normally provides sufficient warning to allow the hot spot to be located and cooled from the outside, or at least to tum off the power. A ground fault detection system should be in place on any electric melter.

| Delete this section - project is comfortable that the current ICV box design and it's layer construction provides adequate secondary containment to comply with RCRA requirements. See comment on 6.2 .2 above.j

\subsection{REFERENCES}

Antonini, M.A., E. Merlini, and R.F. Thomley, EXAFS Structures of Technetium in Glasses Prepared Under Different Redox Conditions, Journal of Non-Crystalline Solids 71, 219 (1985).

Buechele, A.C., S.S. Fu, Q. Yan, and I.L. Pegg, Radionuclide Uptake by Waste Glass Melter Refractories, Ceramic Transactions, Eds. D.K. Pecler and J.C. Marra, vol. 87, p. 583, American Ceramic Socicty (1998).

Darab, J.G. and P.A. Smith, Chemistry of Technetium and Rhenium Species During Low-Level Radioactive Waste Vitrification, Chemistry of Materials 8, 1004 (1996). 
RPP-30570, Rev. 0

Ebert, W.L., A.J. Bakel, D.L. Bowers, E.C. Buck, and J.W. Emery, J. W. The Incorporation of Technctium into a Representitive Low-activity Waste Glass. ANL/CMT/CP-92096, Argonne National Laboratory, Argonne, IL, (1997).

Ebert, W.L., S.F. Wolf, and J.K. Bates, The Release of Technetium from Defense Waste Processing Facility Glasses, Materials Rescarch Socicty Symposium Proceedings 412 , 221 (1996).

Kim, D.-S., C.Z. Soderquist, J.P. Icenhower, B.P. McGrail, R.D. Schecle, B.K. McNamara, L.M. Bagaasen, M.J. Schweiger, J.V. Crum, D.J. Yeager, J. Matyá̧, L.P. Damell, II.T. Schacf, A.T. Owen, A.E. Kozelisky, L.A. Snow, and M.J. Stecle, Te Reductant Chemistry and Crucible Melting Studies with Simulated Ilanford Low-Activity Wastc, PNNL-15131, March (2005).

Lanza, F., M. Cambini, M. Della Rossa, and E. Parnisari, Investigation of the Form in Which Technetium is Retained in a Borosilicate Glass Containing Simulated Iligh Level Nuclear Waste, Journal of Trace and Microprobe Techniques 10, 257 (1992).

Lukens, W.W., D. A McKeown, A.C. Bucchele, I.S. Muller, D.K. Shuh, and I.L. Pegg, Incongruent Behavior of Technetium and Rhenium in Borosilicate Waste Glass as Determined by X-ray Absorption Spectroscopy, to be submitted to Chemistry of Materials, April (2006).

Lukens, W.W. D.K. Shuh, I.S. Muller, and D.A. McKcown, X-ray Absorption Fine Structure Studies of Speciation of Technetium in Borosilicate Glasses, Materials Rescarch Socicty Symposium Procecdings 208, 101 (2004).

Lukens, W.W., D.K. Shuh, N.C. Schroeder, and K.R. Ashley, Identification of the Nonpertechnetate Species in the llanford Waste Tanks, Tc(I) Carbonyl Complexes, Environmental Science and Technology 38, 229 (2004).

Marples, J., N. Godon, F. Lanza, P. Van Iseghem. In Radioactive Waste Management and Disposal: Proceedings of the Third European Community Conference on Radioactive Waste Management; Cecille, L., Ed.; Elsevicr: London, (1991); p 287.

Muller, O., W.B. White and Roy, Crystal Chemistry of Some Technetium-containing Oxides, Journal of Inorganic Nuclear Chemistry 26, 2075 (1964).

Rard, J.A., M.II. Rand, G. Anderegg, and II. Wanner, Chemical Thermodynamics of Technetium; Elsevier Science: Amsterdam, (1999). 
Technical Assessmeid of Bulk Vitrification Process:Product for Tank Wasle Treatment at ile Depantment of Iinergy Ilanford Site

D-1 (n)
RPP-30570, Rev. 0
APPENDIX D:
CONINENT AND RESIONSE SUMINAY FOR TECINICAL ASSESS.IENT OF
BULK VITRIFICATION PROCESS AT TIE DOE IIANFORD SITE UNDER
TECIINICAL EXPERTISE PROJECT 608
RPP-30570, Rev. 0
APPENDIX D:
CONINENT AND RESIONSE SUMINAY FOR TECINICAL ASSESS.IENT OF
BULK VITRIFICATION PROCESS AT TIE DOE IIANFORD SITE UNDER
TECIINICAL EXPERTISE PROJECT 608
RPP-30570, Rev. 0
APPENDIX D:
CONINENT AND RESIONSE SUMINAY FOR TECINICAL ASSESS.IENT OF
BULK VITRIFICATION PROCESS AT TIE DOE IIANFORD SITE UNDER
TECIINICAL EXPERTISE PROJECT 608
RPP-30570, Rev. 0
APPENDIX D:
CONINENT AND RESIONSE SUMINAY FOR TECINICAL ASSESS.IENT OF
BULK VITRIFICATION PROCESS AT TIE DOE IIANFORD SITE UNDER
TECIINICAL EXPERTISE PROJECT 608
RPP-30570, ReV. 0
APPENDIX D:
BOINIENT AND RESPONSE SUMIARY FOR TECINICAL ASSESS.NIENT
BULK VITRIFICATION PROCESS AT TIIE DOE IIANFORD SITE UNDER
TECIINICAL EXPERTISE PROJECT 608

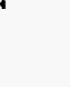

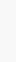

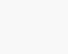


RPP-30570, Rev. 0

Comments and Response Summary

(This is a summary of team responses to signiflcant comments in Appendix $C$ and is organized by response number)

FW1: A general comment on the repeated reviews and revisions of this report:

An attempt has been made to incorporate all the changes suggested by the project staff. A number of changes, however, have not been incorporated, in some cases because the review team feels they are outside the scope of our review (e.g., plans for future activities, which we were not given the opportunity to review). In other cases, the changes suggested seemed to indicate a desire to minimize or ignore a potentially important problem of crystaltization of glass during cooling after melting.

The review team considered that our principal duty is to provide technical recommendations to address the three specific problem areas highlighted in the SOW. We did not see it as our duty either to criticize or praise the project team for their efforts. Rather, we took a snapshot of the technical issues as they stood in January, 2006, based on a subset of the then-available reports and presentations, and made technical recommendations that we hope will be helpful to the project team in resolving those problems.

FW6: The word Significantly is not changed in the text - this is a quote from the SOW, and we have no data to assess it.

FW7: The statement regarding the issue of metal inclusions is not changed to incorporate a statement regarding recent data- this section is simply a list of issues, not a discussion of all relevant facts.

FW11: The text is not changed to add "due to the limits of analytical capabilities" - this is not the only reason for the gaps in knowledge of physical and chemical properties of Tc - the topics listed in the next sentence simply have not been addressed yet.

FW12: The statement that recycling of Tc from the off-gas filter system may change the amount and form of TC is not changed -the recommended change is not relevant to a review of BV.

FW:16: The text is not changed - a lengthy discussion about a material balance is beyond scope of Exec Summary.

FW20: The text is not changed - a discussion of planned testing is too detailed for this summary.

FW21: The text is not changed - a discussion of planned testing in 50 box melts is too detailed for this summary.

FW26: The text is not changed - for reasons explained in the report, we believe the goal should be to eliminate metallic inclusions, not just reduce them.

FW27: The text is not changed to add "during start-up and operations" - when would one control current density and bath temperature other than during start up and operation?

FW31: The text is not changed to add "minimize metal inclusions" - goal should be to eliminate inclusions.

FW44: The text is not changed - the suggested change is not relevant to the discussion of this paragraph, and probably inaccurate if the large scale tests were properly sampled - it is ridiculous (and totally unnecessary) to imply that the BV process produces no devitrification.

FW45: The text is not changed - the water of concern here is groundwater to which the product will be exposed during long-term storage, not water in the melt.

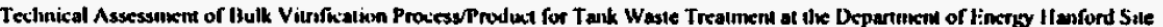


RPP-30570, Rev. 0

FW46: The text regarding sulfur volatilization ( $40 \%$ retained in the melt) is not changed - the range is supported by the data provided to us.

FW51: The text is not changed - The review team fully recognizes the value of and need for hot testing. but believes that too many issues have not yet been investigated with simulants to justify starting hot testing now. We are concerned that plans are based primarily on the hope that all will go well with the hot tests, making the simulant testing unnecessary, and not on solid results showing that success is likely with full-scale hot tests. This seems to us imprudent.

FW54: The report is not changed - the team intended only to subjectively prioritize the recommendations.

FW55: The text is not changed - it is not the purpose of this review to explain all the future plans of the project team.

FW57: The text is not changed to add reference to other radioactive glass products - it should be abundantly clear to any reader that this review is confined to the BV process.

FW68: The discussion of recommendations for mitigation of Tc loss is not changed - As explained at the end of Section 1, some of the recommendations are intended to raise possibilities, the practicality of which the review panel was not provided with enough information to assess.

FW70: The text is not changed to indicate the elimination of ingots in recent tests - the ingots were not eliminated in the test results presented to us.

FW73: The text is not changed to discuss any requirements regarding removal of metal inclusions to meet PA - not relevant to the discussion at this point.

FW74: The text regarding multi-phase materials and product quality requirements is not changed - the text proposed for deletion is factually correct, and is focused on a topic of considerable importance to the question of glass performance.

FW79: The text is not changed to replace the term devitrification with fracturing - proposed change is factually incorrect.

FW82: The concern that $\mathrm{Tc}$ is strongly enriched in the metal phase is not changed - it is based on data provided to us.

FW85: The statement regarding sulfur volatilization - that about $40 \%$ is retained - is not changed - and was addressed by a previous response (FW84) to comment.

FW86: The statement regarding the increase in concentration of sulfur in the feed is not changed.

FW89: The text is not changed to add the word potentially to the discussion of an estimate of Tc fate repeated attempt to understate a genuine problem is contrary to the best interests of DOE.

FW90: The text discussion of an estimated percent of Tc recovery is not changed - a range better indicates the level of uncertainty

FW96R95: No text change made regarding the need to determine the range of crystal contents and types of phases - the comment is valid.

Teclinical Ascessmeat of Bulk Vitrification ProcessProduct for Tauk Wasie Trealuxent at ite Deparimert of Iinergy Hanford Sile 


\section{RPP-30570, Rev. 0}

FW101: The text is not changed - If DVBS is purely for demonstration, then that implies that it will not be built until a fully satisfactory process is found by other testing. That is clearly not the present situation. Thus, DVBS will either be used to continue testing, or it is premature to be designing it now.

FW103: The text regarding the current lack of decontamination factor data for each of the unit operations is not changed - the data are clearly not available now.

FW 107: The text is not changed to discuss the statistical basis for future sampling activities - this is a topic for a future project report, not this review.

FW111: The text is not changed - the purpose of curbs or a trench is to reduce the cost and exposure to workers involved in cleaning up after a penetration of the shell, not to meet RCRA requirements. The possibility of penetration is real in spite of the layer construction, since the mechanism of failure (electrical leakage through the refractories producing a hole in refractories and shell) is unrelated to layer structure. 